Final Report

FHWA/IN/JTRP-2009/

\title{
FIELD INVESTIGATION OF SUBGRADE LIME MODIFICATION
}

\author{
By \\ Chulmin Jung \\ Postdoctoral Researcher \\ Purdue University \\ Sochan Jung \\ Graduate Research Assistant \\ Purdue University \\ Antonio Bobet \\ Professor \\ Purdue University \\ Nayyar Zia Siddiki \\ Supervisor \\ Indiana Department of Transportation \\ Joint Transportation Research Program \\ Project No. \\ File No. \\ SPR- \\ Conducted in Cooperation with the \\ Indiana Department of Transportation \\ and Federal Highway Administration
}

The contents of this report reflect the views of the authors who are responsible for the facts and the accuracy of the data presented herein. The contents do not necessarily reflect the official views or policies of the Indiana Department of Transportation or the Federal Highway Administration at the time of publication. This report does not constitute a standard, specification, or regulation.

School of Civil Engineering

Purdue University

November 2009 


\section{ACKNOWLEDGEMENTS}

The project (SPR-) was funded by the Joint Transportation Research Program of Purdue University in conjunction with the Indiana Department of Transportation and the Federal Highway Administration. The authors acknowledge and appreciate their support and assistance. The authors also are thankful for the input from the Study Advisory Committee members. The authors would like to thank Mr. Felipe Ochoa, a doctoral student at Purdue University, who helped the authors to do field tests, and Ms. Janet Lovell, the Laboratory Manager of the School of Civil Engineering at Purdue University, who performed the TGA and XRD tests for the project. 


\section{TABLE OF CONTENTS}

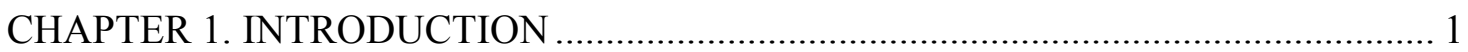

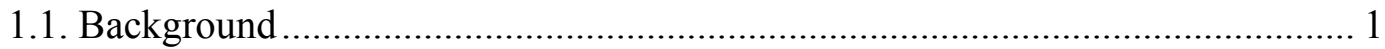

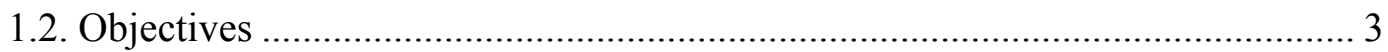

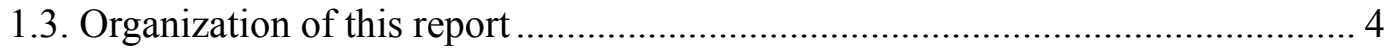

CHAPTER 2. SITE AND TEST METHDOS .............................................................. 5

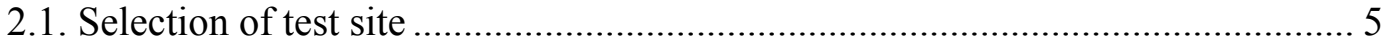

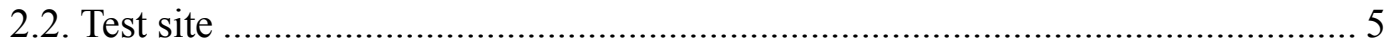

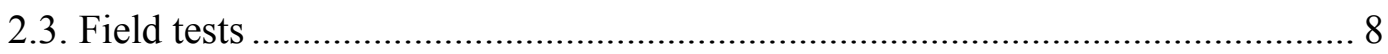

2.3.1. Dynamic Cone Penetrometer test.......................................................... 10

2.3.2. Light Weight Deflectometer test ......................................................... 12

2.3.3. Nuclear gauge test.......................................................................... 14

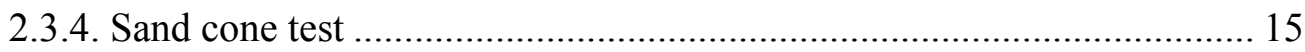

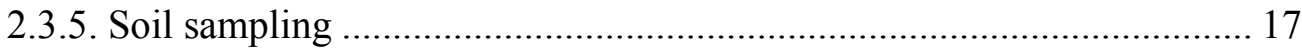

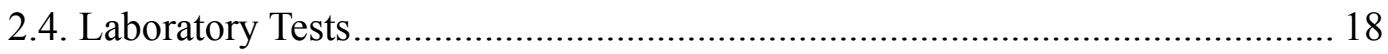

2.4.1. X-Ray Diffraction test...................................................................... 18

2.4.2. Thermogravimetric Analysis test ....................................................... 19

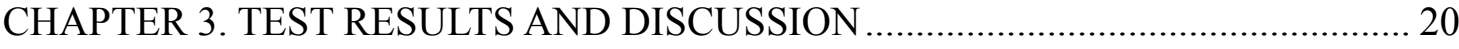

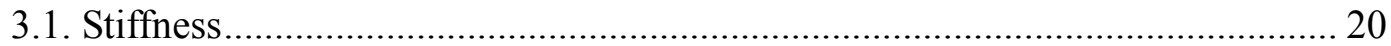

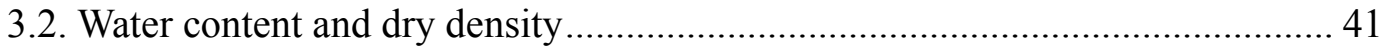

3.3. Identification and quantification of minerals ................................................ 43

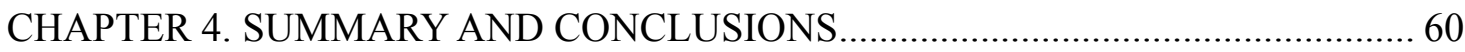

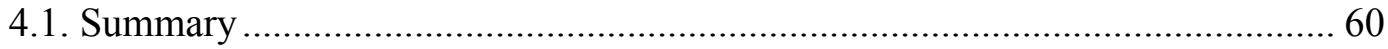

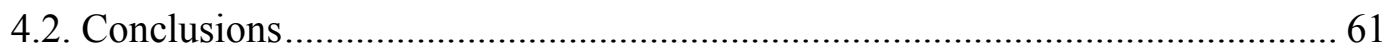

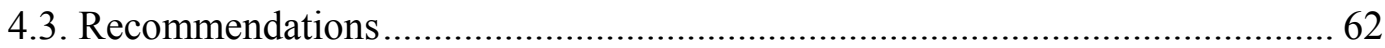




\section{LIST OF TABLES}

Table 2.1 Number of tests performed in each section 10

Table 3.1 Water content from nuclear gauge and sand cone tests (in \%). Section (1)..... 42

Table 3.2 Water content from nuclear gauge and sand cone tests (in \%). Section (2)...... 42

Table 3.3 Dry density from nuclear gauge and sand cone tests (in $\mathrm{Mg} / \mathrm{m}^{3}$ ). Section (1).. 43

Table 3.4 Dry density from nuclear gauge and sand cone tests (in $\mathrm{Mg} / \mathrm{m}^{3}$ ). Section (2).. 43

Table 3.5 Percentage of calcium carbonate in soil..... 59

Table 3.6 Comparison between percentage of calcium carbonate of treated soil and CBR of treated subgrade soil 59 


\section{LIST OF FIGURES}

Figure 2.1 Location of test site (http://www.in.gov/indot/div/projects/ sr641/maps.html) 6

Figure 2.2 Typical pavement cross section at test site (INDOT). 7

Figure 2.3 (a) Test site during chemical treatment (b) test site after completion of chemical treatment 8

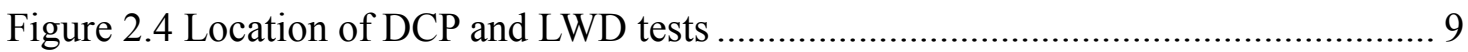

Figure 2.5 Dynamic Cone Penetrometer (DCP) testing....................................................11

Figure 2.6 Schematic of DCP device (ASTM D 6951-03) ........................................... 12

Figure 2.7 Light Weight Deflectometer (right) and data aquisition system (left)............ 14

Figure 2.8 Schematic design of sand cone apparatus (ASTM D 1556-07) ..................... 16

Figure 2.9 Sand cone test: (a) excavation of soil; (b) pouring reference sand into test hole 16

Figure 2.10 Soil sampled from borehole for the laboratory tests ................................. 18

Figure 3.1 DCP test results with depth at STA. 6+700. Section (1) ............................... 22

Figure 3.2 DCP test results with depth at STA. 6+710. Section (1) ............................. 23

Figure 3.3 DCP test results with depth at STA. 6+720. Section (1) ................................ 23

Figure 3.4 DCP test results with depth at STA. 6+730. Section (1) ............................... 24

Figure 3.5 DCP test results with depth at STA. 6+740. Section (1) .............................. 24

Figure 3.6 DCP test results with depth at STA. 6+750. Section (1) ............................... 25

Figure 3.7 DCP test results with depth at STA. 6+760. Section (1) .............................. 25

Figure 3.8 DCP test results with depth at STA. 6+770. Section (1) ............................... 26

Figure 3.9 DCP test results with depth at STA. 6+780. Section (1) ................................ 26

Figure 3.10 DCP test results with depth at STA. 6+790. Section (1) ............................. 27 
Figure 3.11 DCP test results with depth at STA. 6+800. Section (1)............................. 27

Figure 3.12 DCP test results with depth at STA. 6+560. Section (2) .............................. 28

Figure 3.13 DCP test results with depth at STA. 6+570. Section (2) .............................. 28

Figure 3.14 DCP test results with depth at STA. 6+580. Section (2) .............................. 29

Figure 3.15 DCP test results with depth at STA. 6+590. Section (2) .............................. 29

Figure 3.16 DCP test results with depth at STA. 6+600. Section (2) ............................... 30

Figure 3.17 DCP test results with depth at STA. 6+610. Section (2) ............................... 30

Figure 3.18 DCP test results with depth at STA. 6+620. Section (2) ............................. 31

Figure 3.19 DCP test results with depth at STA. 6+630. Section (2) ............................. 31

Figure 3.20 DCP test results with depth at STA. 6+640. Section (2) ............................. 32

Figure 3.21 DCP test results with depth at STA. 6+650. Section (2) ............................. 32

Figure 3.22 DCP test results with depth at STA. 6+660. Section (2) ............................. 33

Figure 3.23 Effective thickness of chemically treated subgrade soil layer (in inches).

Section (1). 34

Figure 3.24 Effective thickness of chemically treated subgrade soil layer (in inches).

Section (2). 34

Figure 3.25 Average CBR calculated within effective thickness of chemically treated subgrade soil layer below top of subgrade. Section (1) 35

Figure 3.26 Average CBR calculated within effective thickness of chemically treated subgrade soil layer below top of subgrade. Section (2). 36

Figure 3.27 Average CBR calculated over target treatment thickness of subgrade below top of subgrade. Section (1). 37

Figure 3.28 Average CBR calculated over target treatment thickness of subgrade below 
top of subgrade. Section (2). 37

Figure 3.29 Incremental ratio of CBR of chemically treated subgrade soil layer to CBR of natural subgrade soil layer. Section (1) 38

Figure 3.30 Incremental ratio of CBR of chemically treated subgrade soil layer to CBR of natural subgrade soil layer. Section (2)

Figure 3.31 Dynamic deflection modulus of subgrade soil layer (in MPa). Section (1). . 40

Figure 3.32 Dynamic deflection modulus of subgrade soil layer (in MPa). Section (2). . 40

Figure 3.33 XRD pattern for chemically treated soil sample at 2-in. depth at STA. $6+700$. Section (1). 45

Figure 3.34 XRD pattern for chemically treated soil sample at $8-$ in. depth at STA. $6+700$. Section (1) 45

Figure 3.35 XRD pattern for chemically treated soil sample at 14-in. depth at STA. 6+700. Section (1). 46

Figure 3.36 XRD pattern for chemically treated soil sample at 2-in. depth at STA. $6+760$ ). Section (1). 46

Figure 3.37 XRD pattern for chemically treated soil sample at 8-in. depth at STA. $6+760$ ).

Section (1). 47

Figure 3.38 XRD pattern for chemically treated soil sample at 14-in. depth at STA. $6+760$. Section (1). 47

Figure 3.39 XRD pattern for chemically treated soil sample at 2-in. depth at STA. 6+560.Section (2) 48

Figure 3.40 XRD pattern for chemically treated soil sample at 7-in. depth at STA. $6+560$.

Section (2). 48 
Figure 3.41 XRD pattern for chemically treated soil sample at 12-in. depth at STA. 6+560. Section (2) 49

Figure 3.42 XRD pattern for chemically treated soil sample at 2-in. depth at STA. $6+600$ at Section (2). 49

Figure 3.43 XRD pattern for chemically treated soil sample at $7-$ in. depth at STA. $6+600$. Section (2). 50

Figure 3.44 XRD pattern for chemically treated soil sample at 12-in. depth at STA. $6+600$. Section (2). 50

Figure 3.45 TGA result for chemically treated soil sample at 2-in depth at STA. $6+700$ ). Section (1). 53

Figure 3.46 TGA result for chemically treated soil sample at 8-in. depth at STA. $6+700$ ). Section (1) 53

Figure 3.47 TGA result for chemically treated soil sample at 14 -in. depth at STA. $6+700$. Section (1) 54

Figure 3.48 TGA result for chemically treated soil sample at 2-in. depth at STA. $6+760$.

Section (1) 54

Figure 3.49 TGA result for chemically treated soil sample at 8-in. depth at STA. $6+760$.

Section (1) 55

Figure 3.50 TGA result for chemically treated soil sample at 14-in. depth at STA. 6+760.

Section (1) 55

Figure 3.51 TGA result for chemically treated soil sample at 2-in. depth at STA. $6+560$. Section (2) 56

Figure 3.52 TGA result for chemically treated soil sample at 7-in. depth at STA. 6+560). 
Section (2). 56

Figure 3.53 TGA result for chemically treated soil sample at 12-in. depth at STA. $6+560$. Section (2) 57

Figure 3.54 TGA result for chemically treated soil sample at 2-in. depth at STA. $6+600$. Section (2). 57

Figure 3.55 TGA result for chemically treated soil sample at $7-$ in. depth at STA. $6+600$. Section (2). 58

Figure 3.56 TGA result for chemically treated soil sample at 12-in. depth at STA. 6+600. Section (2). 58 


\section{CHAPTER 1. INTRODUCTION}

\subsection{Background}

This is an implementation project for the completed research (INDOT SPR3007) Post-Construction Evaluation of Lime-Treated Soils. In the previous research, a comprehensive field investigation was carried out to determine the engineering properties of subgrade soils treated with LKD (Lime Kiln Dust) in pavements that had been in service for at least five years. Six test sites were selected for the field tests. At each site, SPT (Standard Penetration Test), DCPT (Dynamic Cone Penetration Test), and FWD (Falling Weight Deflectometer) tests were performed to evaluate the in-situ stiffness and/or strength properties of the chemically treated subgrade. Laboratory tests were performed on soil samples taken from the SPT spoon sampler to obtain index properties of the chemically treated subgrade and the lime content that remains in the soil. The long-term performance of the chemically treated subgrade at each site was evaluated based on the results of the laboratory and field tests. The evaluation was done by comparing the soil indices and stiffness and/or strength properties of the chemically treated subgrade soil with those of the natural soil. In addition, the lime content of the treated and the natural soil were measured to establish the remaining lime in the treated subgrade and detect any leaching of lime into the underlying natural soil.

The previous research found that the fines content of the original soil was reduced by a factor of $20 \%$ to $40 \%$, by the addition of lime. In general the lime treatment changed the original soil from silty/clayey to non-plastic silty sand. The longitudinal 
distribution of CBR at each site was obtained from DCPT results. It was found that: (1) the addition of lime to the natural soil had the potential to significantly increase the CBR of the natural soil by as much as $500 \%$ to $1500 \%$; and (2) the improved CBR had very large scatter, both along the length of the road and also with depth. Quantification of the lime content in the subgrade was done with thermo-gravimetric (TGA) laboratory tests. The $\mathrm{CaCO}_{3}$ content, which is related to the content of lime that remains in the subgrade, ranged from $1.2 \%$ to $17.5 \%$, with typical values in the range of $5 \%$ to $7 \%$. An important result from the TGA tests, which was confirmed with X-ray diffraction tests, was that the lime was only present in the treated subgrade and not in the natural soil. This provided a strong indication, together with $\mathrm{pH}$ measurements, that there was no leaching of the lime out of the subgrade, and thus the treatment remained after 5 to 11 years.

In conclusion, the previous research showed that: (1) the lime remains in the soil even after 11 years of service of the roads; (2) the addition of lime decreases the plasticity of the soil and increases its CBR; and (3) the construction quality observed from the field tests is highly variable.

The past project also included recommendations for implementation. Such recommendations were based on consensus among INDOT and FHWA personnel, and from industry. In the light of the positive results obtained from the research it was deemed possible to increase the CBR of LKD-treated subgrade soils by $20-30 \%$ of the natural, untreated, soil. This increase would account for the immediate benefits on the engineering properties of the treated soil as well as for the long-term benefits. It was also thought that INDOT quality control had improved over the years. Future (long-term) 
increases of the CBR of the treated subgrade could be considered with new field data from construction sites, which would be a measure of quality control during all the phases of subgrade treatment with LKD.

The problems that the research identified as the source of non-uniform engineering properties of treated subgrade layers were associated with low reactive lime content of the LKD delivered at the site, and to non-ideal construction practices including non-optimal spreading of lime, mixing of lime and soil, and compaction. It was recommended to build a pilot project with subgrade treated with lime to investigate directly the quality of the treatment that is obtained using current construction procedures, as well as to explore other methods that could provide a more uniform and better quality subgrade.

\subsection{Objectives}

The objectives of the project are to investigate in the field the degree of uniformity and quality that is obtained with soil modification with LKD using current construction techniques, and also to explore changes in construction methods that may result in a better product.

The objectives are accomplished by: (1) selecting an appropriate construction site where LKD is used for soil modification; (2) performing field and laboratory tests to ascertain the magnitude of the engineering properties of the chemically treated soil and the degree of uniformity accomplished with the treatment; (3) analyzing the field and laboratory data to provide recommendations for changes in construction methods; and (4) providing recommendations for considering the modified subgrade as a structural layer 
for pavement design.

\subsection{Organization of this report}

The report consists of three additional chapters. Chapter 2 provides the selection process and preliminary information for the test site, and the methodology used for field and laboratory tests. Chapter 3 presents and discusses the results of the field and laboratory tests. From the test results, the engineering properties of the chemically treated subgrade soil layer are compared with those of the natural (untreated) soil layer. In addition, the engineering properties of the subgrade with a target treatment thickness of 16 inches are compared with those with a target treatment thickness of 14 inches. Chapter 4 summarizes the work done in this report and provides conclusions and recommendations. 


\section{CHAPTER 2. SITE AND TEST METHDOS}

A test site was selected for the field tests based on construction schedule and traffic and safety issues. Field tests were conducted to evaluate in-situ properties of the chemically treated subgrade and laboratory tests were performed to estimate the lime content in the soil. This chapter includes: (1) the selection process and preliminary information for the test site, and (2) the methodology used for field and laboratory tests.

\subsection{Selection of test site}

Mr. Neil Ryan from Mt. Carmel Stabilization Group, Inc. led the search for an appropriate test site in May 2009. He suggested a section on SR 641, i.e. US 41 Bypass in Terre Haute, IN, given that: (1) construction of the subgrade chemical treatment was scheduled in July 2009; (2) there would be no traffic; and (3) the site would be accessible for the project. A meeting was held with Mr. Nayyar Zia Siddiki and Tim Buckner from Indiana Department of Transportation (INDOT), Mr. Neil Ryan, Prof. Antonio Bobet and Mr. Sochan Jung from Purdue University on July 16, 2009 regarding the site location and scope of work.

\subsection{Test site}

The test site is located in SR 641 (Des. 9738220; R-28976), South of Terre Haute, Indiana (Figure 2.1). "Des." is the designation number given by INDOT to a road construction project. "R-" is the contract number used between a contractor and INDOT. 
The road has four lanes, two lanes north-bound and two lanes south-bound, and will interconnect I-70 and US 41. See Figure 2.2 that shows a typical cross section of the north-bound road.
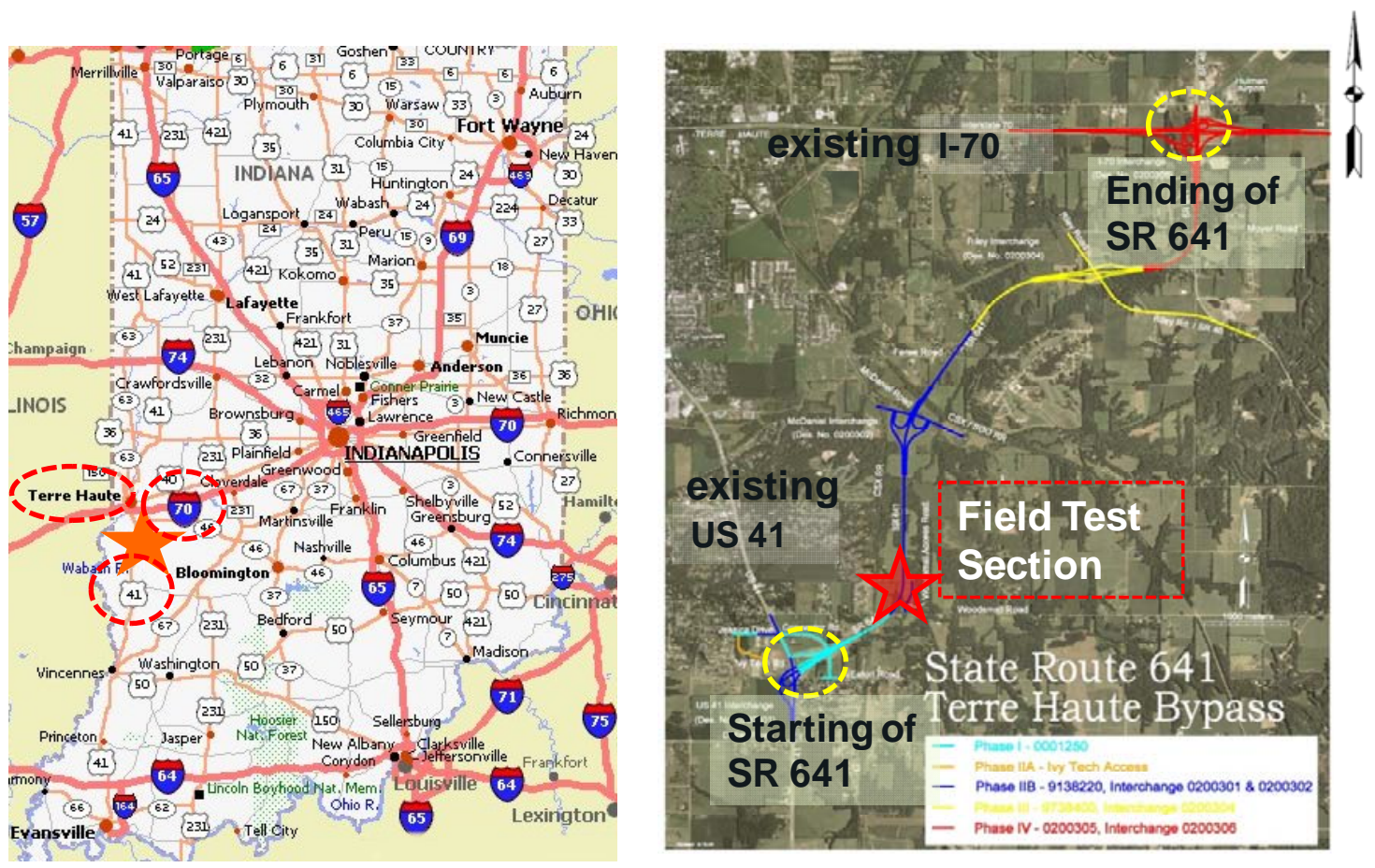

Figure 2.1 Location of test site (http://www.in.gov/indot/div/projects/ sr641/maps.html) 


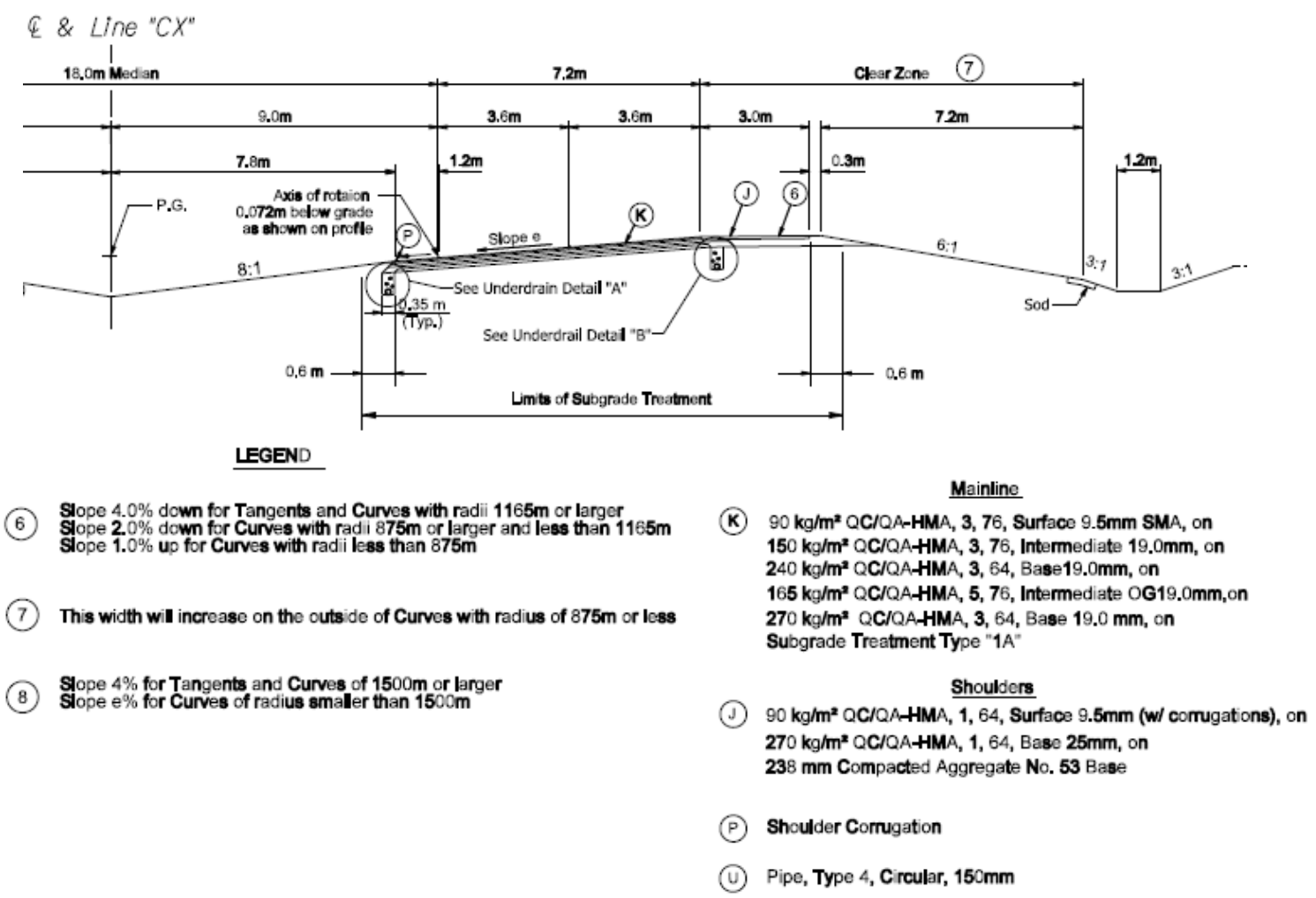

Figure 2.2 Typical pavement cross section at test site (INDOT)

A $280-\mathrm{m}$ long portion of the north-bound road between STA. $6+540$ and STA. $6+820$ was chosen for the field tests. "STA." means station number, as used in the road construction project, and denotes the longitudinal location along the center line of the (north-bound and south-bound) road. The total $280-\mathrm{m}$ portion was divided into two construction and test sections. The first 140-m long subgrade section, between STA. $6+540$ and STA. 6+680, was chemically treated with LKD with a target thickness of 14 inches. The remaining 140-m, between STA. 6+680 and STA. 6+820, were treated with a target thickness of 16 inches. The field tests were conducted on the subgrade after seven days of curing of the chemical treatment (Figure 2.3). 

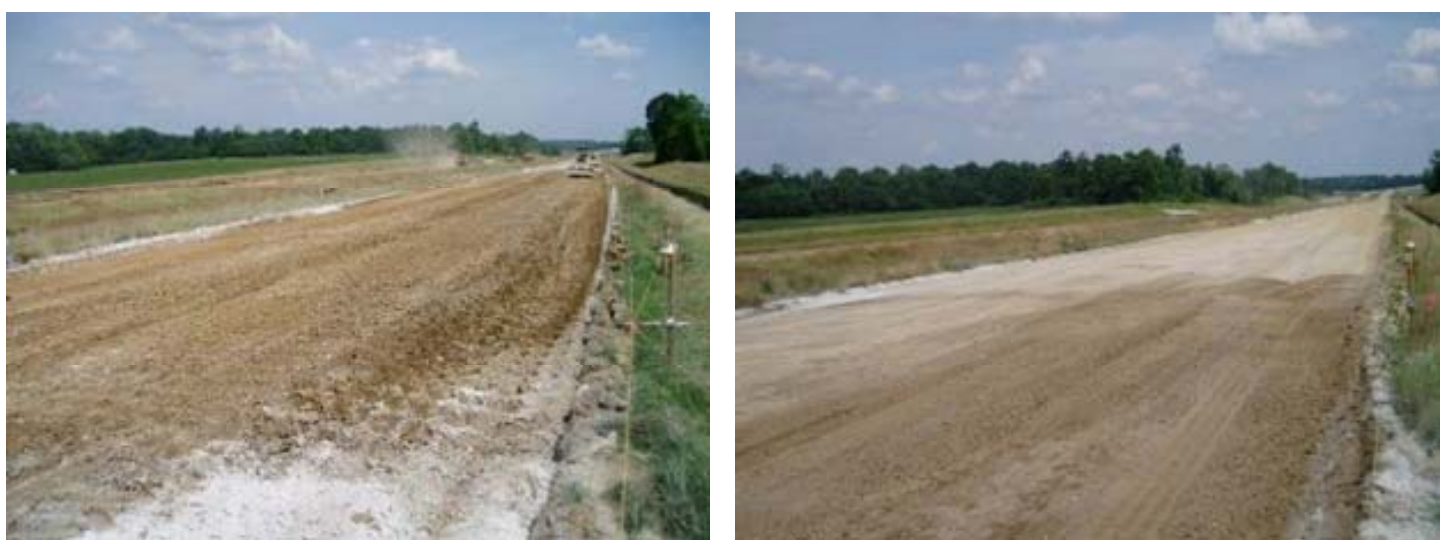

Figure 2.3 (a) Test site during chemical treatment (b) test site after completion of chemical treatment

It needs to be mentioned that both sections are located on a curved part of the road. Figure 2.2 indicates a higher elevation of the driving lane than the passing lane.

The natural subgrade soil at the test site was characterized from existing geotechnical investigation data, which is included in the Appendix. The geotechnical investigation data is available at the INDOT website (https://netservices.indot.in.gov/ViewDocs2.0/) and for contract number R-28976. The soil was fine grained with $73 \%$ passing No. 200 sieve. The soil had a Liquid Limit (LL) of $22 \%$, a Plastic Limit (PL) of $12 \%$, and a Plastic Index (PI) of 10. Based on the soil particle distribution and the soil index properties, it was classified as A-4(4), following the AASHTO classification system, and as low plasticity clay (CL), based on the Unified Soil Classification System.

\subsection{Field tests}

Field tests were conducted on July 28, 2009. The DCP (Dynamic Cone 
Penetrometer) tests were performed by a technician from Alt \& Witzig Engineering in both sections (i.e. those with treatment thickness 14 and 16 inches, respectively). Twenty three DCP tests were done at each section. The location where the DCP tests were done is shown in Figure 2.4. LWD (Light Weight Deflectometer) tests were performed by technicians from Division of Research of INDOT at the same locations where the DCP tests were done. The LWD tests were repeated three times at each location to improve the confidence of the results. Two sand cone tests were conducted in each section, and two different soil samples were taken also at each section. Nuclear gauge tests were conducted by a technician from Alt \& Witzig Engineering on the following day, July 29, 2009. Nine nuclear gauge tests were done at the section with a target treatment thickness of 14 inches and eight tests at the section with a target treatment thickness of 16 inches. Table 2.1 summaries the type and the number of field tests performed.

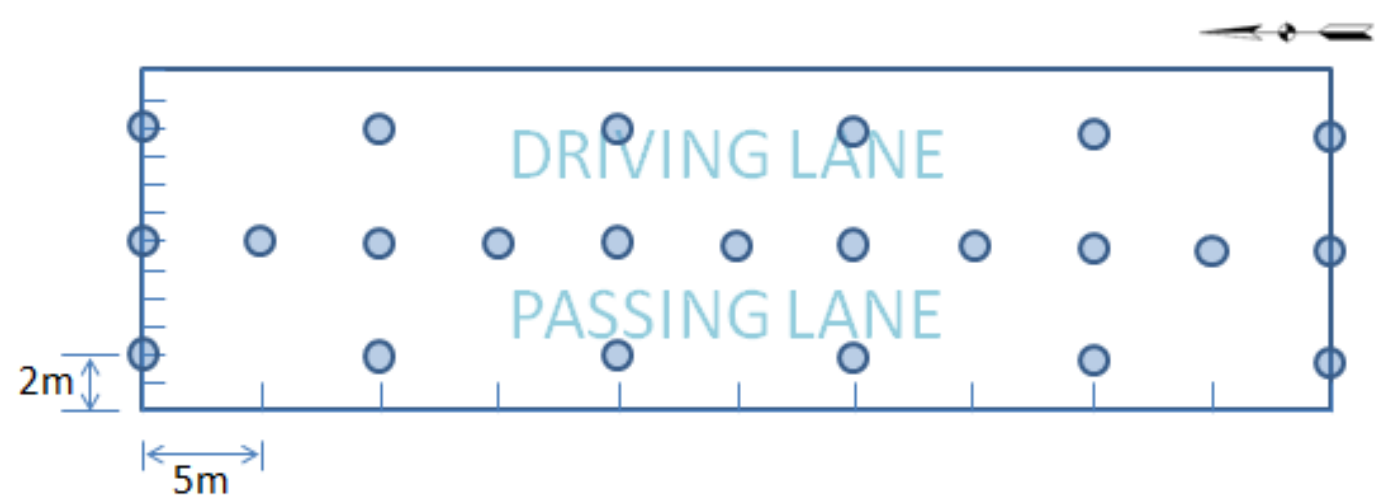

Figure 2.4 Location of DCP and LWD tests 
Table 2.1 Number of tests performed in each section

\begin{tabular}{|c|c|c|c|c|c|}
\hline & DCP & LWD & $\begin{array}{c}\text { Nuclear } \\
\text { gauge }\end{array}$ & Sand cone & $\begin{array}{c}\text { Soil } \\
\text { sampling }\end{array}$ \\
\hline $\begin{array}{c}14 \text { inch } \\
\text { treatment }\end{array}$ & 23 & 69 & 9 & 2 & 2 \\
\hline $\begin{array}{c}16 \text { inch } \\
\text { treatment }\end{array}$ & 23 & 69 & 8 & 2 & 2 \\
\hline
\end{tabular}

\subsubsection{Dynamic Cone Penetrometer test}

Dynamic Cone Penetrometer (DCP) tests were conducted to evaluate directly the stiffness of both the chemically treated and the underlying natural (untreated) subgrades. DCP blow counts were recorded for every 2 inches penetration of the cone into the subgrade soil. The DCP tests started at the top of the subgrade (Figure 2.5), and terminated after a penetration of 30 inches. The cone went through the theoretical 14 or 16 inches thickness of the chemically treated subgrade soil layer and continued over an additional depth of 16 or 14 inches into the natural (untreated) subgrade soil.

The DCP tests were performed in accordance with ASTM D 6951-03, that specifies a standard method for the use of the Dynamic Cone Penetrometer (DCP) in shallow pavement applications. The soil strength is measured by the penetration, usually in millimeters or inches, per hammer blow. The cone has a tip angle of $60^{\circ}$, and a diameter of $20 \mathrm{~mm}(0.79 \mathrm{inch})$. The weight of the hammer is $8 \mathrm{~kg}(17.7 \mathrm{lb})$, and the drop height is $575 \mathrm{~mm}$ (22.6 inch). The DCP device consists of a steel rod with a steel cone (replaceable or disposable cone) attached to one end, which is driven into a pavement structure or a subgrade using a sliding hammer (Figure 2.6).

In this research, the correlation proposed by Webster et al. (1992) is used to 
estimate the CBR values of the subgrade soil layer from the DCP test results. This is consistent with what was done in previous research (INDOT SPR-3007). The correlation is:

$$
\log (C B R)=2.46-1.12 \log (D C P I)
$$

Where DCPI $=$ DCP Index or penetration resistance $(\mathrm{mm} / \mathrm{blow})$.

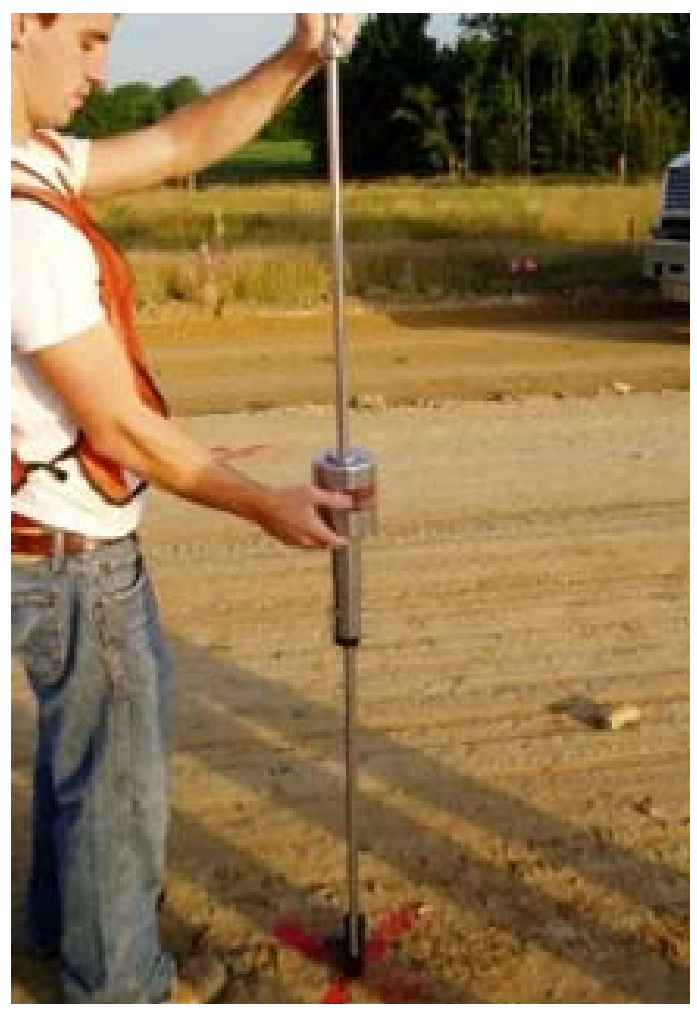

Figure 2.5 Dynamic Cone Penetrometer (DCP) testing 

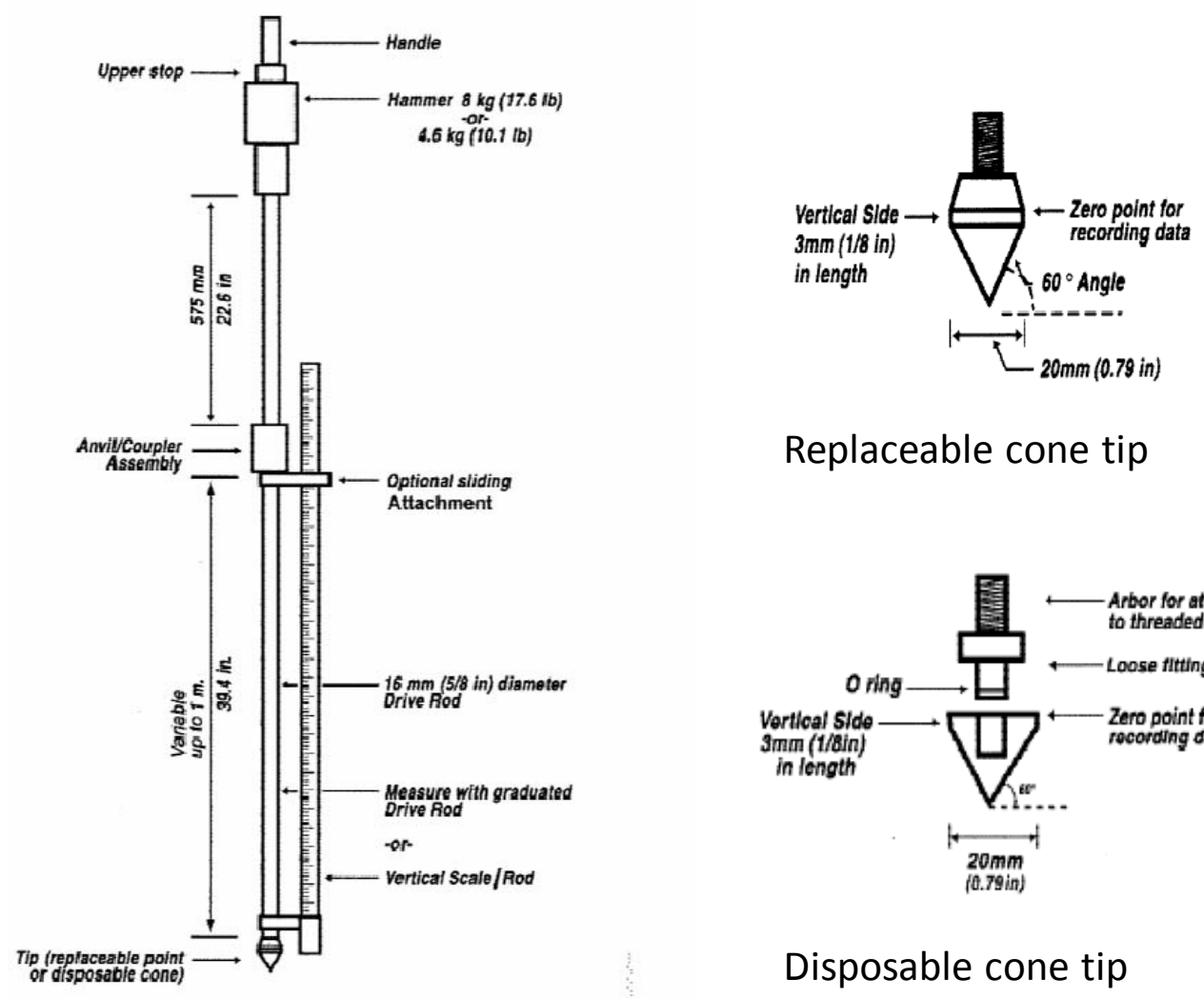

Replaceable cone tip

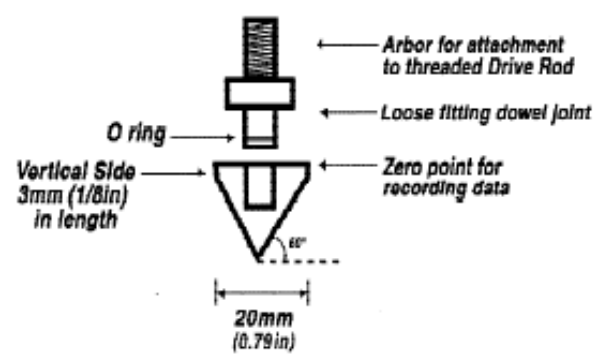

Disposable cone tip

Figure 2.6 Schematic of DCP device (ASTM D 6951-03)

\subsubsection{Light Weight Deflectometer test}

Light Weight Deflectometer (LWD) tests were conducted to obtain the stiffness of the treated subgrade and to compare the results with those from the DCP tests. The Light Drop-Weight Tester ZFG 2000, manufactured by Zorn company, Germany, was used for the LWD tests (Figure 2.7).

The LWD test, also referred to as a Portable Falling-Weight Deflectometer (PFWD), measures the deflection of paved and unpaved surfaces, which can be used to determine the stiffness of paved or unpaved surfaces (ASTM E 2583-07). The standard LWD configuration has $10 \mathrm{~kg}(22 \mathrm{lb})$ of falling weight, $300 \mathrm{~mm}$ (12 inch) of load plate 
diameter and $500 \mathrm{~mm}$ (19.7 inch) of guide rod. The guide rod and falling weight together weigh about $15 \mathrm{~kg}(33 \mathrm{lb})$. The influence depth is approximately 1 to 1.5 times the plate diameter (MNDOT manual, 2009).

To estimate the stiffness of the subgrade soil layer from the deflection, an elastic half-space model is used. The model assumes that the soil layer is homogenous, isotropic and elastic. It is also assumed that the load distribution is uniform at the contact between the test plate and the top of the subgrade. The elastic modulus (or dynamic deflection modulus) of the subgrade soil layer can be estimated using the following equation (Zorn manual 2005; Ruta and Szydlo, 2005; and Kim et al., 2007):

$$
E_{v d}=\frac{2\left(1-v^{2}\right)}{\pi r} \frac{Q_{\max }}{s}
$$

Where $E_{v d}=$ elastic modulus (or dynamic deflection modulus), $v=$ Poisson's ratio of the subgrade soil, $r=$ radius of the plate, $Q_{\max }=$ maximum dynamic impact load, $s=$ vertical deflection of the subgrade soil. 


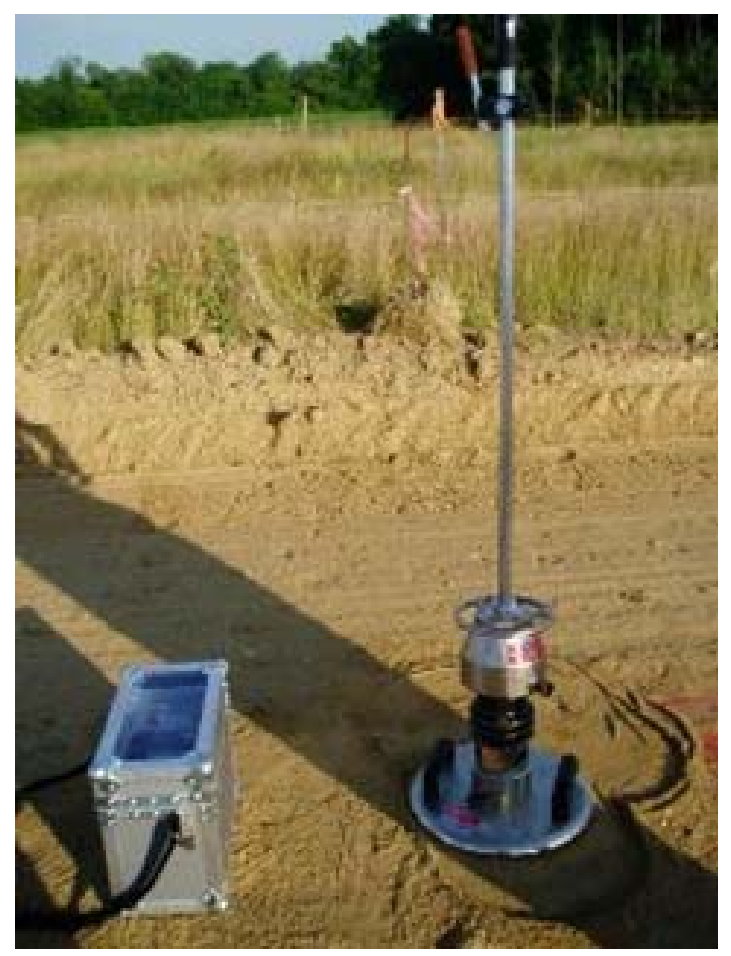

Figure 2.7 Light Weight Deflectometer (right) and data aquisition system (left)

\subsubsection{Nuclear gauge test}

Nuclear gauge tests were performed to measure the water content and density of the subgrade soil at the site. The tests were conducted following ASTM D 6938-09 that specifies a standard method for such test.

The nuclear gauge test is an in-situ, non-destructive test, that rapidly measures the density and water content of the soil. The in-situ density of the soil can be measured by either direct transmission method or backscatter method. The nuclear gauge consists of a source and a detector. Gamma rays are emitted from the source at the end of a retractable rod and interact with electrons in the soil. The source is lowered at a known depth in the direct transmission method or remains on the surface in the backscatter method. The 
detector inside the gauge is on the surface in both methods and collects the attenuated gamma rays from the source. The in-situ density of the soil is correlated with the number of gamma rays collected and the in-situ water content of the soil is correlated with the number of neutrons collected.

\subsubsection{Sand cone test}

Sand cone tests were conducted to measure the density of the subgrade soil. The tests were done in accordance with ASTM D 1556-07 that specifies a standard method to measure the density of soil in place by a sand cone apparatus. The sand cone apparatus consists of a sand container on one end and a large metal funnel on the other end. The details of the apparatus are shown in Figure 2.8.

ASTM D 1556-07 suggests that the sand using in the test must be clean, dry, and uniform in density and grading. The sand requires a uniformity coefficient $\left(\mathrm{C}_{\mathrm{u}}=\mathrm{D}_{60} / \mathrm{D}_{10}\right)$ less than 2.0, all particles passing $2.0 \mathrm{~mm}$ (No. 10 sieve), and less than $3 \%$ by weight passing $250 \mu \mathrm{m}$ (No. 60 sieve). 


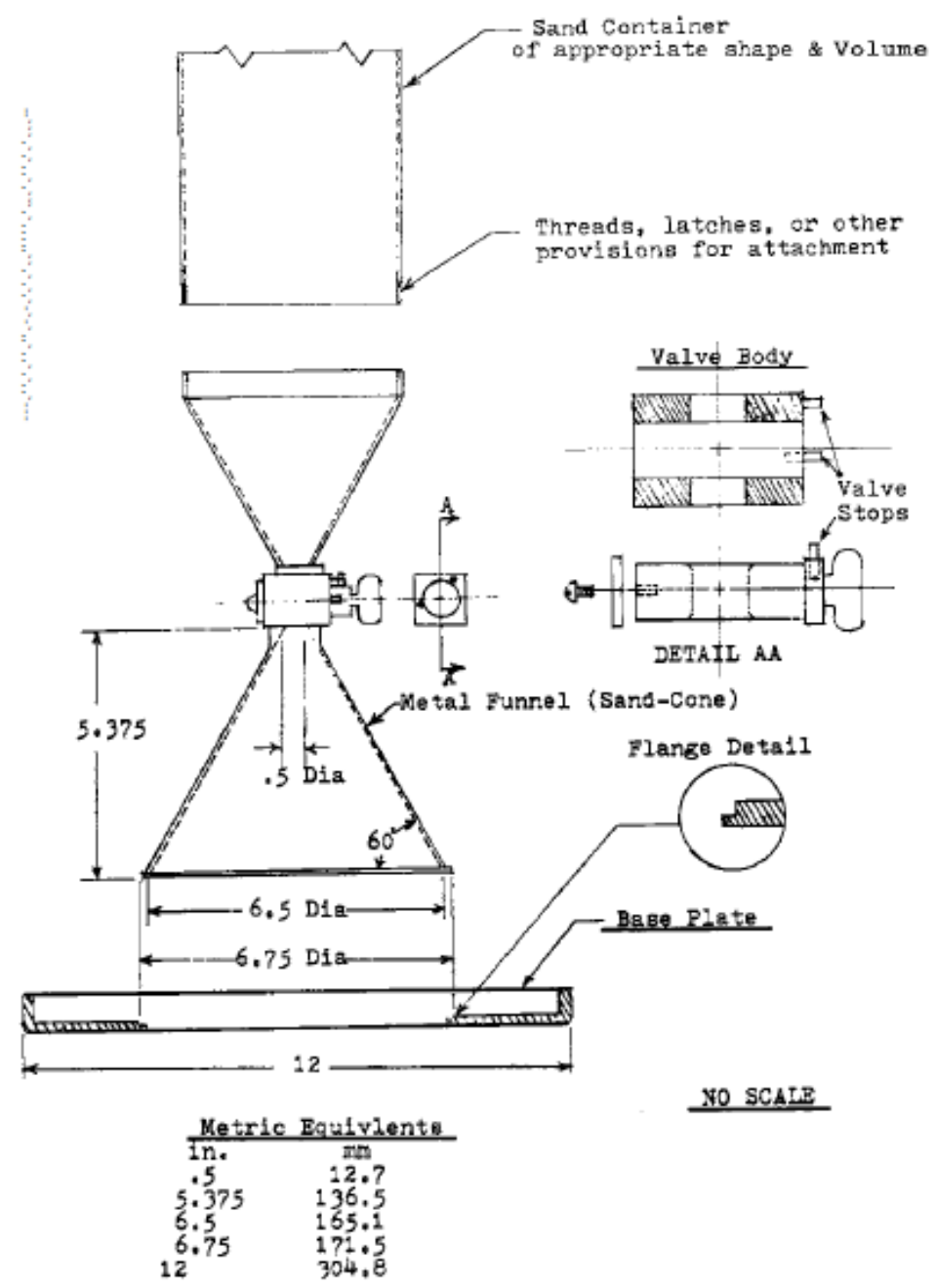

Figure 2.8 Schematic design of sand cone apparatus (ASTM D 1556-07)
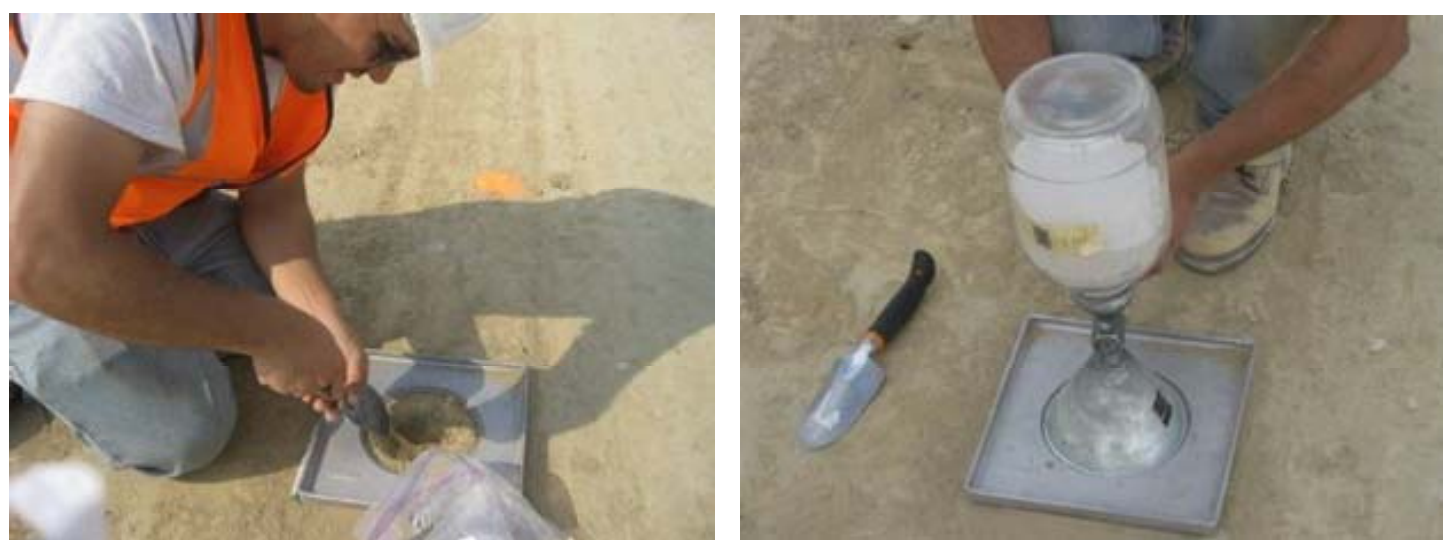

Figure 2.9 Sand cone test: (a) excavation of soil; (b) pouring reference sand into test hole 
To perform the test, soil was excavated from the top of the subgrade and was carefully collected with an air-tight container (Figure 2.9a). The mass of the excavated soil was measured in the field and the volume of the excavated soil was obtained by pouring the reference sand into the test hole (Figure 2.9b). Afterwards, the water content of the soil was obtained by placing the excavated soil in the oven at $110 \pm 5{ }^{\circ} \mathrm{C}$ for $24 \mathrm{hrs}$ following ASTM D 2216-05. The results from the sand cone tests are compared with those from the nuclear gauge tests.

\subsubsection{Soil sampling}

Soil samples were taken from the subgrade to the laboratory for mineral identification and quantification. A hand drill was used to bore the subgrade soil (Figure 2.10).

Soil was collected at two different locations in each section. At each location, soil samples were taken at three different depths within the theoretical thickness of the chemical treatment. Specifically, soil was collected at depths of 2, 7, and 12 inches below the top of the subgrade at the section where the subgrade was chemically treated with a target thickness of 14 inches, while soil was collected at depths of 2, 8, and 14 inches, at the section with a target treatment thickness of 16 inches. 

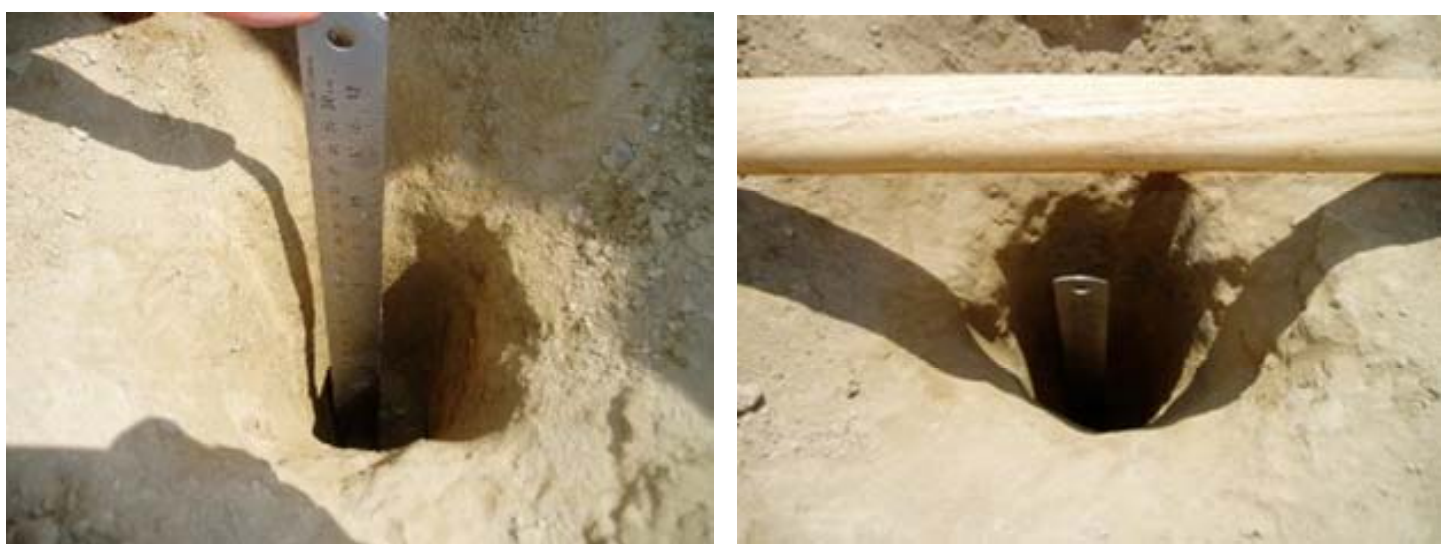

Figure 2.10 Soil sampled from borehole for the laboratory tests

\subsection{Laboratory Tests}

$\mathrm{X}$-ray diffraction (XRD) and thermogravimetric analysis (TGA) tests were performed on the soil samples collected in the field to identify and quantify minerals in the soil.

\subsubsection{X-Ray Diffraction test}

$\mathrm{X}$-ray diffraction (XRD) tests were performed to identify the minerals present in the soil samples. The tests focused on identifying the minerals associated with the chemical reactions of the soil with LKD. The tests were conducted on the fraction of the soil passing No. $200(0.075 \mathrm{~mm})$ sieve. A SIMENS D500, an X-ray diffractometer, was used for the study. From the test results, the presence of calcium oxide $(\mathrm{CaO})$, calcium hydroxide $\left(\mathrm{Ca}(\mathrm{OH})_{2}\right)$, or calcium carbonate $\left(\mathrm{CaCO}_{3}\right)$ in a soil sample are detected. Note that the XRD test can identify the minerals in the sample, but cannot provide a quantitative estimate of the mineral. 


\subsubsection{Thermogravimetric Analysis test}

Thermogravimetric analysis (TGA) tests were performed on the chemically treated soil samples to determine the percentage of calcium hydroxide $\left(\mathrm{Ca}(\mathrm{OH})_{2}\right)$ or calcium carbonate $\left(\mathrm{CaCO}_{3}\right)$ in the soil.

A TGA-2050, thermogravimetric analyzer manufactured by TA Instruments, was used for the study. Approximately $10 \mathrm{mg}$ of soil were placed in the furnace of the analyzer and then heated in a nitrogen gas at a rate of $10{ }^{\circ} \mathrm{C} / \mathrm{min}$ from $20{ }^{\circ} \mathrm{C}$ to $1000{ }^{\circ} \mathrm{C}$. As a result of the test, the weight loss of the soil is plotted with temperature. Different minerals decompose at well-defined temperatures. For example, at $550{ }^{\circ} \mathrm{C}$, calcium hydroxide $\left(\mathrm{Ca}(\mathrm{OH})_{2}\right)$, a hydrated form of lime, decomposes into calcium oxide $(\mathrm{CaO})$ and water $\left(\mathrm{H}_{2} \mathrm{O}\right)$. At $650 \sim 800{ }^{\circ} \mathrm{C}$, calcium carbonate $\left(\mathrm{CaCO}_{3}\right)$, which may be created by carbonation of $\mathrm{Ca}(\mathrm{OH})_{2}$ in the lime-treated subgrade soil, decomposes into calcium oxide $(\mathrm{CaO})$ and carbon dioxide $\left(\mathrm{CO}_{2}\right)$. 


\section{CHAPTER 3. TEST RESULTS AND DISCUSSION}

The results of the field and laboratory tests are presented and discussed in this chapter. The stiffness (or strength) of the chemically-treated and natural (untreated) subgrade soil layers are obtained from the DCP test results. The stiffness of the treated subgrade soil layer is also back-calculated from the LWD deflection data. The water content and dry density of the chemically treated subgrade soils are determined from the nuclear gauge and sand cone test results. Minerals present in the soil are also identified and quantified with the XRD and TGA test results.

The material properties of the subgrade soil with a target treatment thickness of 16 inches are compared with those with a target treatment thickness of 14 inches.

\subsection{Stiffness}

The stiffness of the subgrade soil layer is determined by two methods: DCP and LWD tests. The stiffness of the chemically treated and the natural subgrade soil layers is obtained from the DCP tests. The stiffness of the treated subgrade soil layer is also obtained from the LWD tests.

Figures 3.1 to 3.22 show DCPI (Dynamic Cone Penetration Index) with depth of penetration, measured at all forty six locations. Note that DCPI is in inches per blow. Figures 3.1 to 3.11 correspond to section (1), namely, the section (between STA. $6+700$ and STA. $6+800$ ) where chemical treatment was done with a target thickness of 16 inches, while Figures 3.12 to 3.22 correspond to section (2) or the section (between STA. $6+560$ 
and STA. $6+660$ ) where chemical treatment was done with a target thickness of 14 inches. For example, Figure 3.1 shows three plots obtained at STA. $6+700$, section (1): one recorded at the center of the north-bound road, one at the driving lane, and the last one at the passing lane. The figure illustrates some of the features that are discussed in the following comments.

At the center of the road, at STA. $6+700$, the DCPI was less than 0.25 inches/blow at depths between 2 and 12 inches below the top of the subgrade, and was equal to or larger than 1 inches/blow at depths of 16 inches or deeper (Figure 3.1). In other words, there are two clear layers that show a considerable difference of DCPI values: (1) an upper layer, where the DCPIs are to some extent constant with a smaller value; and (2) a lower layer, where the DCPIs are considerably larger than those measured on the upper layer. This can be interpreted as an increase in strength and/or stiffness of the upper subgrade layer due to the chemical treatment. We introduce the term "effective" thickness of the chemically treated subgrade as the actual thickness of the chemically treated subgrade soil layer, and has low and approximately constant DCPI. Comparing the effective thickness of the chemically treated subgrade with the corresponding target treatment thickness of the subgrade, the success of the quality control done during the chemical treatment can be evaluated. The value of DCPI of 0.5 inches/blow seems to define well the concept of effective thickness in this work (note that a DCPI of 0.2 inches/blow was used in the previous research, i.e. INDOT SPR-3007, to define the effective thickness). For instance, in Figure 3.1, the effective thickness of the treated subgrade soil layer is 14 inches at the center of the road at STA. $6+700$. The increase in stiffness (or a smaller value of DCPI) of the upper subgrade layer is also observed at the 
driving lane at the same STA., while it is not observed at the passing lane (Figure 3.1). The trend is also found in all the plots in Figures 3.2 to 3.22, although some figures, e.g. Figure 3.6, may not show this as clearly as others.

It is also interesting to note that at the transition between the two layers (treated and untreated), and for a short depth, there may be a substantial increase of DCPI values; for example, at a depth of 16 inches at the center of the road in Figure 3.3. This phenomenon is observed in other plots of DCPI with depth. This observation was previously reported in the previous research (INDOT SPR-3007). The spikes may indicate soil disturbance during construction at the contact between the treated and untreated layers.

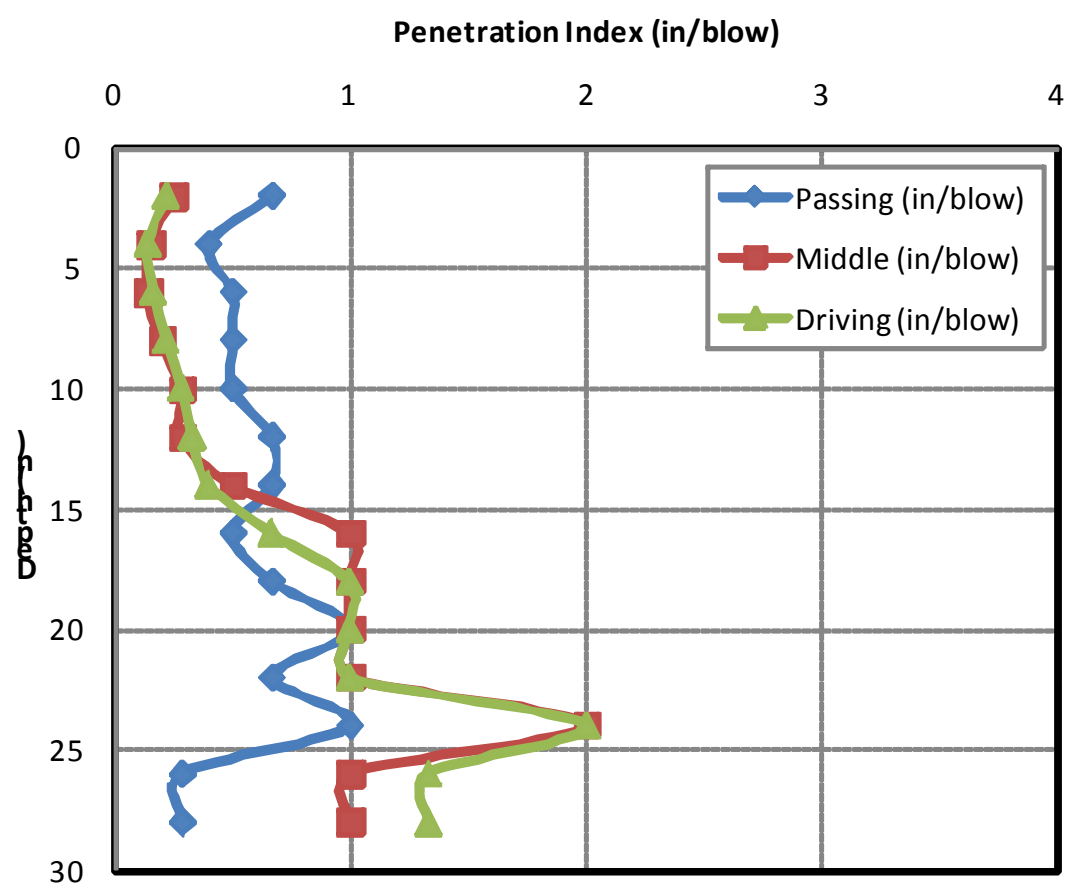

Figure 3.1 DCP test results with depth at STA. 6+700. Section (1) 


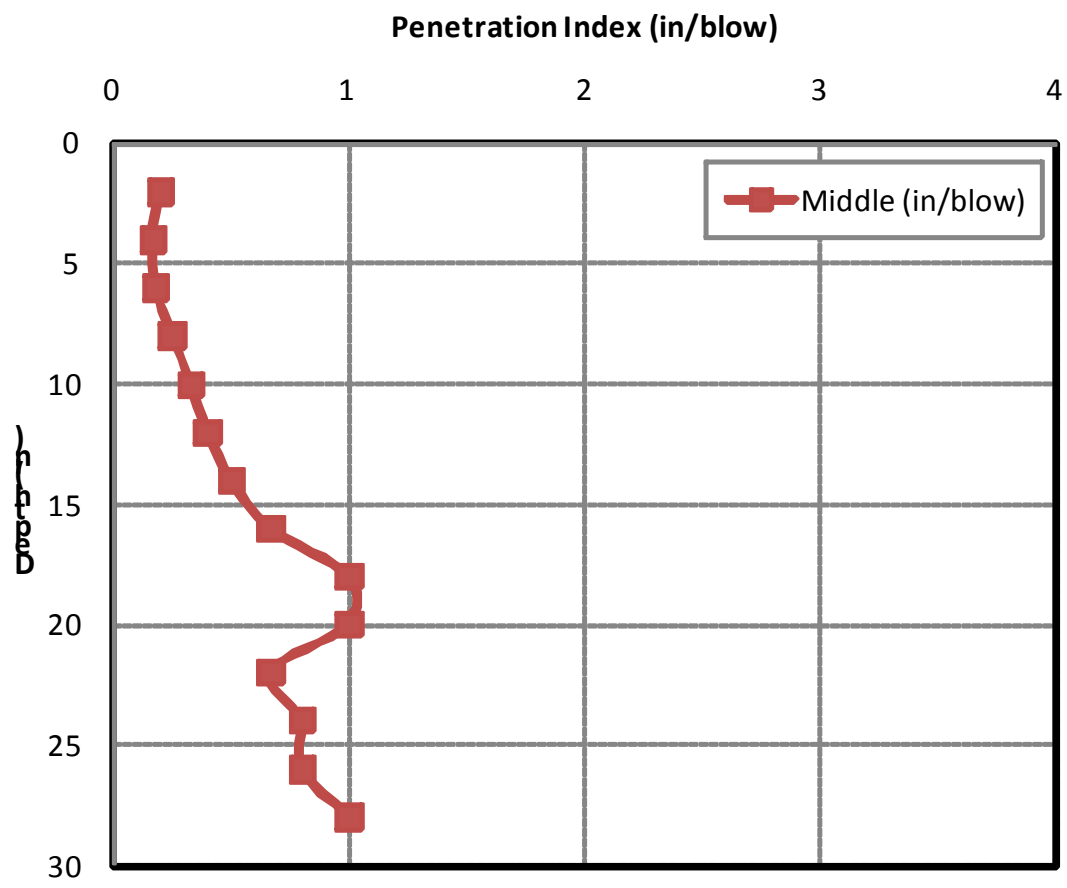

Figure 3.2 DCP test results with depth at STA. $6+710$. Section (1)

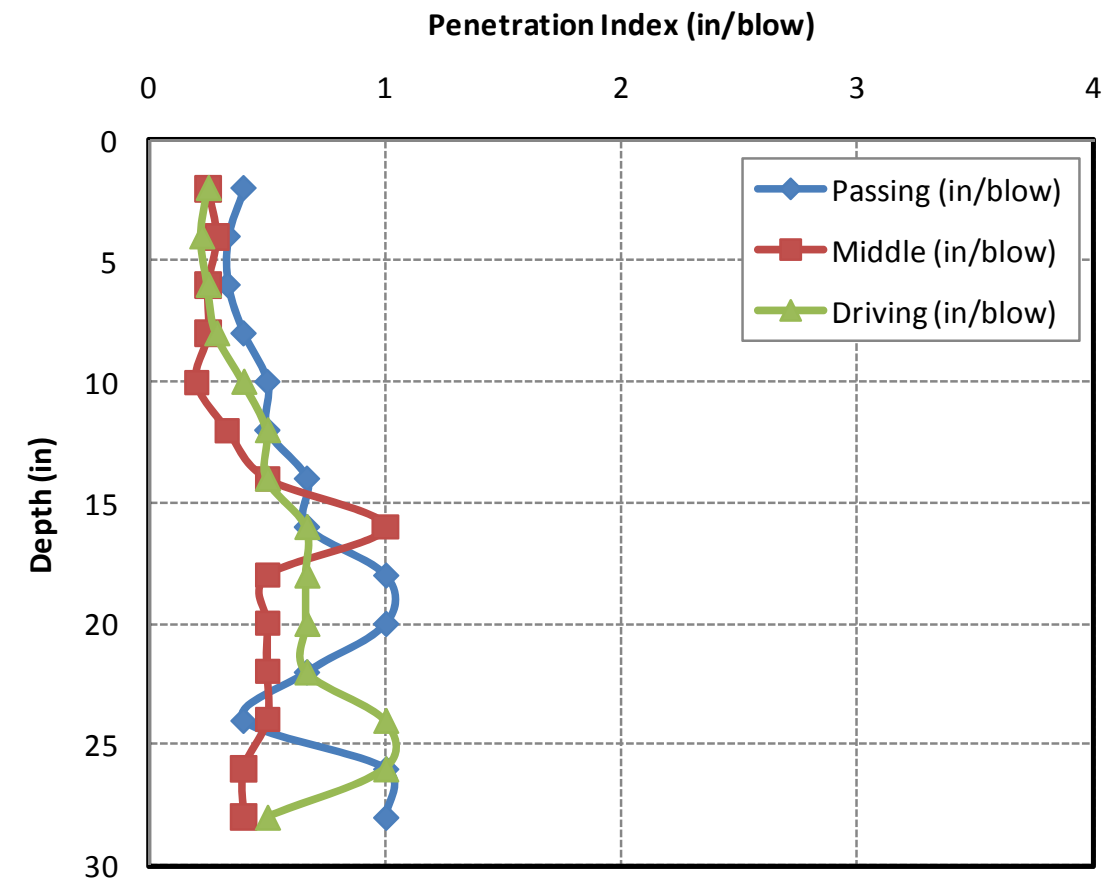

Figure 3.3 DCP test results with depth at STA. 6+720. Section (1) 


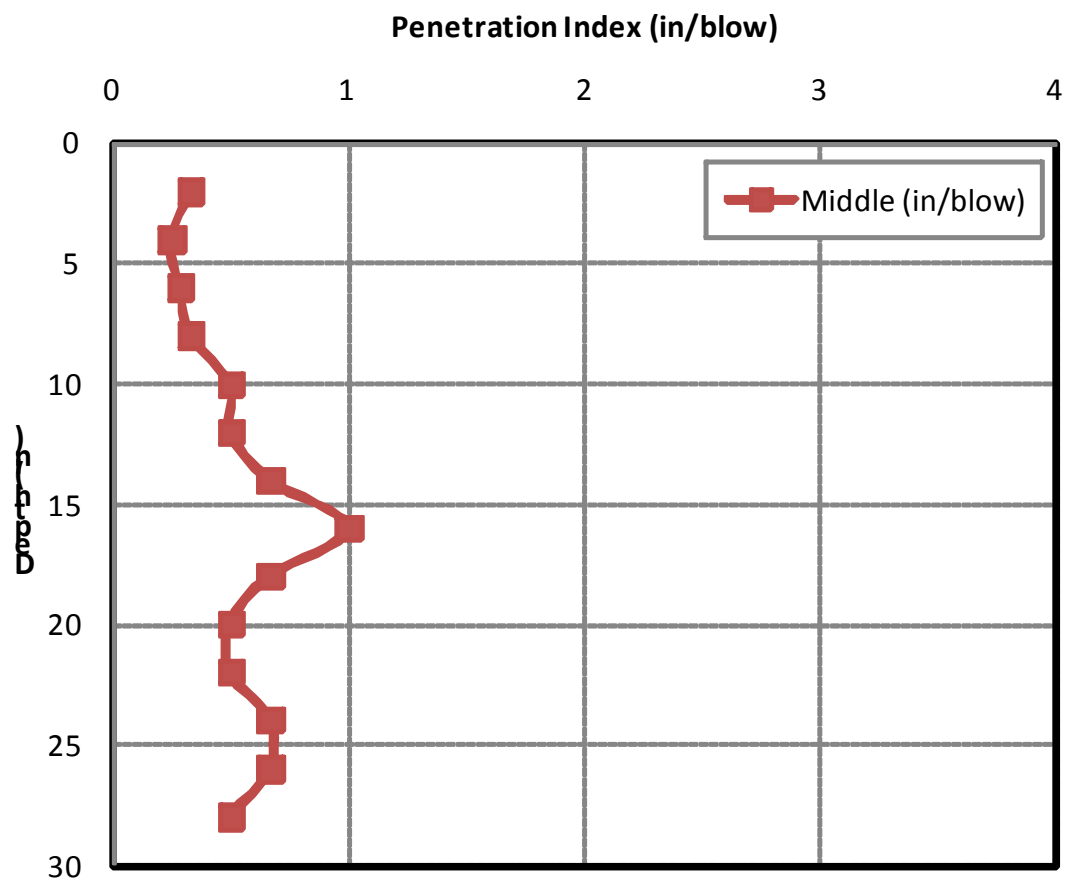

Figure 3.4 DCP test results with depth at STA. 6+730. Section (1)

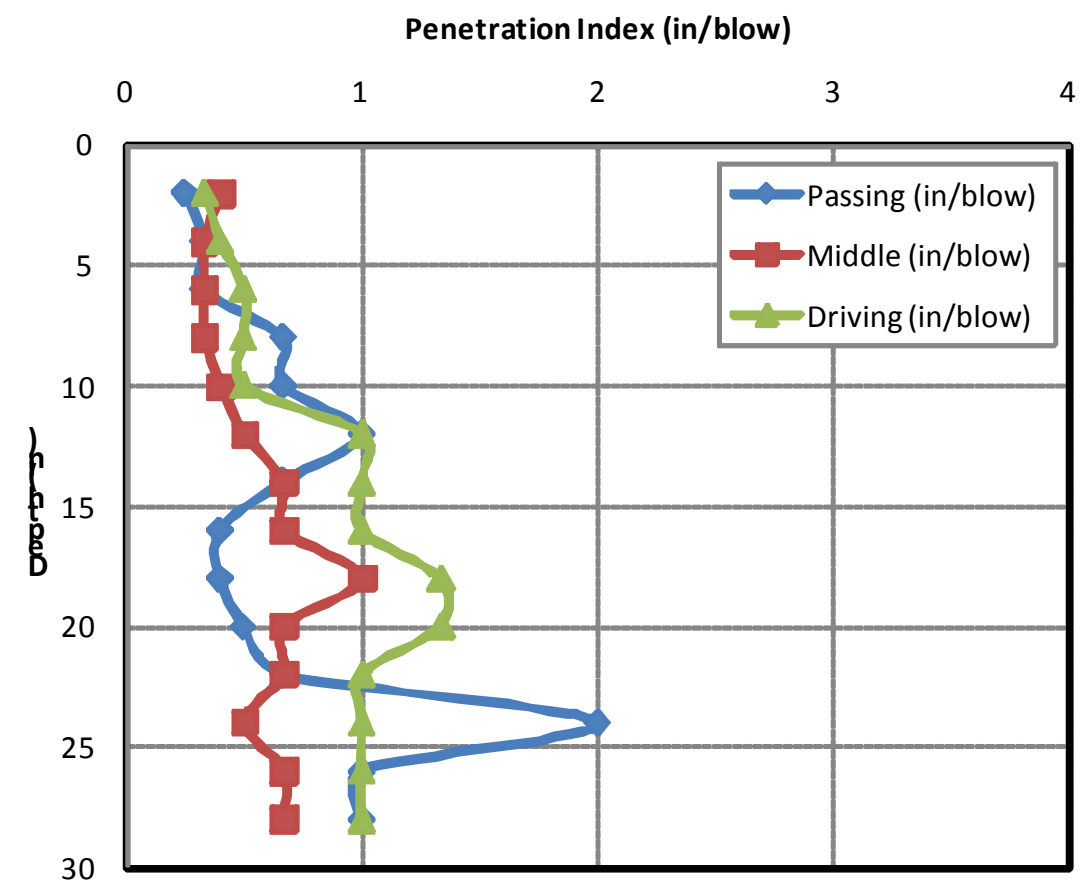

Figure 3.5 DCP test results with depth at STA. 6+740. Section (1) 


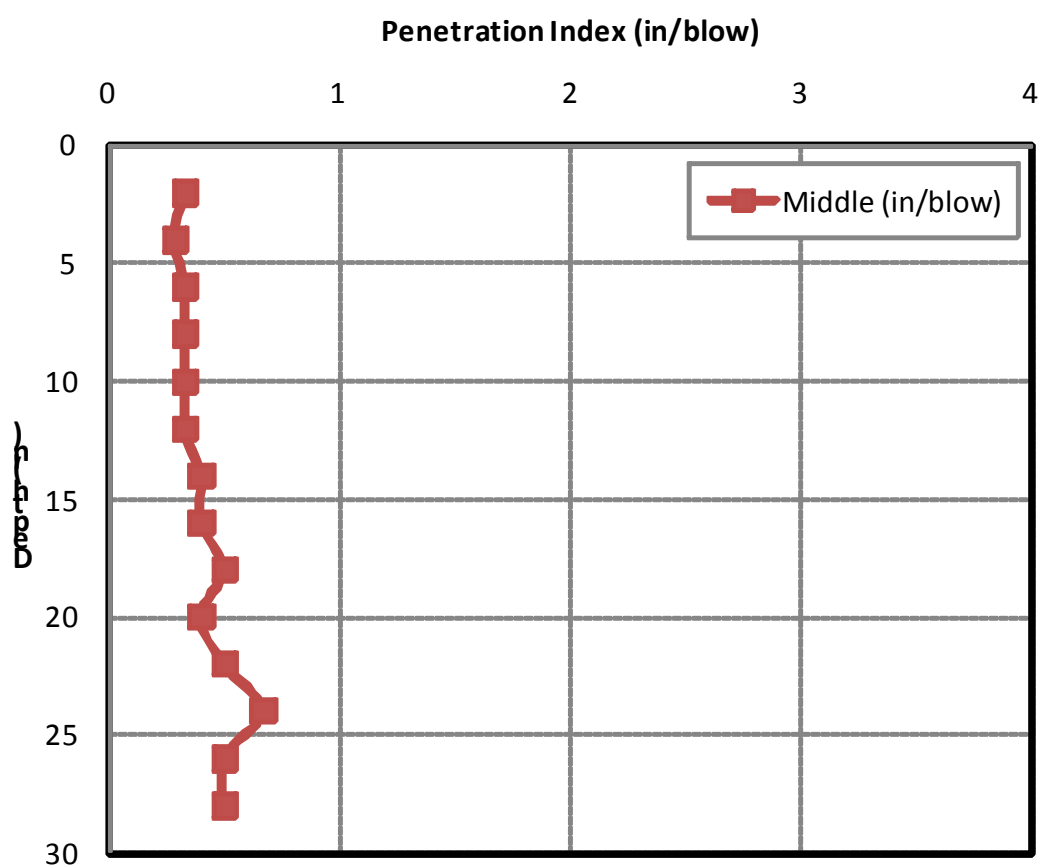

Figure 3.6 DCP test results with depth at STA. $6+750$. Section (1)

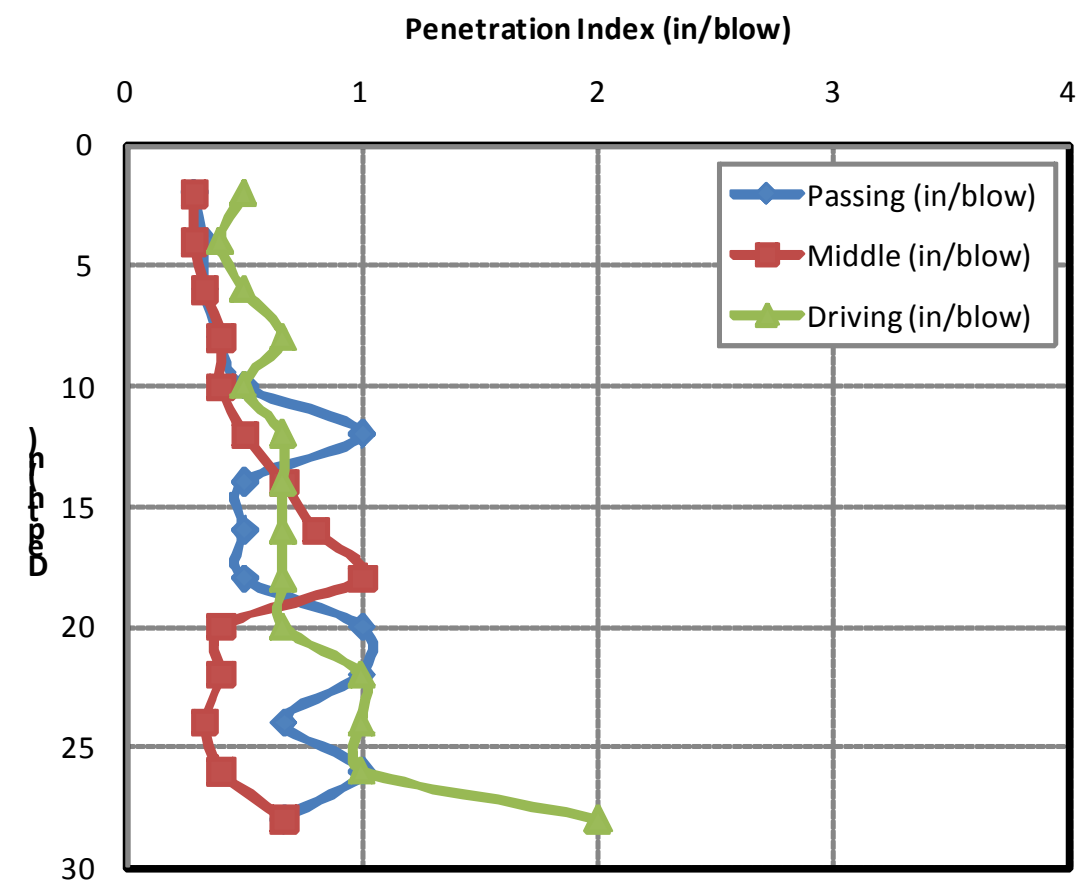

Figure 3.7 DCP test results with depth at STA. 6+760. Section (1) 


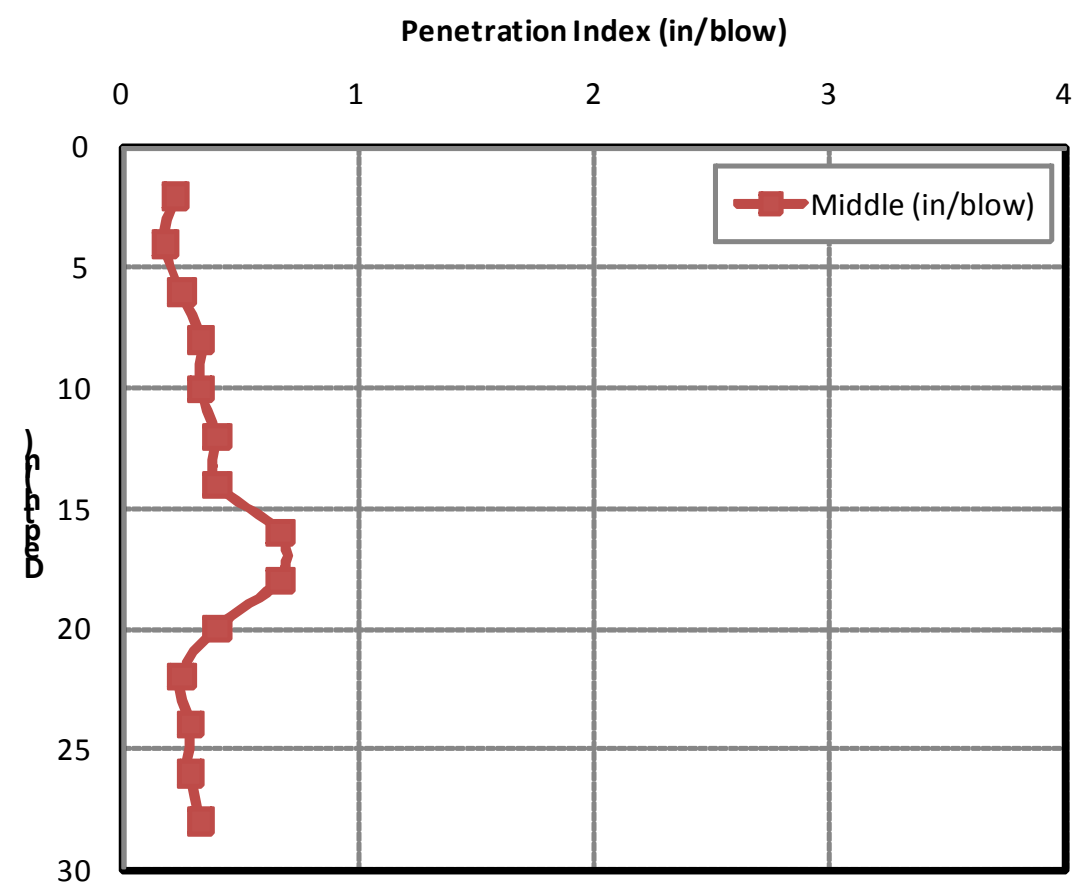

Figure 3.8 DCP test results with depth at STA. 6+770. Section (1)

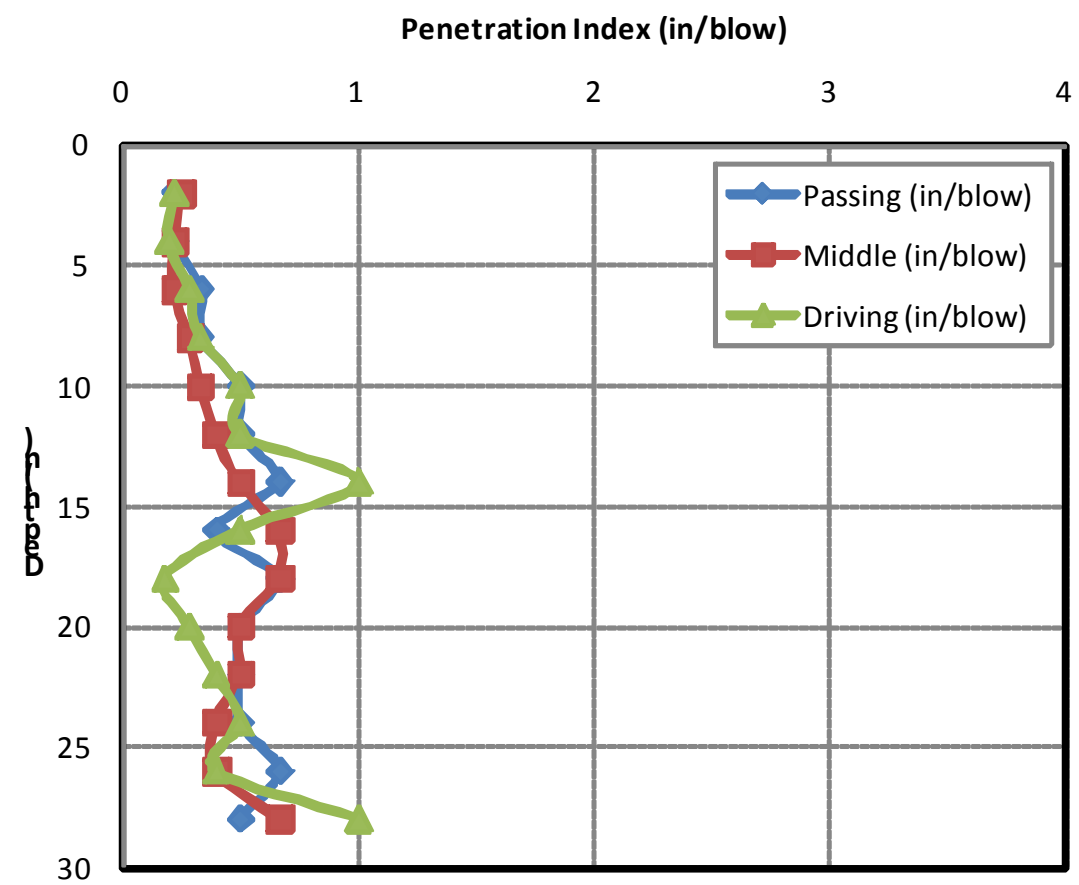

Figure 3.9 DCP test results with depth at STA. $6+780$. Section (1) 


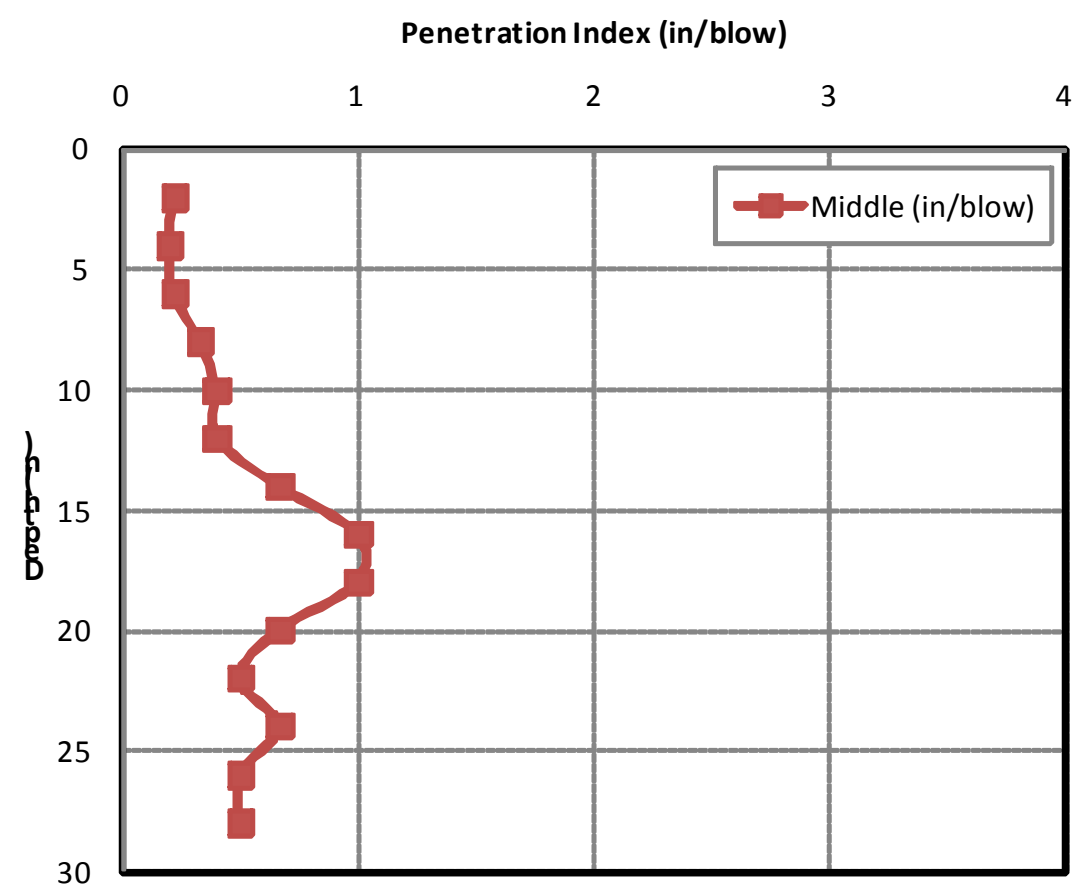

Figure 3.10 DCP test results with depth at STA. 6+790. Section (1)

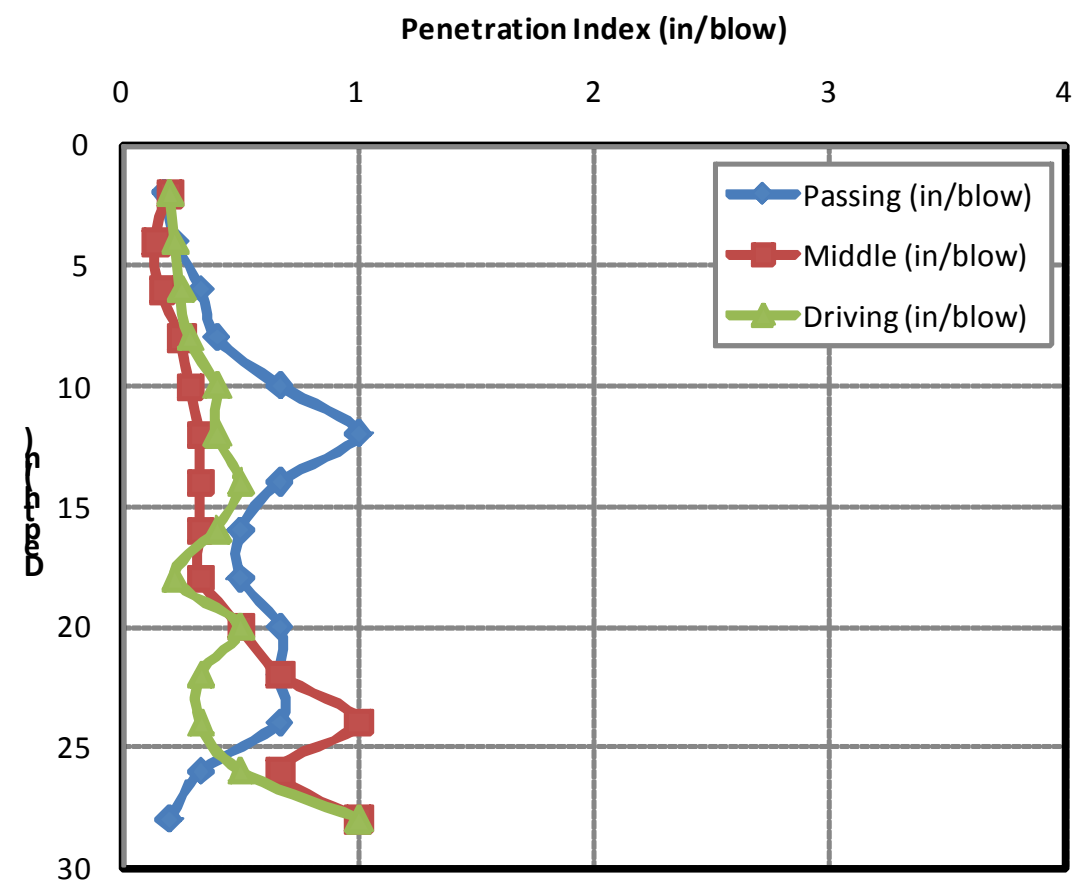

Figure 3.11 DCP test results with depth at STA. 6+800. Section (1) 


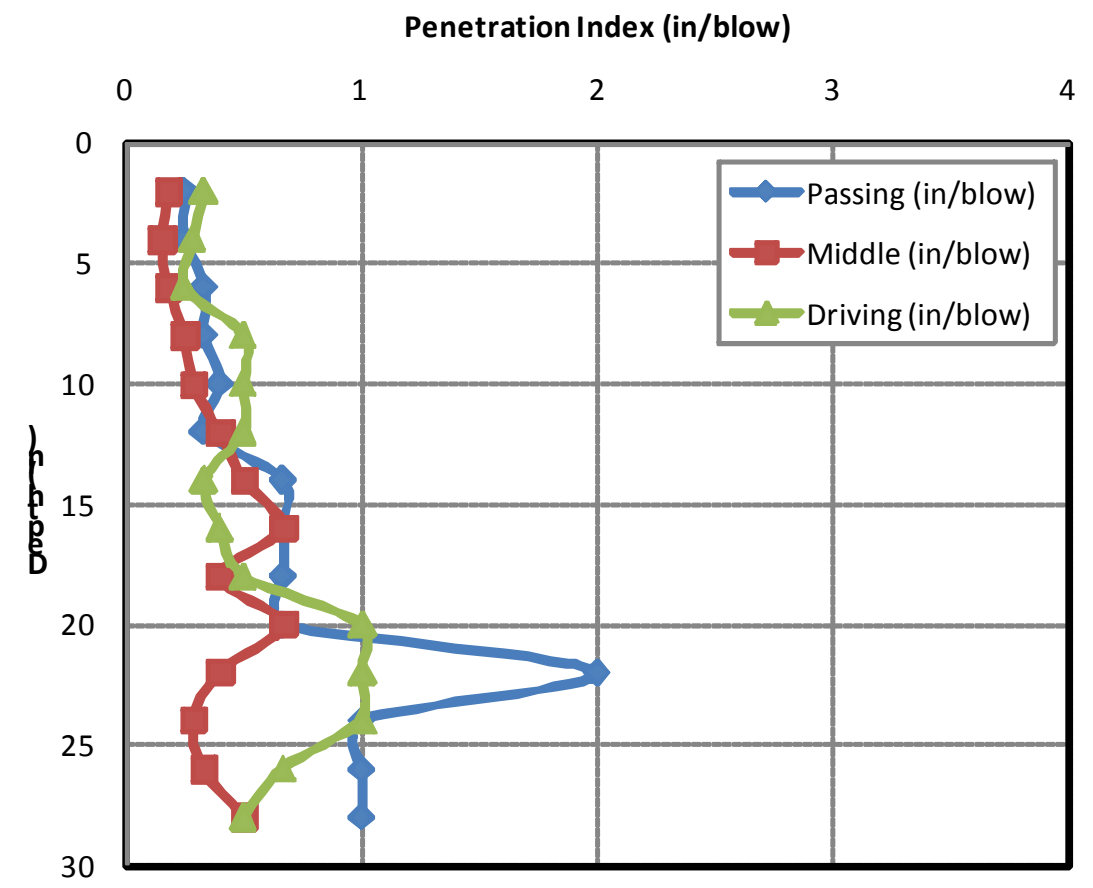

Figure 3.12 DCP test results with depth at STA. 6+560. Section (2)

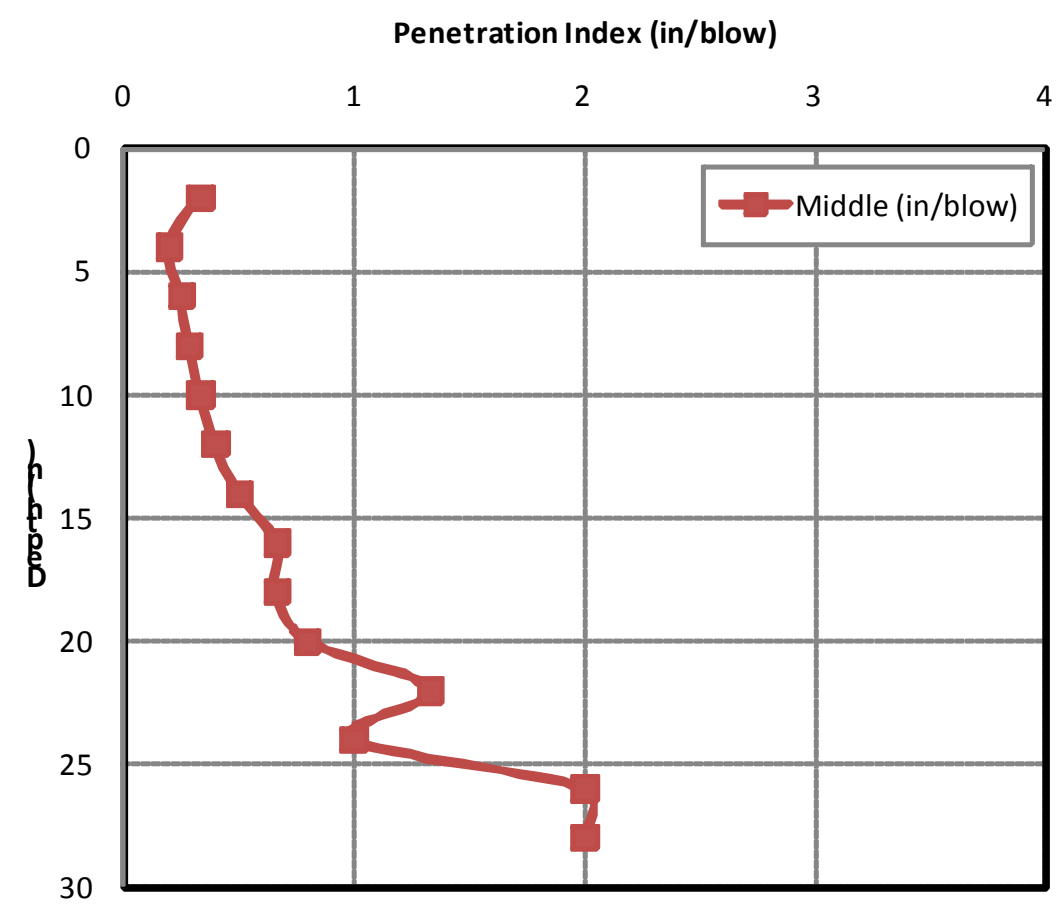

Figure 3.13 DCP test results with depth at STA. 6+570. Section (2) 


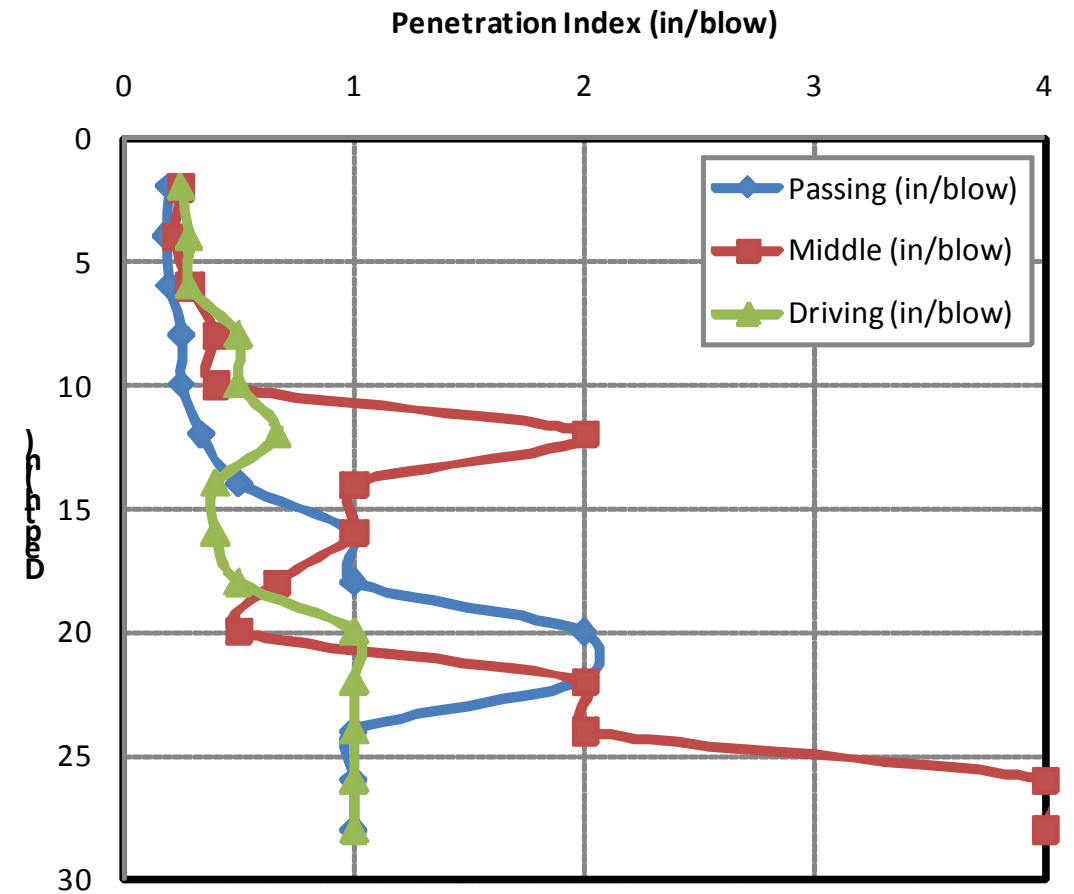

Figure 3.14 DCP test results with depth at STA. 6+580. Section (2)

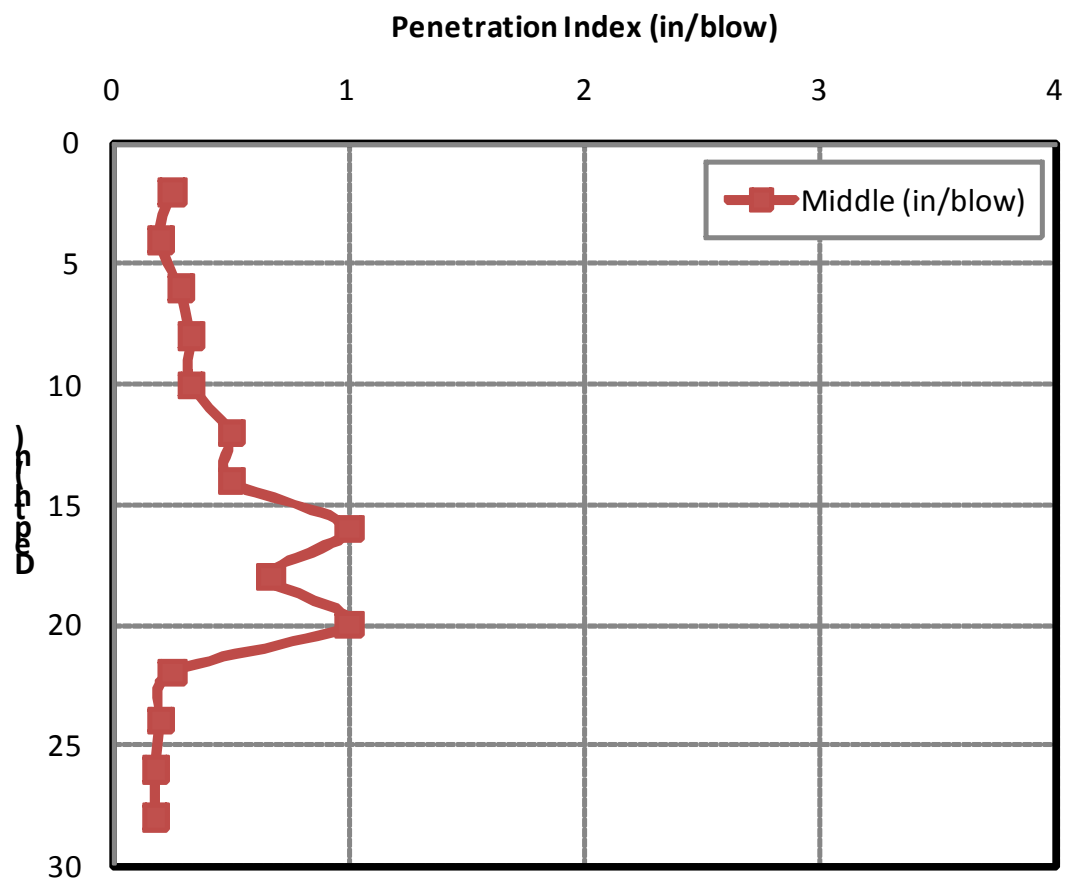

Figure 3.15 DCP test results with depth at STA. 6+590. Section (2) 


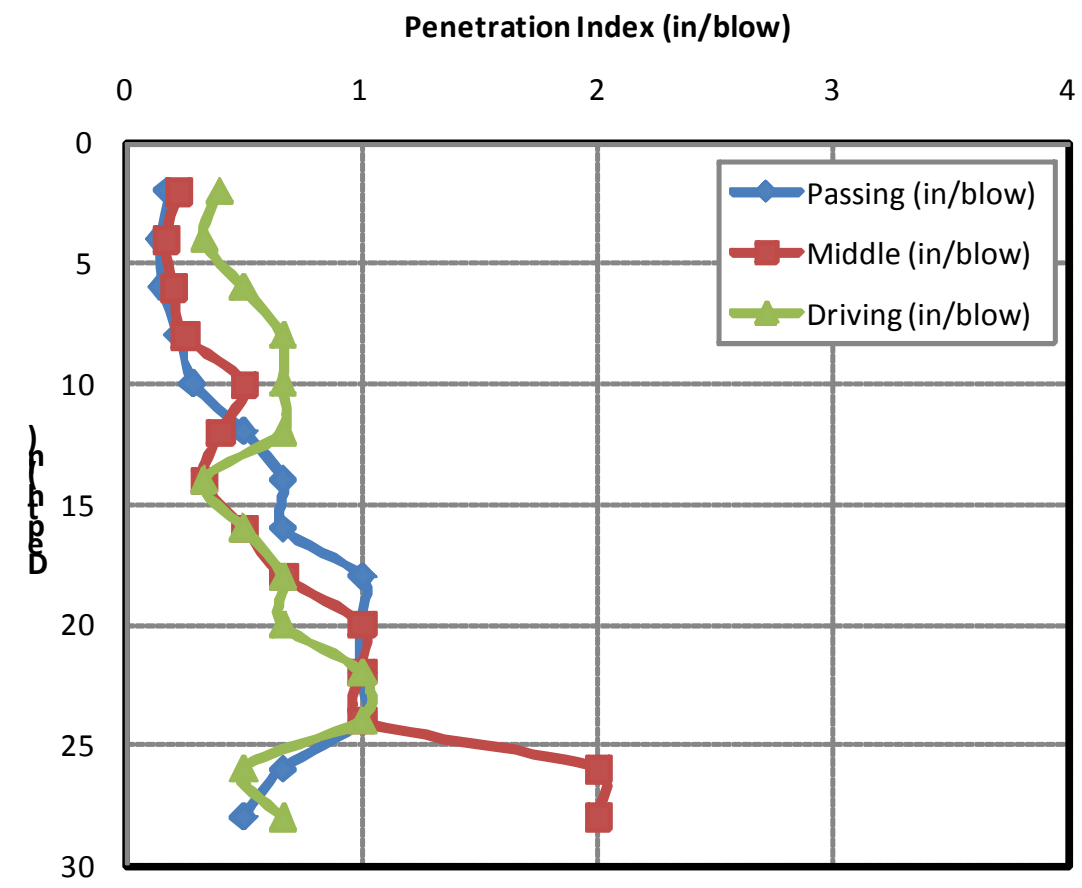

Figure 3.16 DCP test results with depth at STA. $6+600$. Section (2)

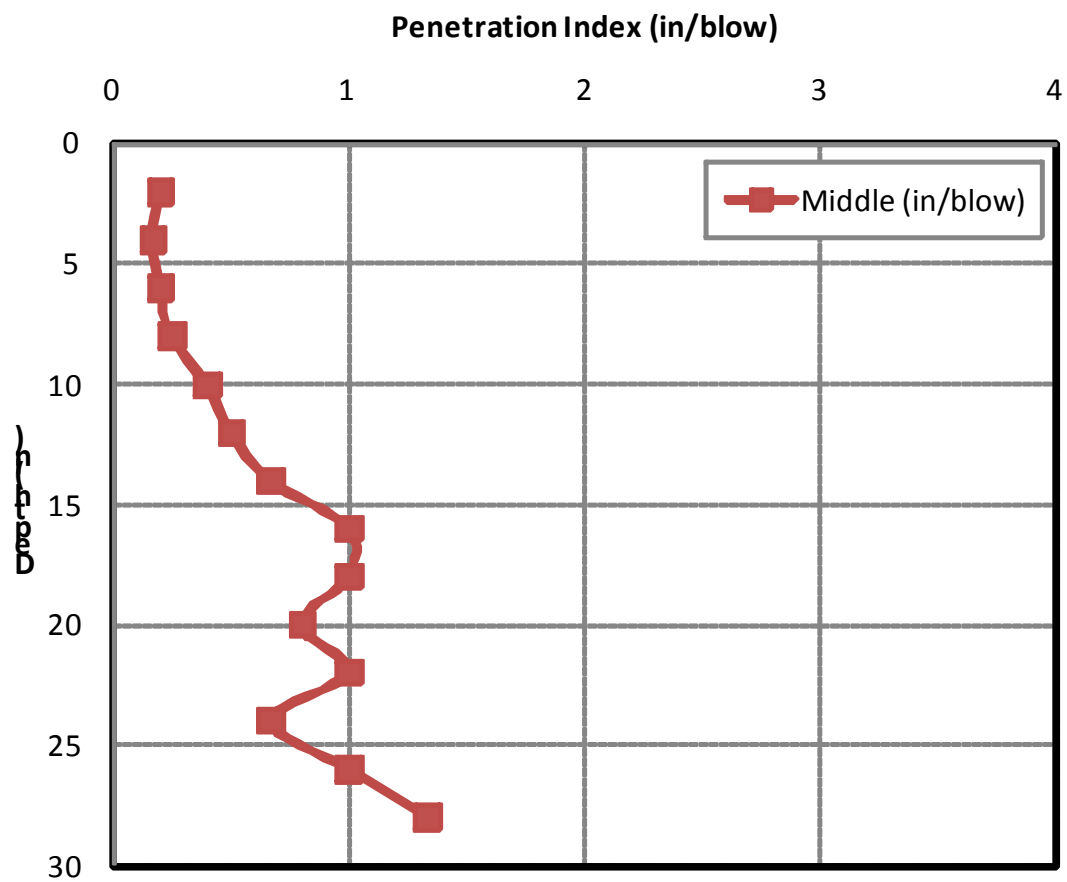

Figure 3.17 DCP test results with depth at STA. 6+610. Section (2) 


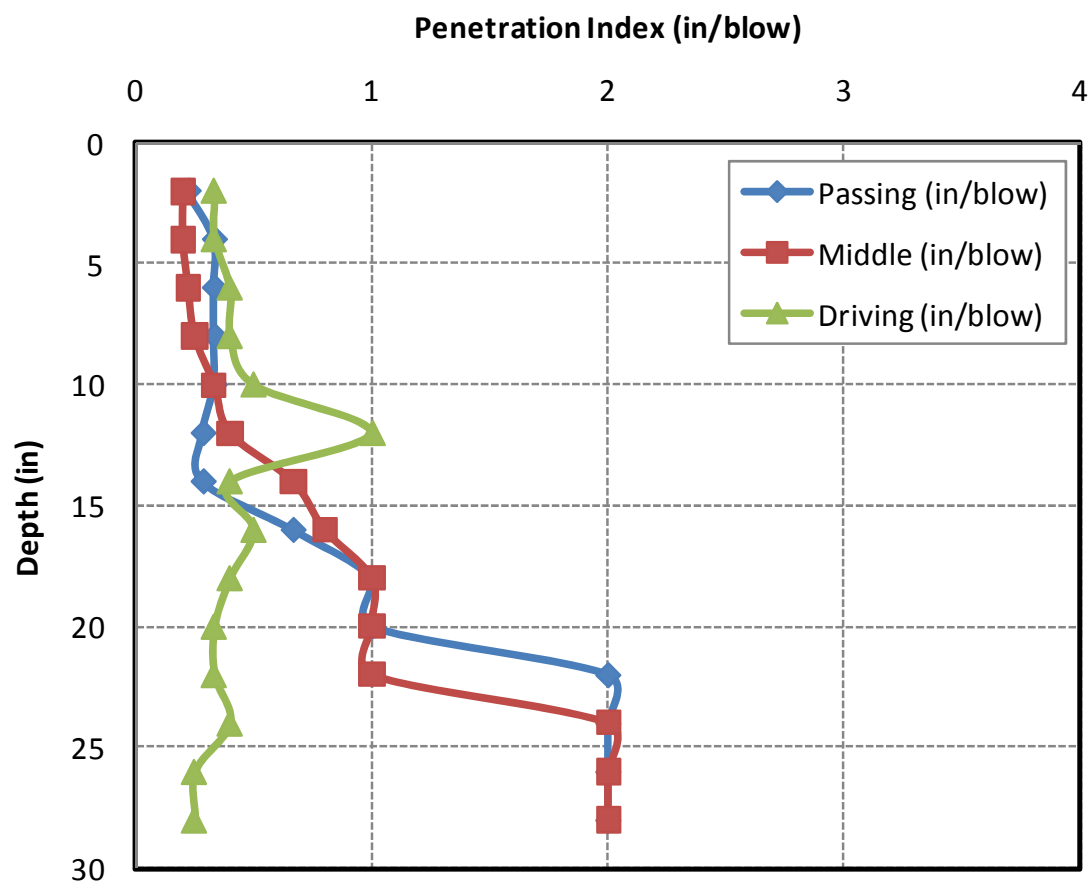

Figure 3.18 DCP test results with depth at STA. $6+620$. Section (2)

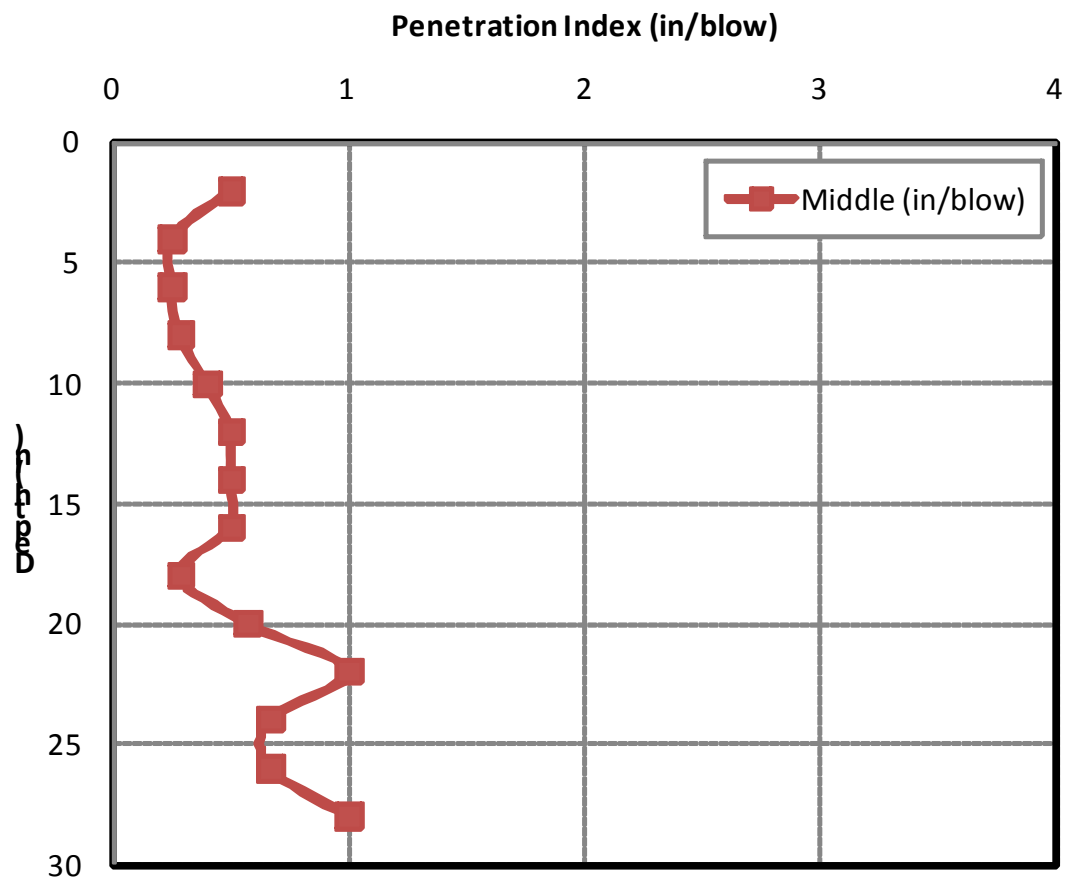

Figure 3.19 DCP test results with depth at STA. 6+630. Section (2) 


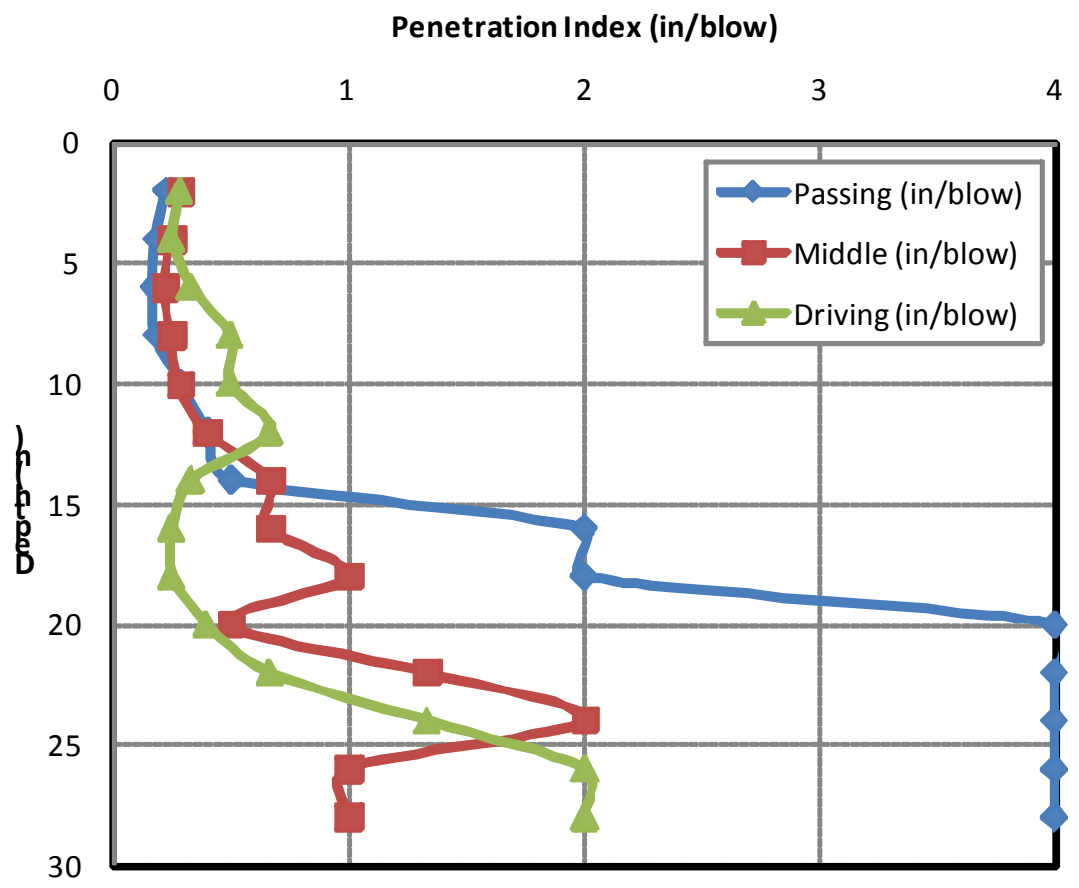

Figure 3.20 DCP test results with depth at STA. $6+640$. Section (2)

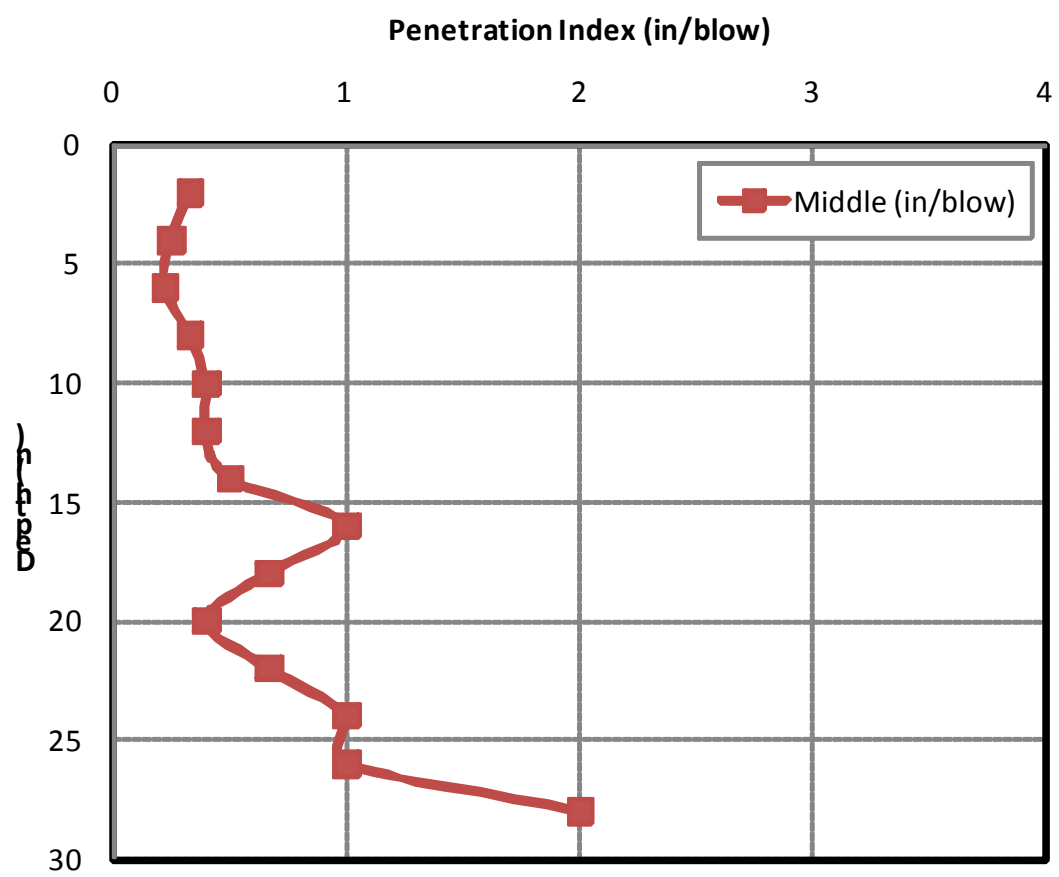

Figure 3.21 DCP test results with depth at STA. 6+650. Section (2) 


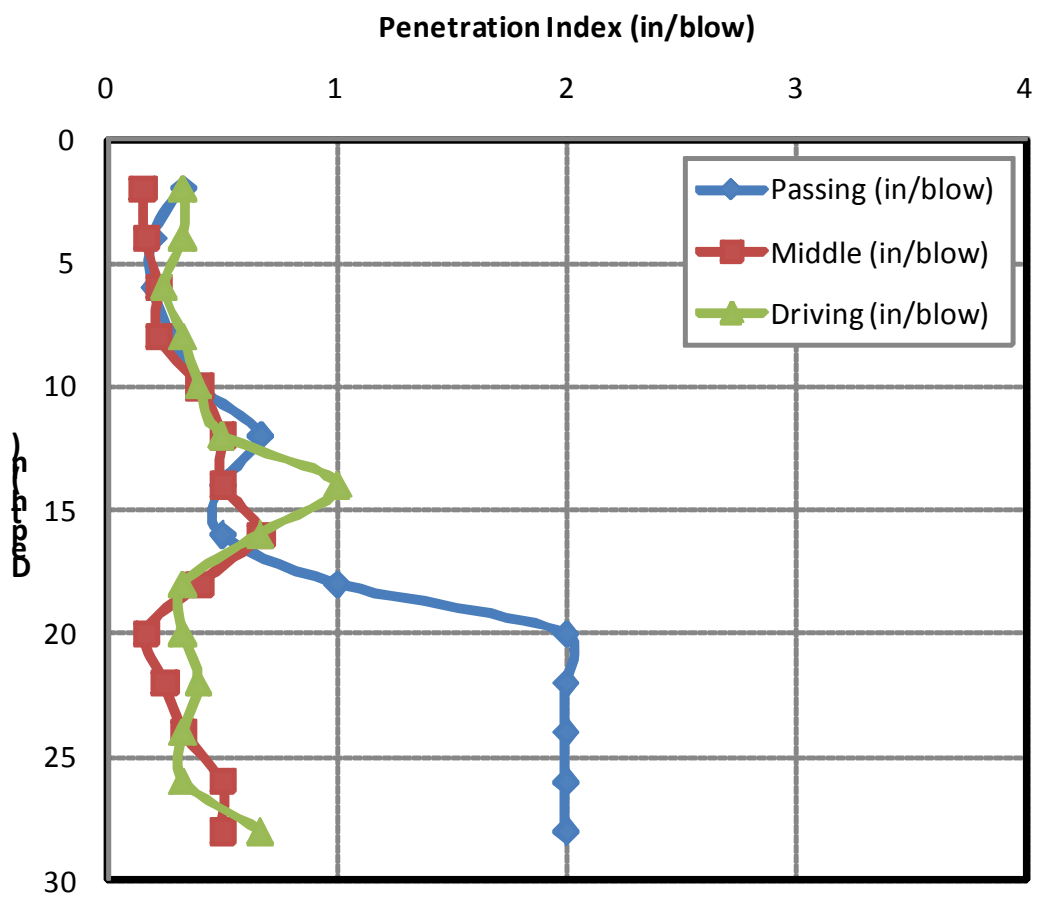

Figure 3.22 DCP test results with depth at STA. 6+660. Section (2)

Figures 3.23 and 3.24 are contour plots of the effective thickness of the chemically treated subgrade soil layer at sections (1), i.e. treatment of 16 inches, and (2) with 14 inches treatment, respectively. The contour plots are obtained from all DCP test results measured at all forty six test locations and presented in Figures 3.1 to 3.22. In Figures 3.23 and 3.24, the horizontal axis represents the road axis while the vertical axis represents the road width. The effective thickness ranges approximately from 11 to 19 inches in section (1), while it ranges from 11 to 15 inches in section (2). The average and standard deviation of the effective thickness are 15.0 and 4.3 inches, respectively, for section (1), and are 13.4 and 2.4 inches for section (2). The smaller value of standard deviation of the effective thickness for section (2) indicates that a better quality control was done in the field, during the chemical treatment, for the section with 14 inches target 
depth, section (2), than for the section with 16 inches target depth, section (1).

It is also observed that, between STA. $6+780$ and STA. $6+700$ at section (1), the effective thickness at the driving lane is in general smaller than that at the passing lane (Figure 3.23). As mentioned in chapter 2, section (1) is located on a curve where the elevation of the driving lane is larger than that of the passing lane. The difference in elevation of the road cross section may have had some influence in quality control, or perhaps there was trimming of the upper part of the subgrade to comply with the geometry requirements.

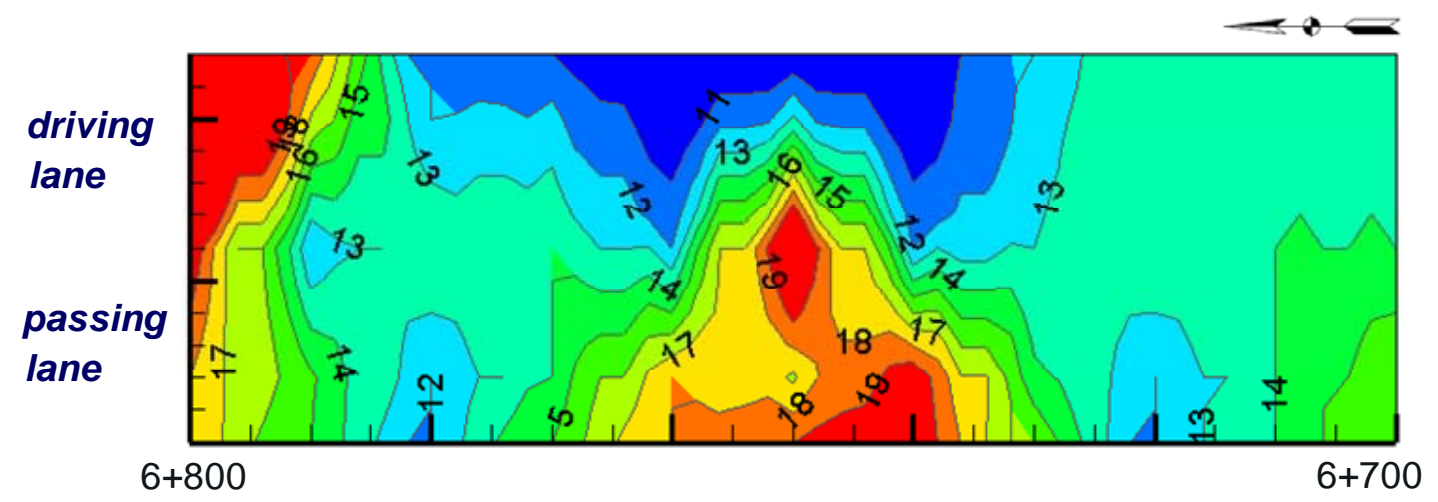

Figure 3.23 Effective thickness of chemically treated subgrade soil layer (in inches). Section (1).

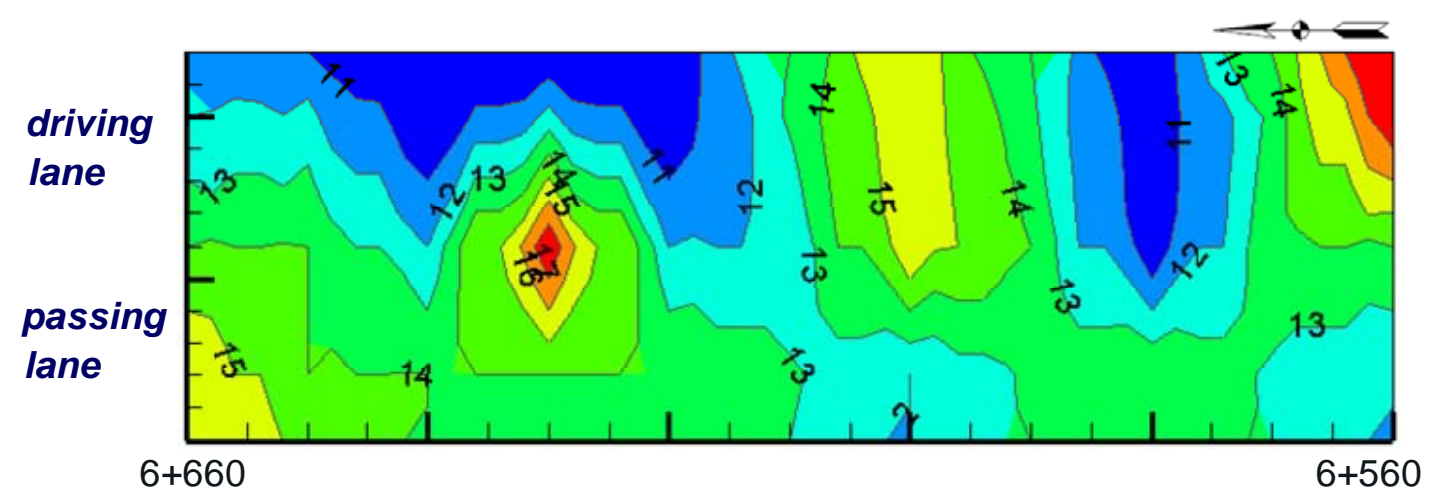

Figure 3.24 Effective thickness of chemically treated subgrade soil layer (in inches). Section (2). 
Figures 3.25 and 3.26 plot contour lines of CBR of the treated subgrade for the 16 inches thick subragde, section (1), and the 14 inches subgrade, section (2), respectively. The CBR values are obtained with the correlation between DCPI and CBR (Webster et al., 1992), which was included in chapter 2 . The contour lines are obtained by averaging, at each location, DCPI values over the effective thickness of treatment. The CBR of the treated subgrade soil layer ranges approximately between 20 and 35 for section (1) and between 25 and 40 for section (2). The average and standard deviation of the CBR of the treated subgrade are 27.5 and 7.4 for the 16 inches thick treated subgrade and 30.7 and 6.6 for the 14 inches subgrade. This represents an increase of about $10 \%$ of the CBR of the 14 inches thick treated subgrade over the 16 inches subgrade. Note that the standard deviation is lower for the 14 inches thick subgrade than for the 16 inches thick subgrade, which denotes a more uniform result.

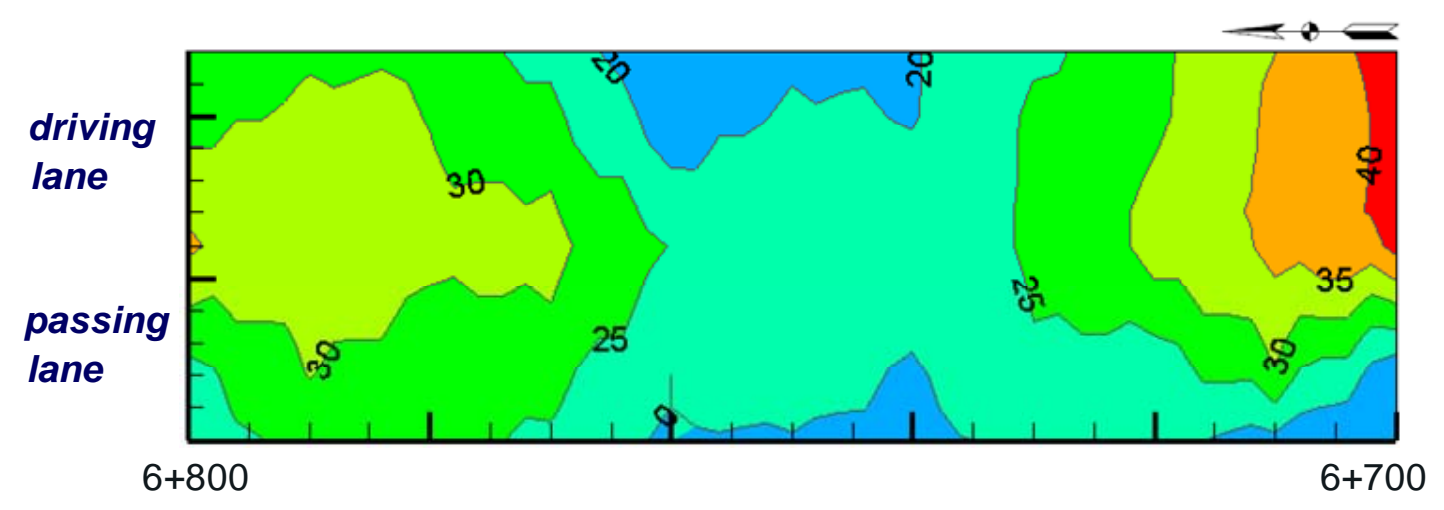

Figure 3.25 Average CBR calculated within effective thickness of chemically treated subgrade soil layer below top of subgrade. Section (1). 


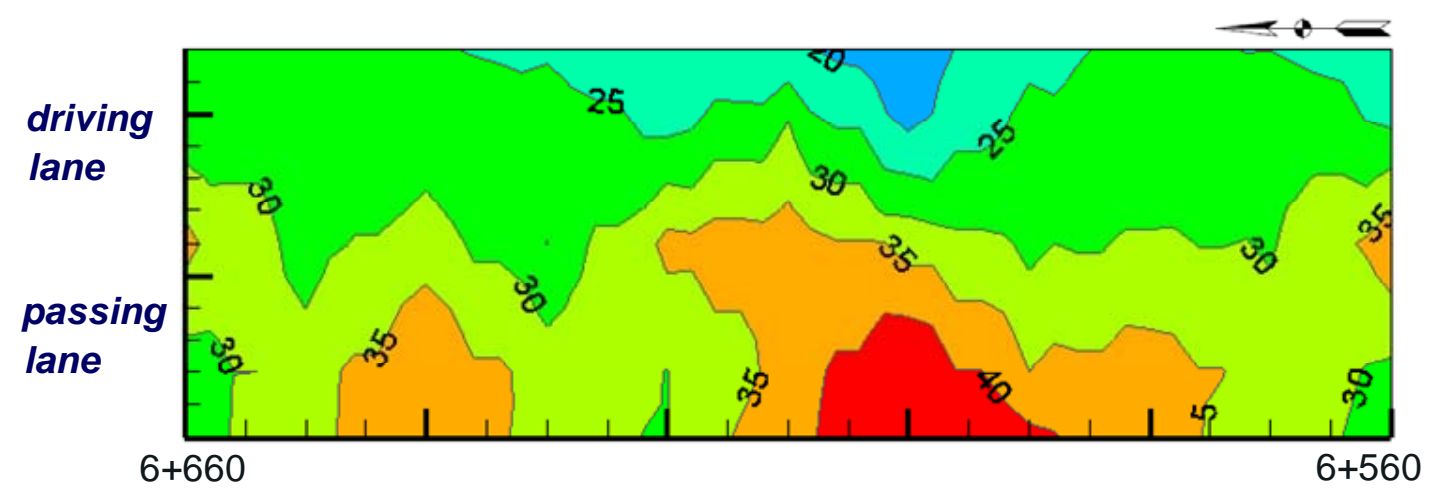

Figure 3.26 Average CBR calculated within effective thickness of chemically treated subgrade soil layer below top of subgrade. Section (2).

Figures 3.27 and 3.28 are contour plots that represent the CBR of the treated subgrade for the 16 inches and 14 inches thick treatment, respectively. The contour lines are obtained by averaging, at each location, DCPI values over the target (theoretical) thickness of treatment. The CBR of the treated subgrade soil layer ranges approximately between 20 and 35 for section (1) that has as target a 16-inch thick treated subgrade, and between 25 and 40 inches for section (2) with a target 14-inch thick treated subgrade. The average and standard deviation are 25.6 and 7.1 for section (1) and 29.4 and 6.5 for section (2). The CBR of the 14 inches thick treated subgrade is about $15 \%$ larger than for the 16 inches subgrade and has smaller standard deviation, i.e. the treatment is more uniform. 


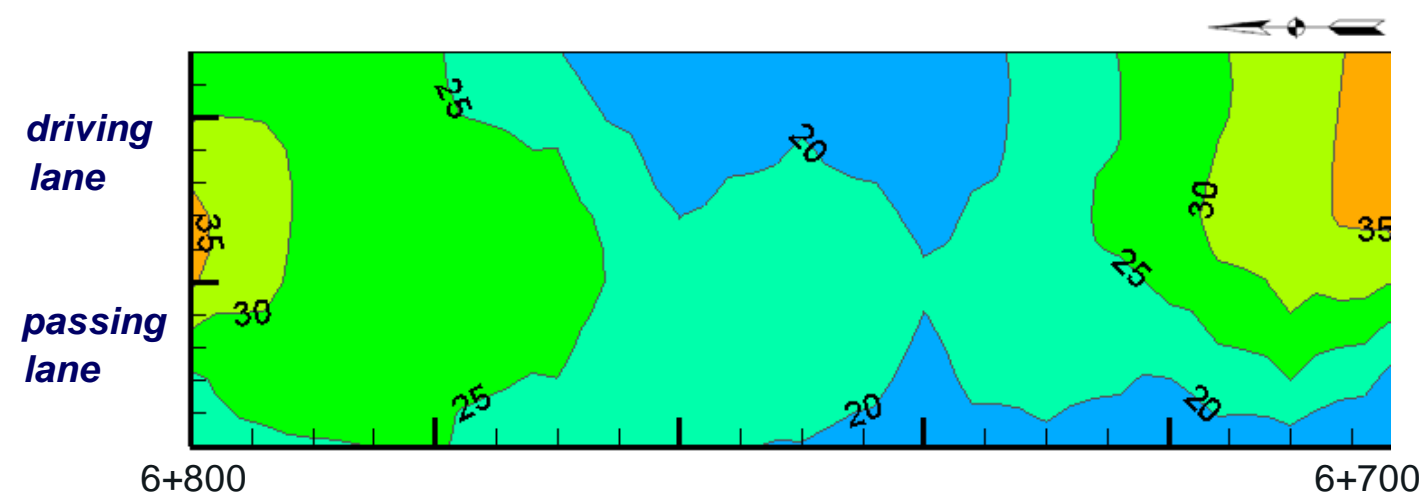

Figure 3.27 Average CBR calculated over target treatment thickness of subgrade below top of subgrade. Section (1).

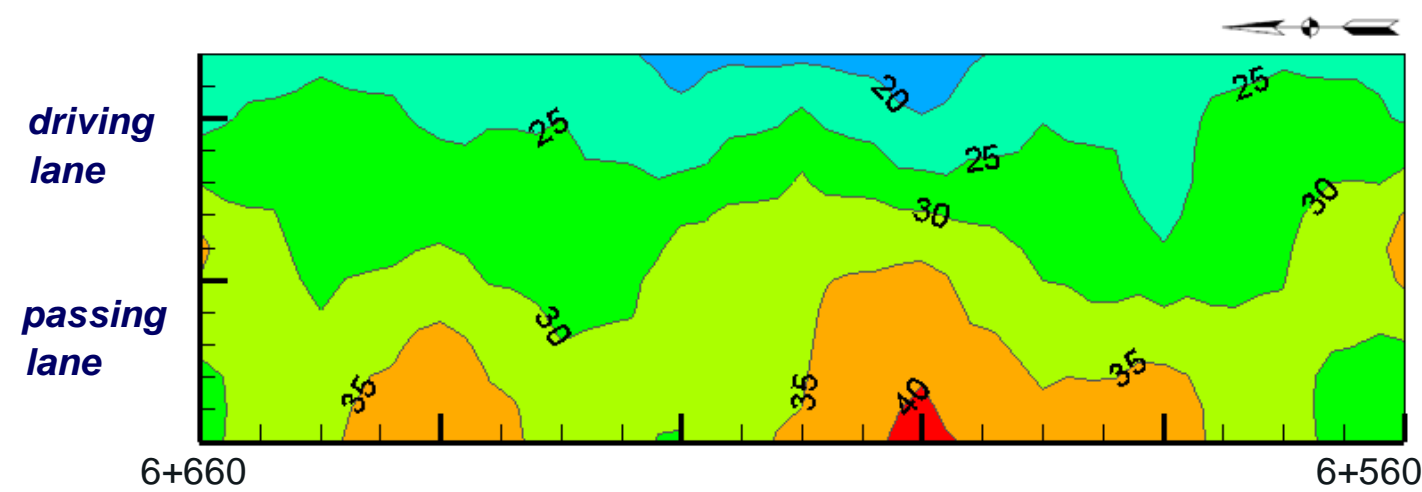

Figure 3.28 Average CBR calculated over target treatment thickness of subgrade below top of subgrade. Section (2).

Figures 3.29 and 3.30 represent how much the stiffness of the treated subgrade improved due to the chemical treatment, compared to the stiffness of the underlying untreated (natural) soil. The figures plot the ratio of the increase of the CBR of the chemically treated subgrade soil with respect to the CBR of the natural subgrade soil layer, and the CBR of the natural subgrade soil layer for sections (1) and (2), respectively. The CBR of the chemically treated subgrade soil is obtained by averaging DCPI values over the target treatment thickness while the CBR of the natural subgrade soil layer is 
obtained by averaging DCPI values of the untreated subgrade layer. The CBR of the natural subgrade soil layer ranges approximately between 10 and 25 for section (1) and between 5 and 25 inches for section (2). The average and standard deviation of the CBR of the natural subgrade soil are 14.5 and 5.7, respectively, for section (1) and 12.6 and 7.7 for section (2). Figures 3.29 and 3.30 show that the increase of CBR ranges approximately between 50 and $400 \%$ for section (1), mostly around $100 \%$, while the increase ranges between 100 and $700 \%$, with an average of $350 \%$, for section (2). The stiffness gain of the subgrade soil layer due to chemical treatment is more important in section (2) with 14 inches, than for section (1) with 16 inches of treated subgrade.

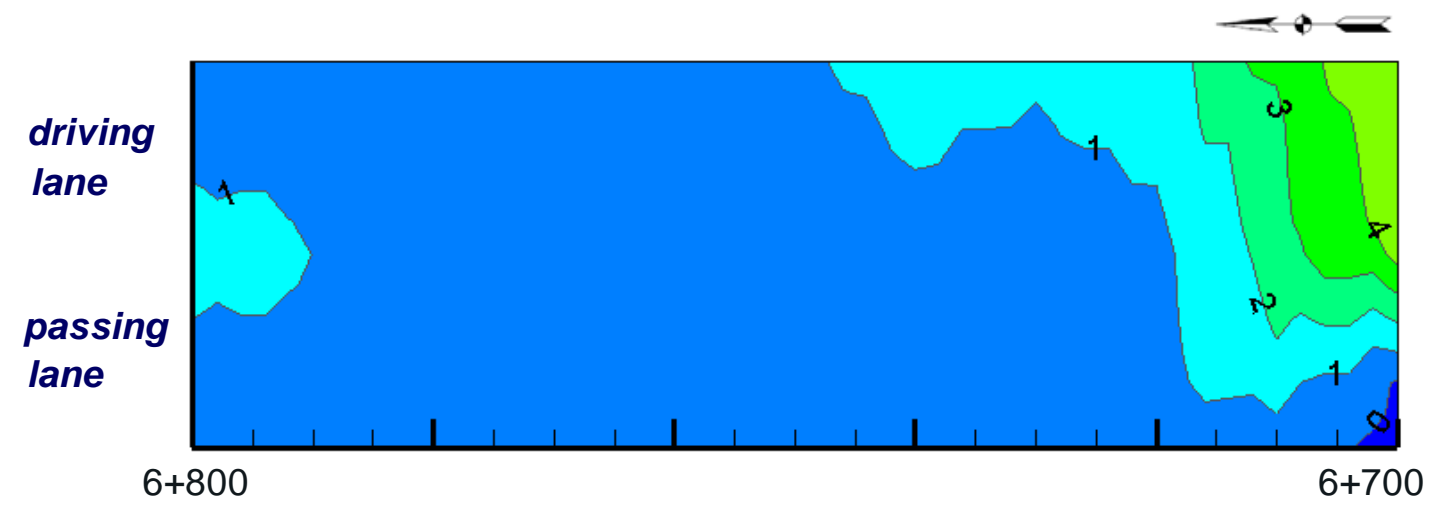

Figure 3.29 Incremental ratio of CBR of chemically treated subgrade soil layer to CBR of natural subgrade soil layer. Section (1). 


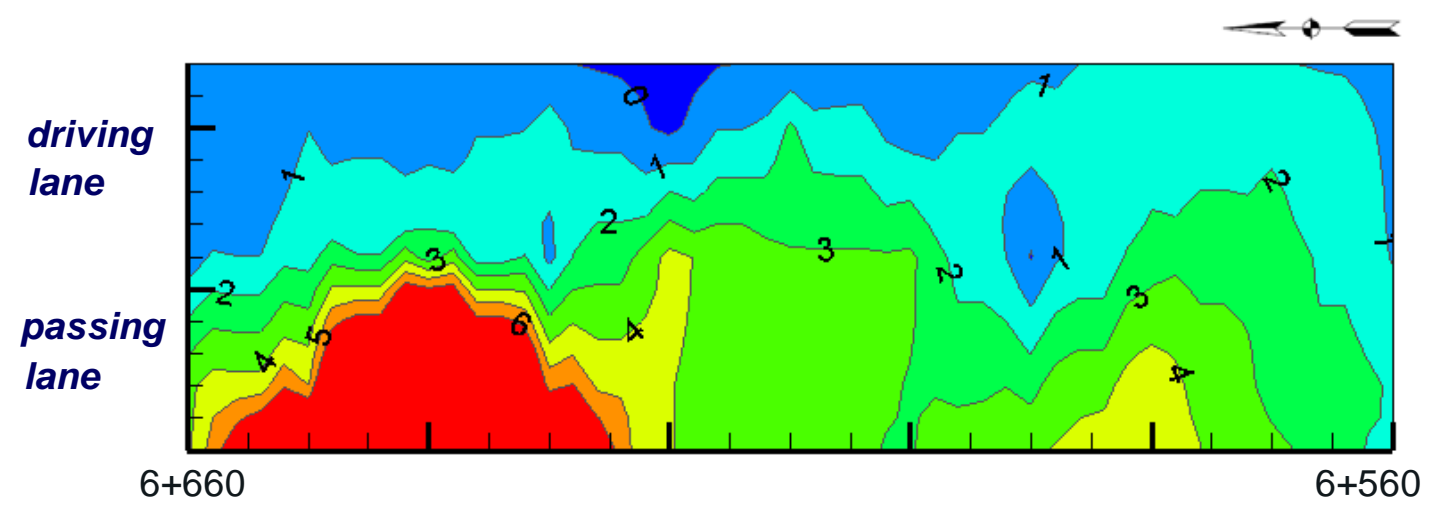

Figure 3.30 Incremental ratio of CBR of chemically treated subgrade soil layer to CBR of natural subgrade soil layer. Section (2).

Figures 3.31 and 3.32 are contour plots of the dynamic deflection modulus of the subgrade soil layer obtained from the LWD tests. The dynamic deflection modulus may be considered an average value of the CBR over 18 inches below the top of the subgrade. In other words, the modulus of the subgrade soil layer may not only reflect the stiffness of the treated soil layer but also, to some extent, the stiffness of the untreated (natural) soil. This is so because only one homogeneous, uniform subgrade soil layer, is assumed to back-calculate the stiffness of the subgrade from the LWD deflection data. From the figures, the dynamic deflection modulus is within the range of 40 and $100 \mathrm{MPa}$ in section (1), and 60 and $100 \mathrm{MPa}$ in section (2). The average and standard deviation of the dynamic deflection modulus are 66.1 and 29.0 MPa, respectively, for section (1), and are 79.9 and 18.5 MPa for section (2). The results for section (2) are about $20 \%$ better than for section (1), while the variation of the modulus at section (1) is smaller than that at section (2).

Comparing Figure 3.31 with Figure 3.27, a similar trend for the distribution of the stiffness is found between the CBR averaged over the target thickness of the treatment 
and the dynamic deflection modulus. For example, the CBR of the treated subgrade is the largest near the driving lane at STA. $6+700$ while the dynamic deflection modulus of the subgrade is also the largest near the driving lane at the same STA. The observation also applies to section (2) (Figures 3.32 and 3.28).

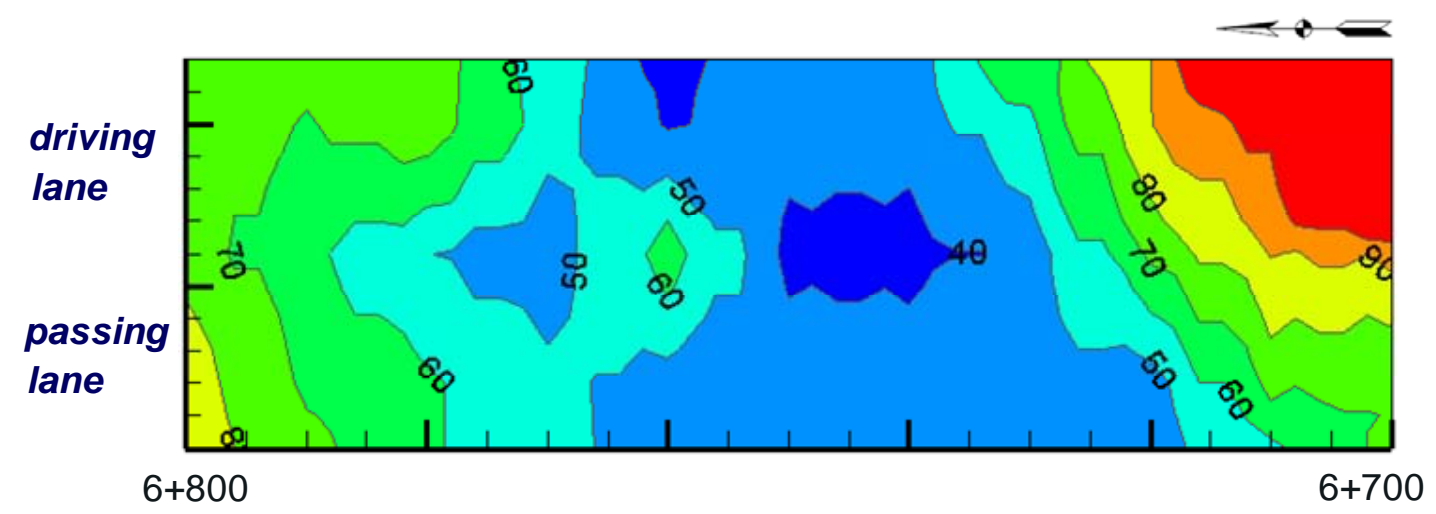

Figure 3.31 Dynamic deflection modulus of subgrade soil layer (in MPa). Section (1).

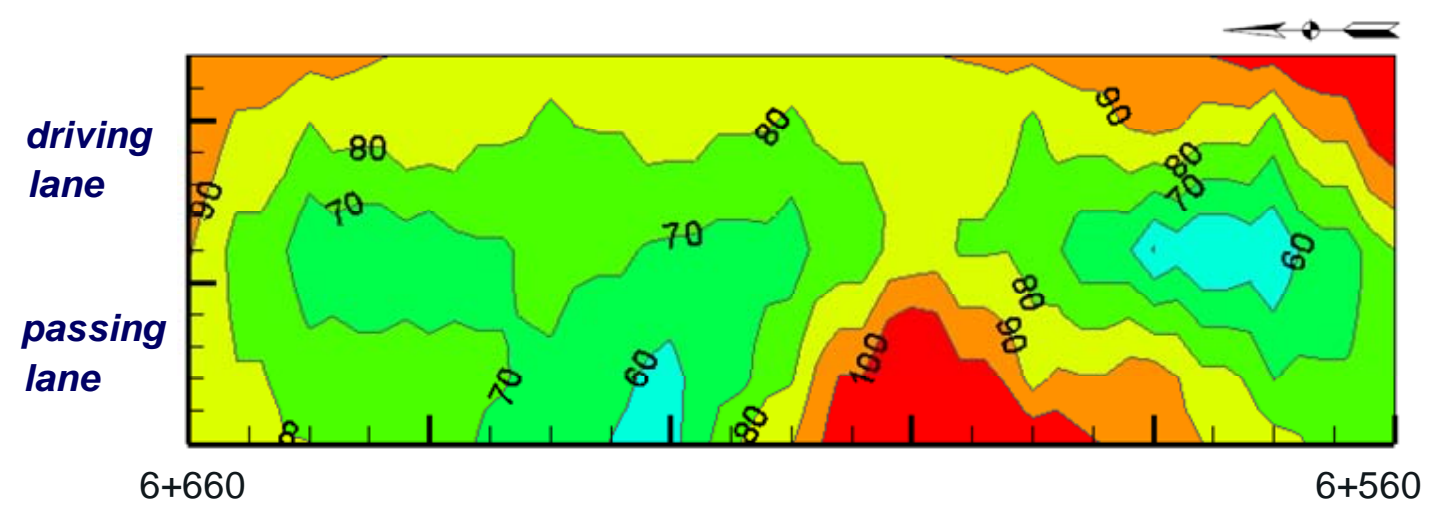

Figure 3.32 Dynamic deflection modulus of subgrade soil layer (in MPa). Section (2). 


\subsection{Water content and dry density}

The water content and dry density of the chemically treated subgrade soils are determined from the nuclear gauge and sand cone tests. The results determined from the nuclear gauge tests correspond to the dry density and water content of the soil at about 6 inches depth below the top of the subgrade (ASTM D 6938-09). The dry density and water content from the sand cone tests were measured at about 4 inches depth below the top of the subgrade.

Tables 3.1 and 3.2 show the water content of the subgrade soil, determined from the nuclear gauge and sand cone tests at sections (1) and (2), respectively. The water content of the subgrade soil ranges between $9.0 \%$ and $13.0 \%$, with an average of $11.0 \%$, at section (1), and between $6.8 \%$ and $10.9 \%$, with an average of $8.4 \%$, at section (2). The average value of the water content determined at section (2) is about $30 \%$ smaller than at section (1).

Tables 3.3 and 3.4 show the dry density of the subgrade soil determined from the nuclear gauge and sand cone tests at sections (1) and (2), respectively. From the nuclear tests, the dry density of the subgrade soil ranges between 1.70 and $1.79 \mathrm{Mg} / \mathrm{m}^{3}$, with an average of $1.73 \mathrm{Mg} / \mathrm{m}^{3}$, at section (1), and between 1.75 and $1.94 \mathrm{Mg} / \mathrm{m}^{3}$, with an average of $1.85 \mathrm{Mg} / \mathrm{m}^{3}$, at section (2). The average value of the dry density determined at section (2) is about $6 \%$ larger than at section (1). 
Table 3.1 Water content from nuclear gauge and sand cone tests (in \%). Section (1)

\begin{tabular}{|c|c|c|c|c|c|c|c|c|c|c|c|c|}
\hline \multicolumn{2}{|c|}{ STA. No. } & 700 & 710 & 720 & 730 & 740 & 750 & 760 & 770 & 780 & 790 & 800 \\
\hline \multirow{4}{*}{$\begin{array}{c}\text { Nuclear } \\
\text { gauge }\end{array}$} & D & - & - & - & - & 10.3 & - & 11.5 & - & - & - & - \\
\cline { 2 - 14 } & C & - & - & - & - & 10.3 & - & 9.0 & - & - & - & - \\
\cline { 2 - 13 } & P & 13.0 & - & 12.9 & - & 11.5 & - & 9.5 & - & - & - & - \\
\hline \multirow{4}{*}{ Sand cone } & D & - & - & - & - & - & - & 13.6 & - & - & - & - \\
\cline { 2 - 12 } & C & - & - & - & - & - & - & - & - & - & - & - \\
\cline { 2 - 12 } & P & 7.8 & - & - & - & - & - & - & - & - & - & - \\
\hline
\end{tabular}

(Note: $\mathrm{D}=$ driving lane, $\mathrm{C}=$ center of road, $\mathrm{P}$ = passing lane, “-” = not available)

Table 3.2 Water content from nuclear gauge and sand cone tests (in \%). Section (2)

\begin{tabular}{|c|c|c|c|c|c|c|c|c|c|c|c|c|}
\hline \multicolumn{2}{|c|}{ STA. No. } & 560 & 570 & 580 & 590 & 600 & 610 & 620 & 630 & 640 & 650 & 660 \\
\hline \multirow{3}{*}{$\begin{array}{l}\text { Nuclear } \\
\text { gauge }\end{array}$} & $\mathrm{D}$ & 6.9 & - & 6.8 & - & 8.1 & - & 8.9 & - & 8.4 & - & 8.7 \\
\hline & $\mathrm{C}$ & - & - & - & - & - & - & - & 8.6 & - & - & - \\
\hline & $\mathrm{P}$ & 8.5 & - & - & - & - & - & 10.9 & - & - & - & - \\
\hline \multirow{3}{*}{ Sand cone } & $\mathrm{D}$ & - & - & - & - & 7.8 & - & - & - & - & - & - \\
\hline & $\mathrm{C}$ & - & - & - & - & - & - & - & - & - & - & - \\
\hline & $\mathrm{P}$ & 9.6 & - & - & - & - & - & - & - & - & - & - \\
\hline
\end{tabular}

(Note: $\mathrm{D}=$ driving lane, $\mathrm{C}=$ center of road, $\mathrm{P}=$ passing lane, “-” = not available) 
Table 3.3 Dry density from nuclear gauge and sand cone tests (in $\mathrm{Mg} / \mathrm{m}^{3}$ ). Section (1)

\begin{tabular}{|c|c|c|c|c|c|c|c|c|c|c|c|c|}
\hline \multicolumn{2}{|c|}{ STA. No. } & 700 & 710 & 720 & 730 & 740 & 750 & 760 & 770 & 780 & 790 & 800 \\
\hline \multirow{3}{*}{$\begin{array}{c}\text { Nuclear } \\
\text { gauge }\end{array}$} & $\mathrm{D}$ & - & - & - & - & 1.76 & - & 1.79 & - & - & - & - \\
\hline & $\mathrm{C}$ & - & - & - & - & 1.75 & - & 1.75 & - & - & - & - \\
\hline & $\mathrm{P}$ & 1.77 & - & 1.70 & - & 1.71 & - & 1.67 & - & - & - & - \\
\hline \multirow{3}{*}{ Sand cone } & $\mathrm{D}$ & - & - & - & - & - & - & 1.87 & - & - & - & - \\
\hline & $\mathrm{C}$ & - & - & - & - & - & - & - & - & - & - & - \\
\hline & $\mathrm{P}$ & 2.07 & - & - & - & - & - & - & - & - & - & - \\
\hline
\end{tabular}

(Note: $\mathrm{D}=$ driving lane, $\mathrm{C}=$ center of road, $\mathrm{P}=$ passing lane, “-” = not available)

Table 3.4 Dry density from nuclear gauge and sand cone tests (in $\mathrm{Mg} / \mathrm{m}^{3}$ ). Section (2)

\begin{tabular}{|c|c|c|c|c|c|c|c|c|c|c|c|c|}
\hline \multicolumn{2}{|c|}{ STA. No. } & 560 & 570 & 580 & 590 & 600 & 610 & 620 & 630 & 640 & 650 & 660 \\
\hline \multirow{3}{*}{$\begin{array}{l}\text { Nuclear } \\
\text { gauge }\end{array}$} & D & 1.89 & - & 1.79 & - & 1.75 & - & 1.80 & - & 1.83 & - & 1.83 \\
\hline & $\mathrm{C}$ & - & - & - & - & - & - & - & 1.86 & - & - & - \\
\hline & $\mathrm{P}$ & 1.94 & - & - & - & - & - & 1.92 & - & - & - & - \\
\hline \multirow{3}{*}{ Sand cone } & $\mathrm{D}$ & - & - & - & - & 2.07 & - & - & - & - & - & - \\
\hline & $\mathrm{C}$ & - & - & - & - & - & - & - & - & - & - & - \\
\hline & $\mathrm{P}$ & 1.95 & - & - & - & - & - & - & - & - & - & - \\
\hline
\end{tabular}

(Note: $\mathrm{D}=$ driving lane, $\mathrm{C}=$ center of road, $\mathrm{P}=$ passing lane, “-” = not available)

\subsection{Identification and quantification of minerals}

Figures 3.33 to 3.44 show the results of the XRD tests from the chemically treated soil samples taken at section (1) (STA. 6+700 and STA. 6+760) and section (2) (STA. $6+560$ and STA. $6+600$ ). All samples were taken at the center of the north-bound road at each STA. The soil samples were collected at 2, 8, and 14 inches below the top of the subgrade at section (1) and at 2, 7, and 12 inches below the top of the subgrade at section 
(2). The presence of three minerals, calcium carbonate $\left(\mathrm{CaCO}_{3}\right)$, calcium oxide $(\mathrm{CaO})$, and calcium hydroxide $\left(\mathrm{Ca}(\mathrm{OH})_{2}\right)$, which are the minerals associated with soil-lime chemical reaction, can be identified with the XRD test results.

In Figure 3.33, it is observed that the XRD pattern has a clear peak at the critical angles for $\mathrm{CaCO}_{3}$; a small peak at the critical angles for $\mathrm{CaO}$; no peak at the critical angles for $\mathrm{Ca}(\mathrm{OH})_{2}$. In other words, the minerals, $\mathrm{CaCO}_{3}$ and $\mathrm{CaO}$, were detected in the soil sample but $\mathrm{Ca}(\mathrm{OH})_{2}$ was not. The same observation applies to Figures 3.34 to 3.38 . Figures 3.39 to 3.44 show the presence of the mineral $\mathrm{CaCO}_{3}$, while $\mathrm{CaO}$ and $\mathrm{Ca}(\mathrm{OH})_{2}$ were not detected. Based on all XRD test results, it can be summarized that: (1) all soil samples tested contained the mineral $\mathrm{CaCO}_{3}$, but did not contain $\mathrm{Ca}(\mathrm{OH})_{2} ;$ (2) the soil samples collected at section (1) contained, to a small extent, $\mathrm{CaO}$ while those collected at section (2) did not. From the fact that the soil samples taken from section (2) did not contain any $\mathrm{CaO}$, it may be inferred that all $\mathrm{CaO}$ in the $\mathrm{LKD}$ reacted with the subgrade soil in section (2), while some remained in section (1). This seems to imply that the chemical treatment was more successful in section (2) than in section (1). 

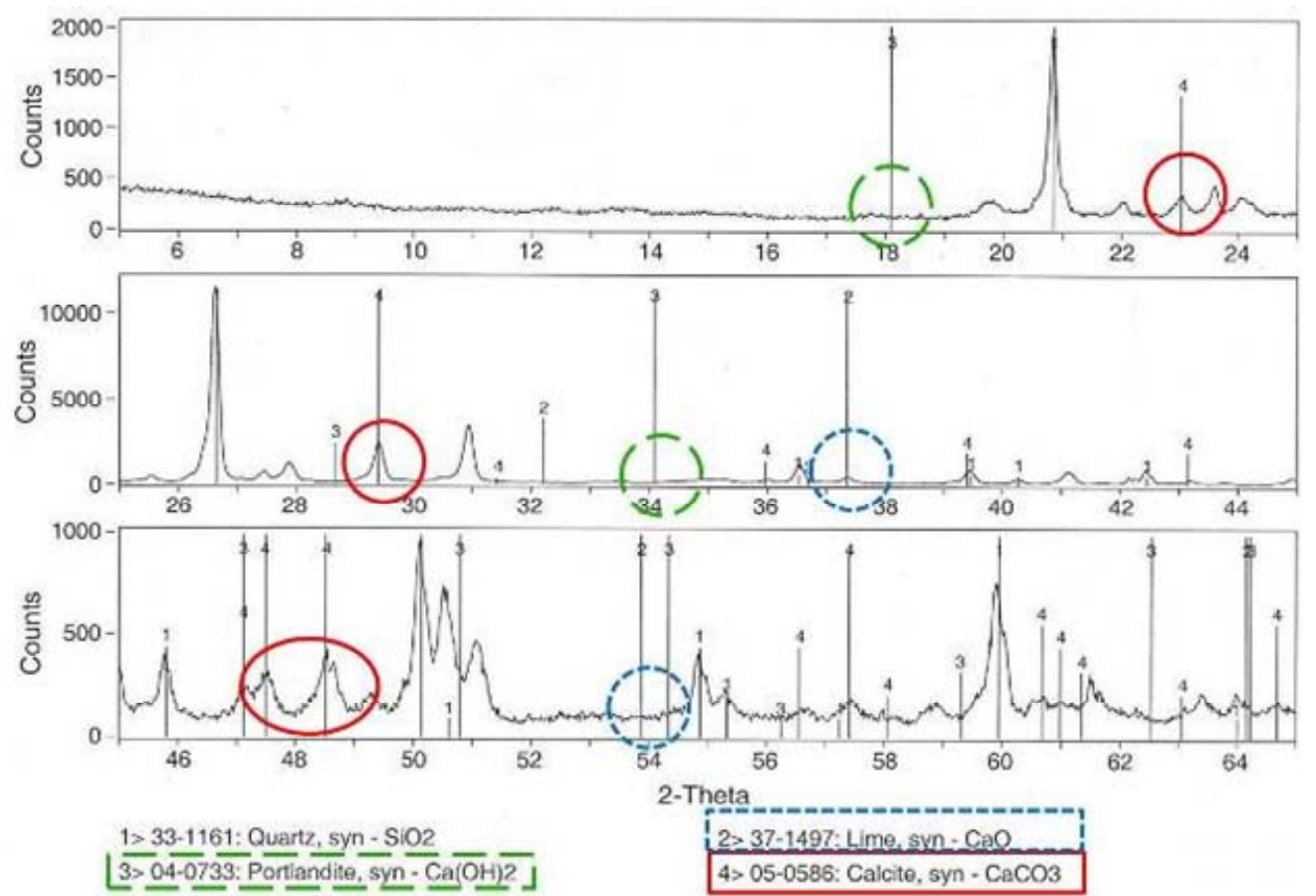

Figure 3.33 XRD pattern for chemically treated soil sample at 2-in. depth at STA. 6+700. Section (1).
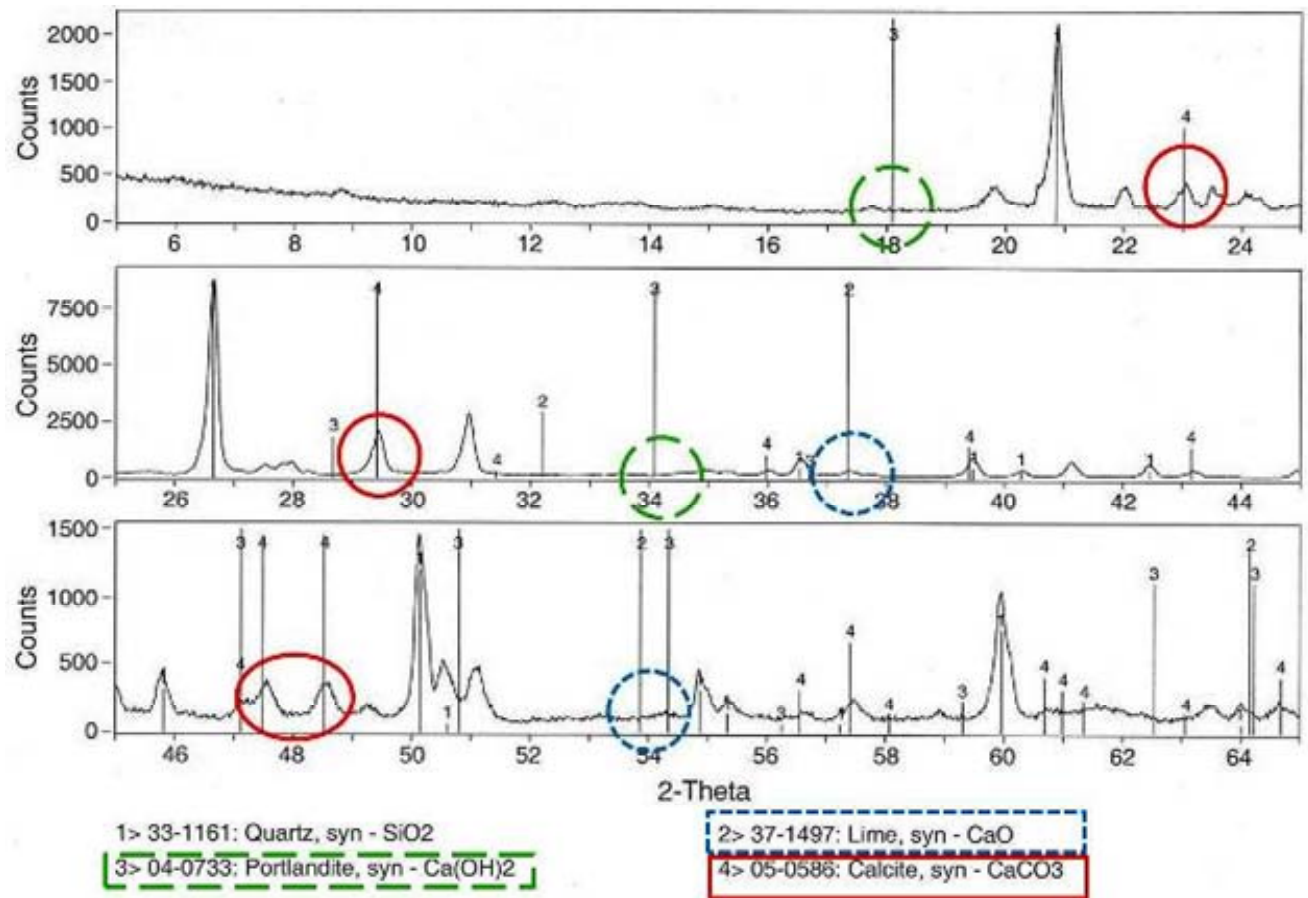

Figure 3.34 XRD pattern for chemically treated soil sample at 8-in. depth at STA. $6+700$. Section (1) 

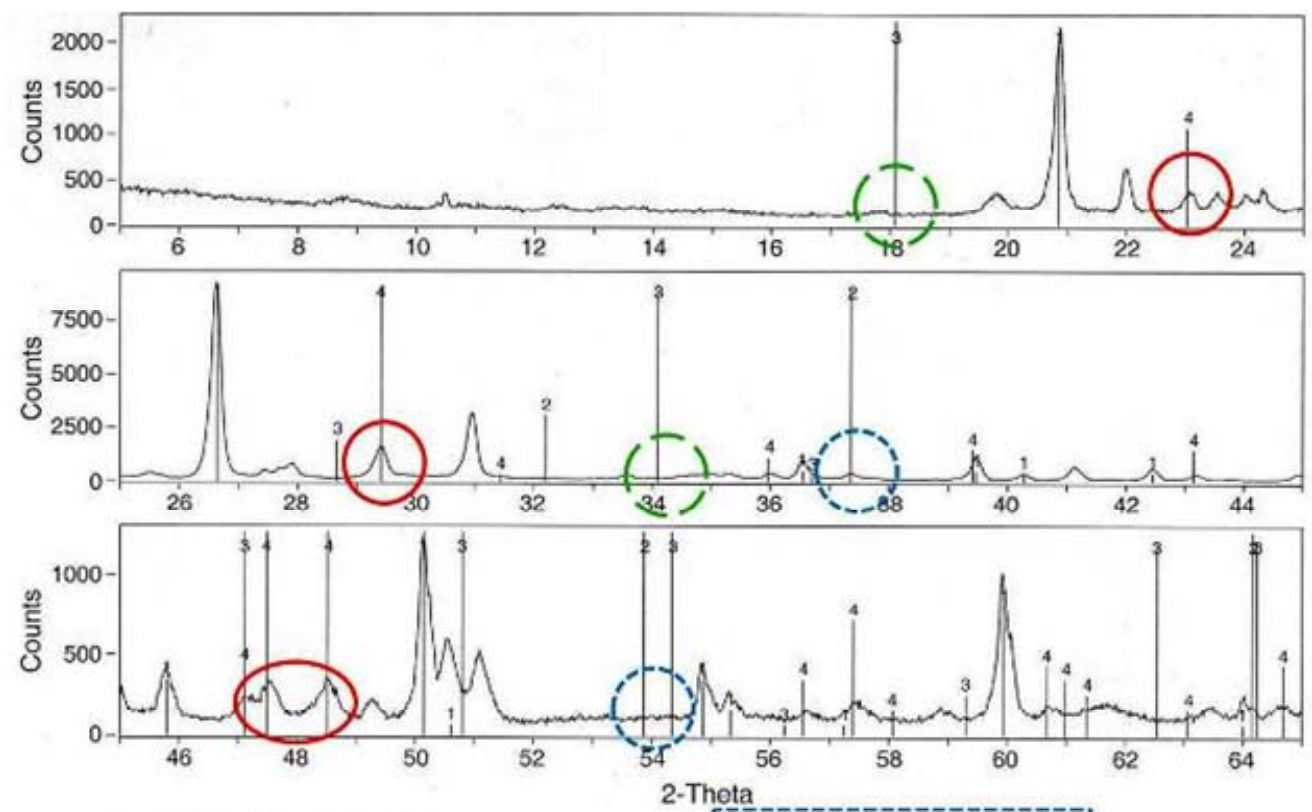

1>33-1161: Quartz, syn - SiO2

[3> 04-0733: Portlandite, syn- $\mathrm{Ca}(\mathrm{OH}) 2\rfloor \quad$ 4> 05-0586: Calcite, syn-CaCO3

Figure 3.35 XRD pattern for chemically treated soil sample at 14-in. depth at STA. 6+700. Section (1).
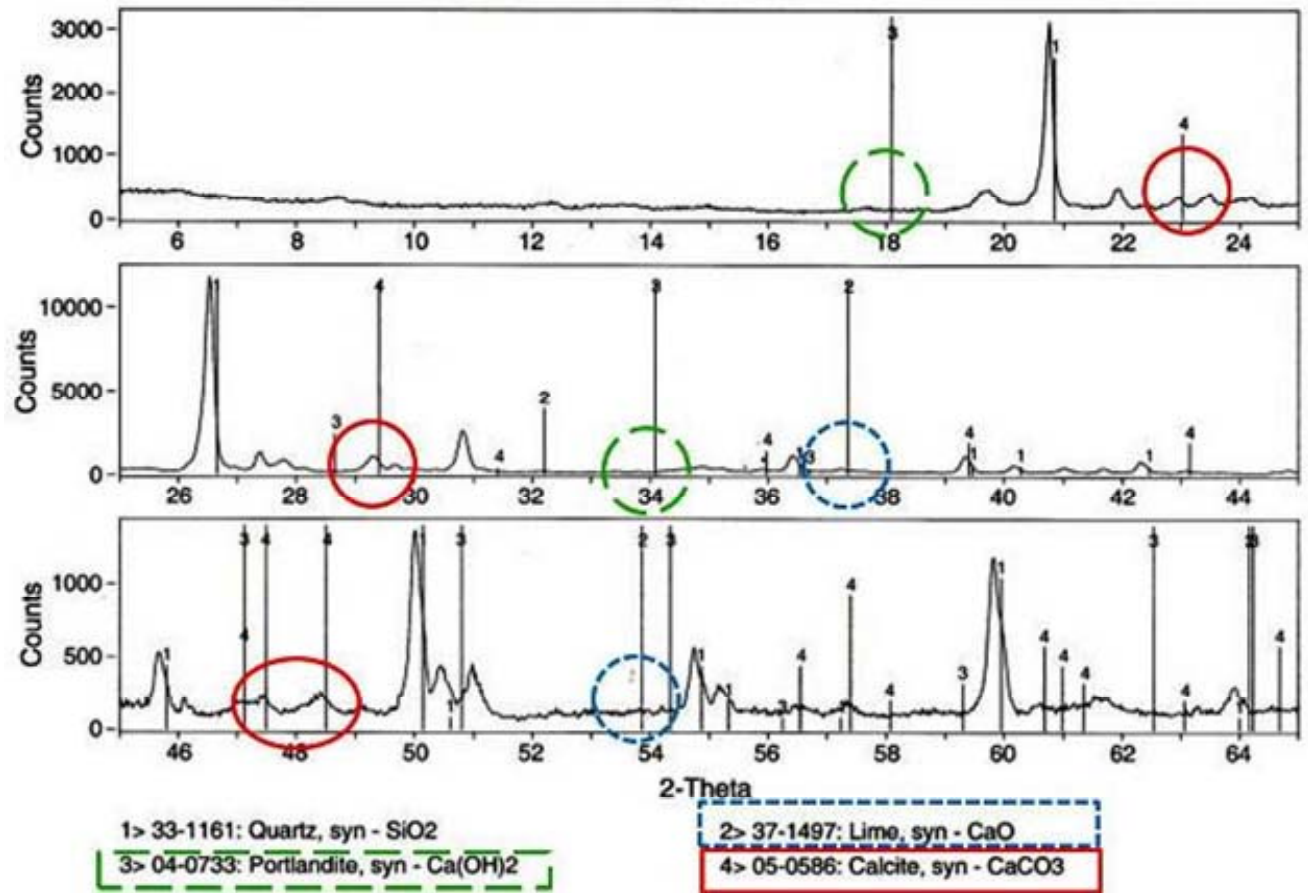

Figure 3.36 XRD pattern for chemically treated soil sample at 2-in. depth at STA. 6+760). Section (1). 

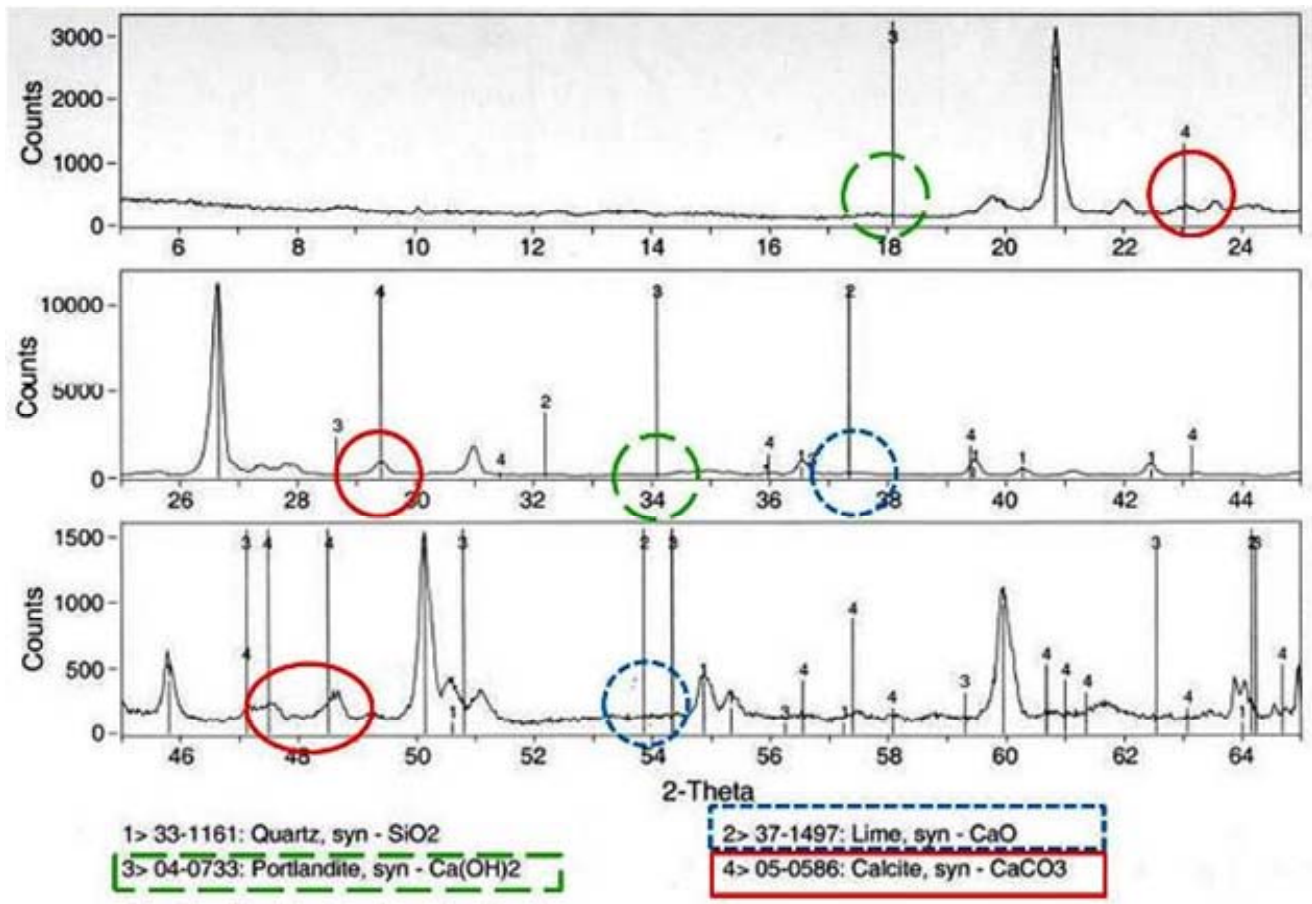

Figure 3.37 XRD pattern for chemically treated soil sample at 8-in. depth at STA. $6+760)$. Section (1).
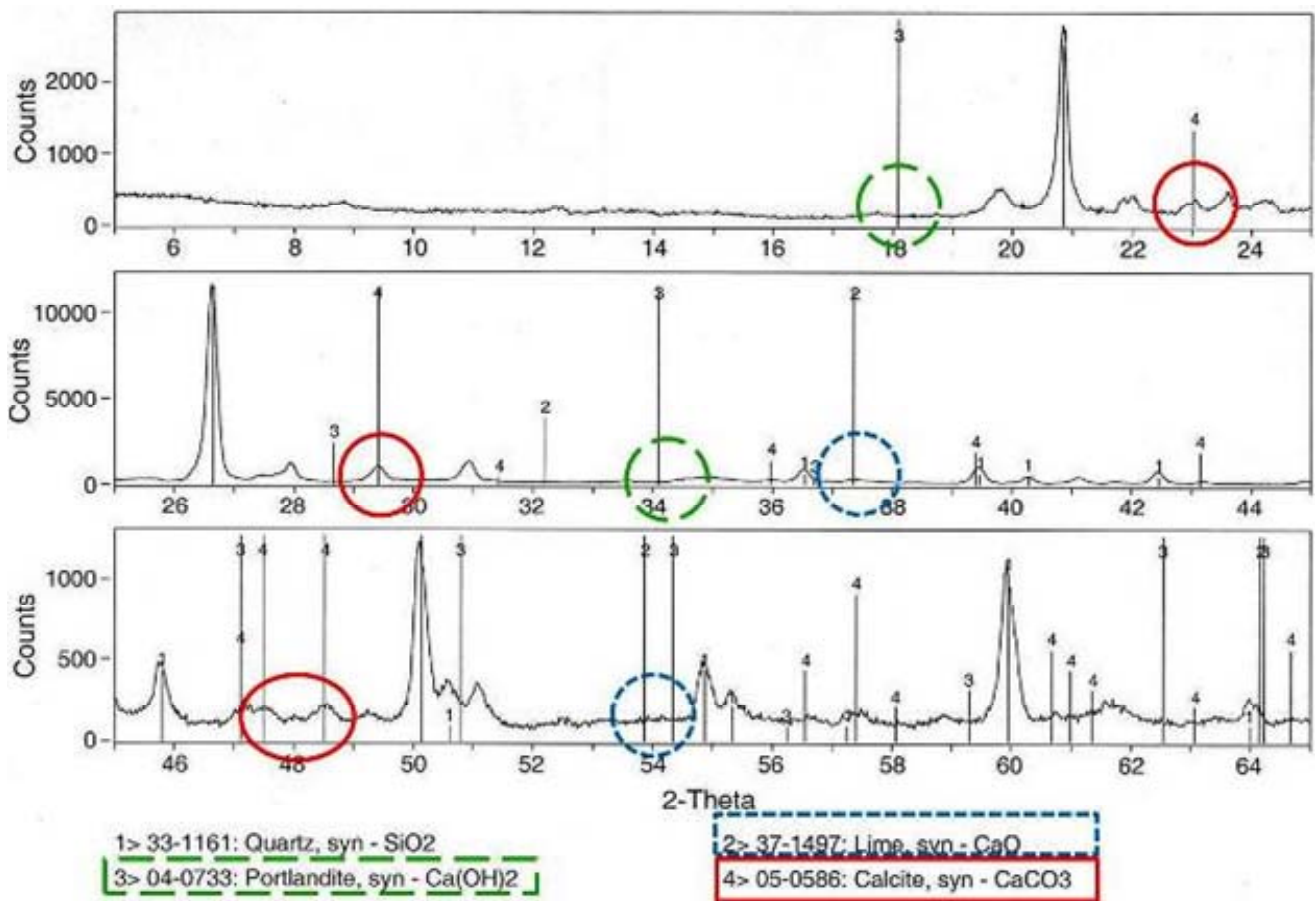

Figure 3.38 XRD pattern for chemically treated soil sample at 14-in. depth at STA. 6+760. Section (1) 

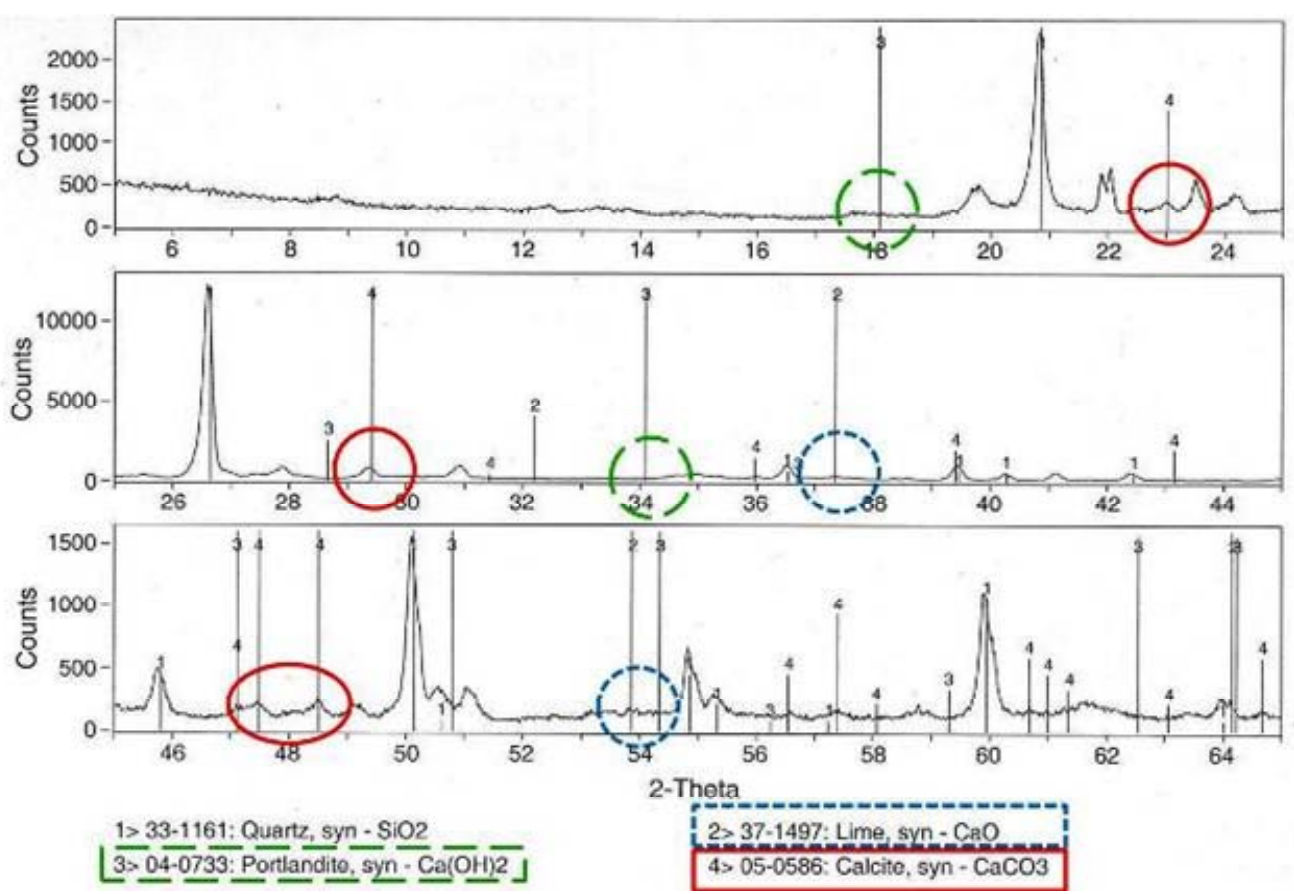

Figure 3.39 XRD pattern for chemically treated soil sample at 2-in. depth at STA. $6+560$. Section $(2)$
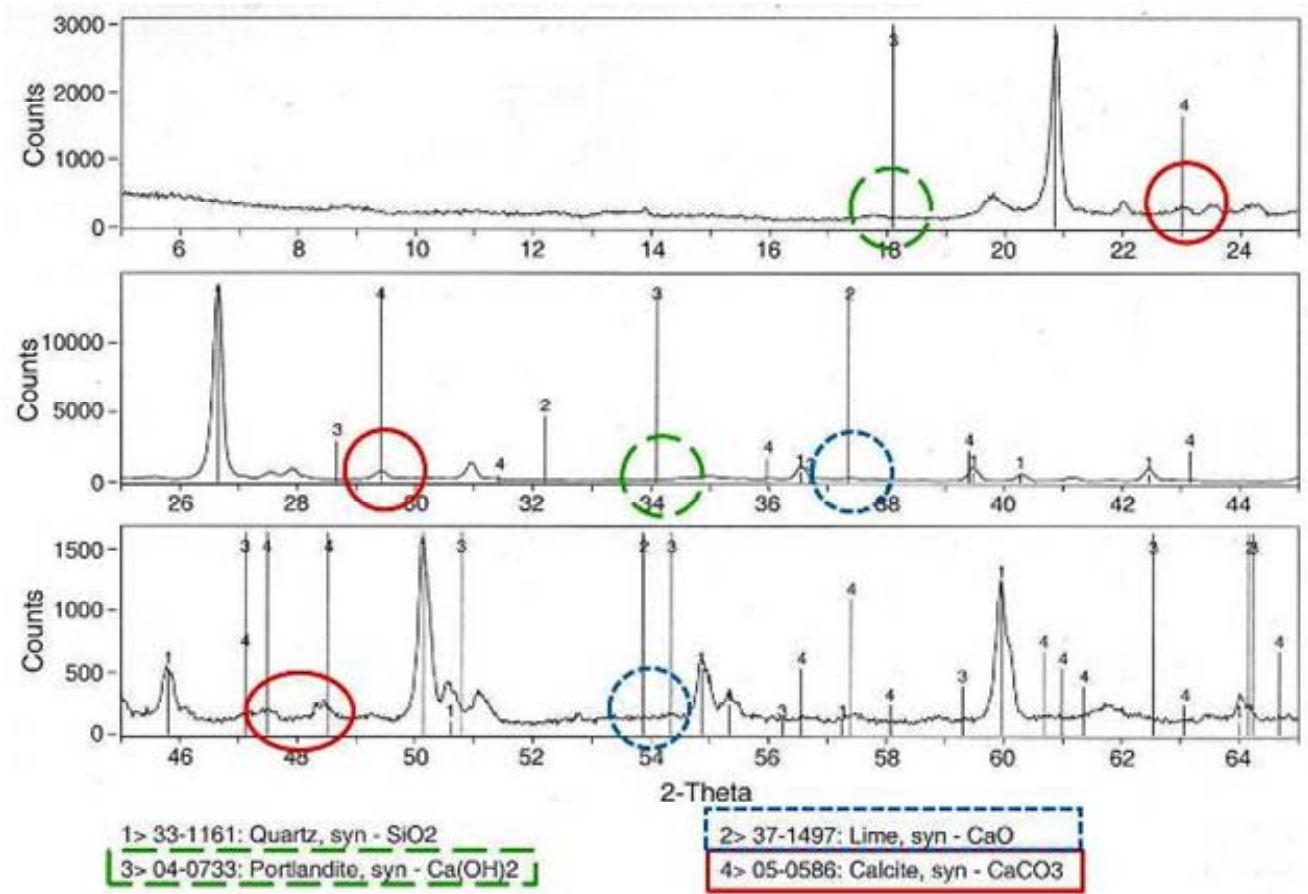

Figure 3.40 XRD pattern for chemically treated soil sample at 7-in. depth at STA. $6+560$. Section $(2)$ 

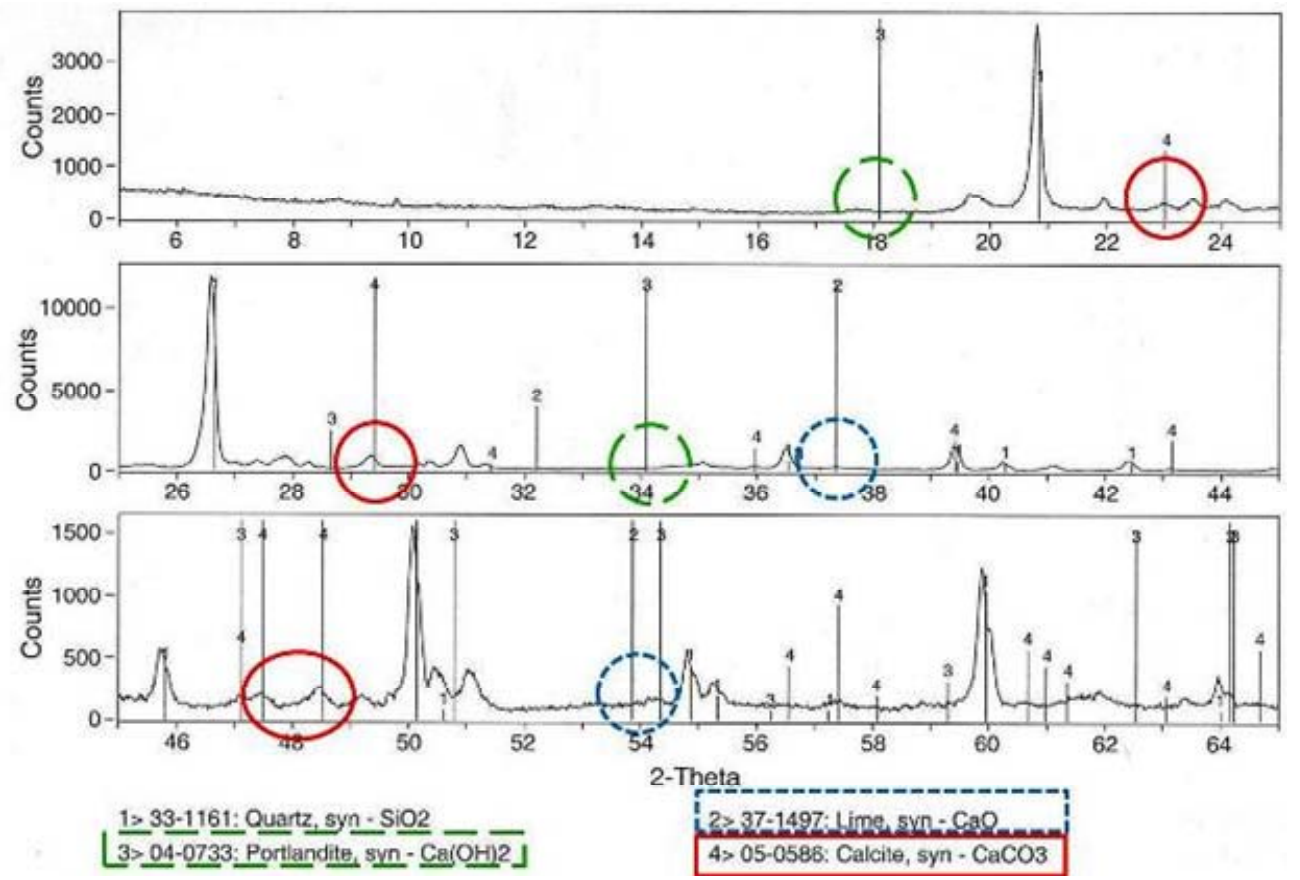

Figure 3.41 XRD pattern for chemically treated soil sample at 12-in. depth at STA. 6+560. Section (2).
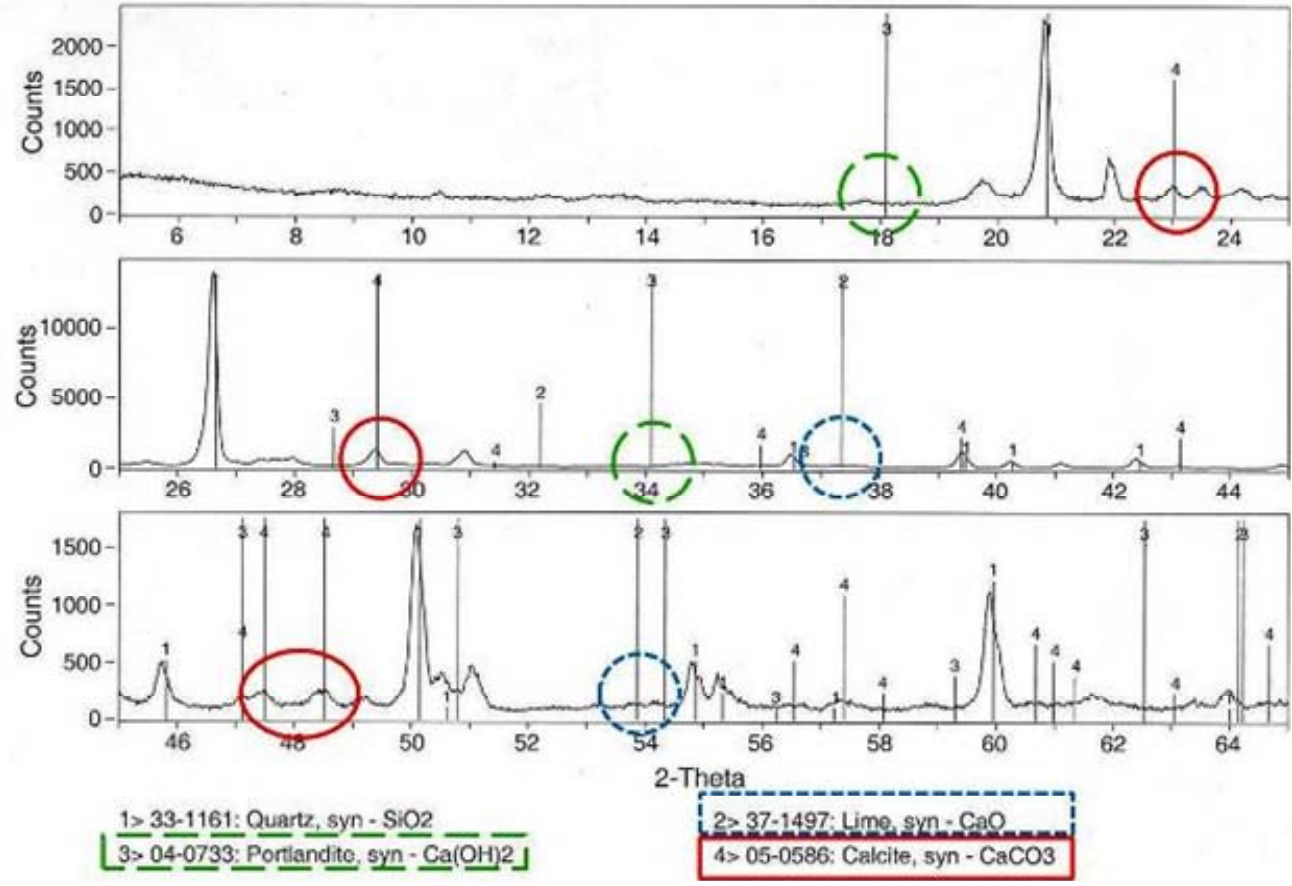

Figure 3.42 XRD pattern for chemically treated soil sample at 2-in. depth at STA. $6+600$ at Section (2) 

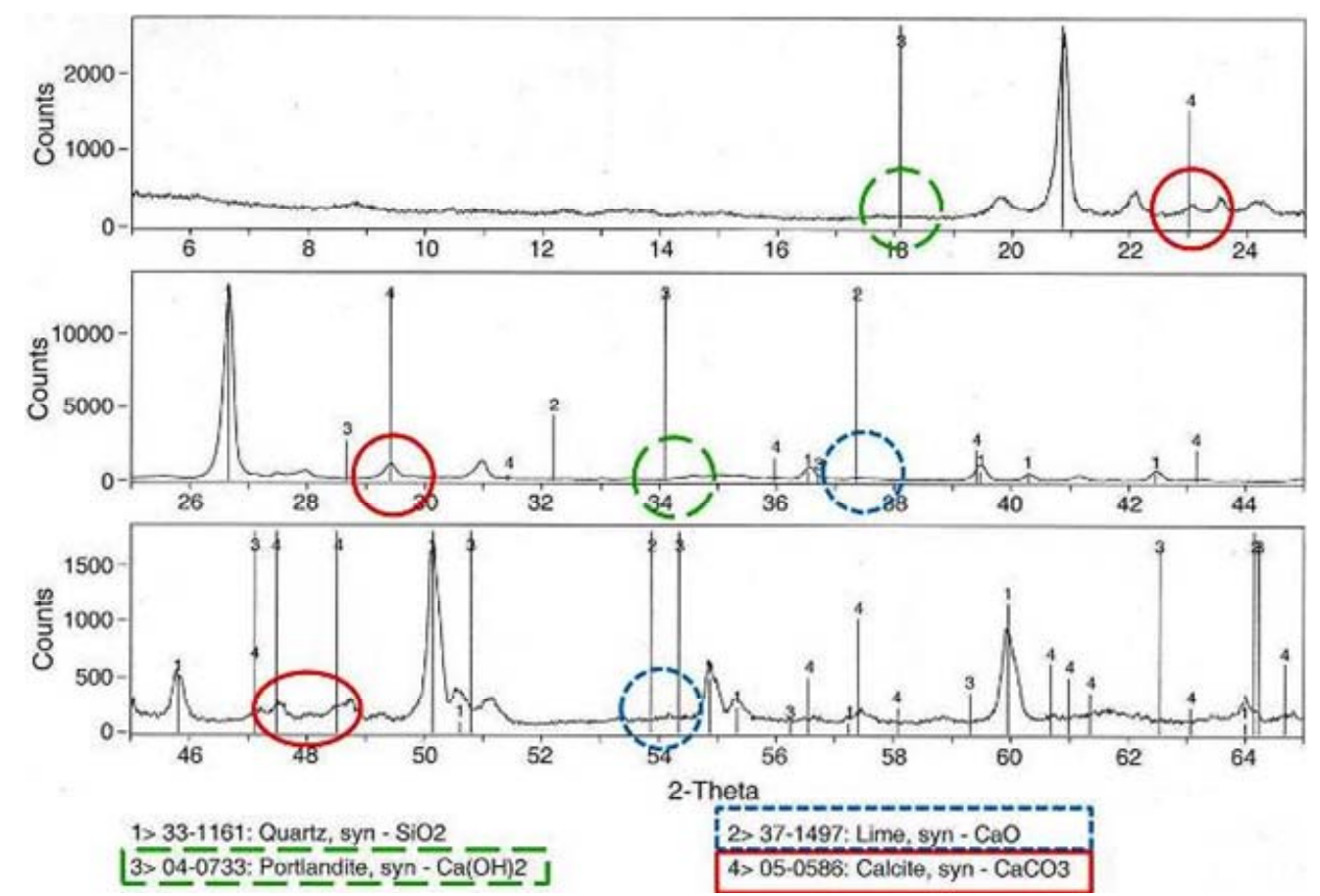

Figure $3.43 \mathrm{XRD}$ pattern for chemically treated soil sample at 7 -in. depth at STA. $6+600$. Section (2).
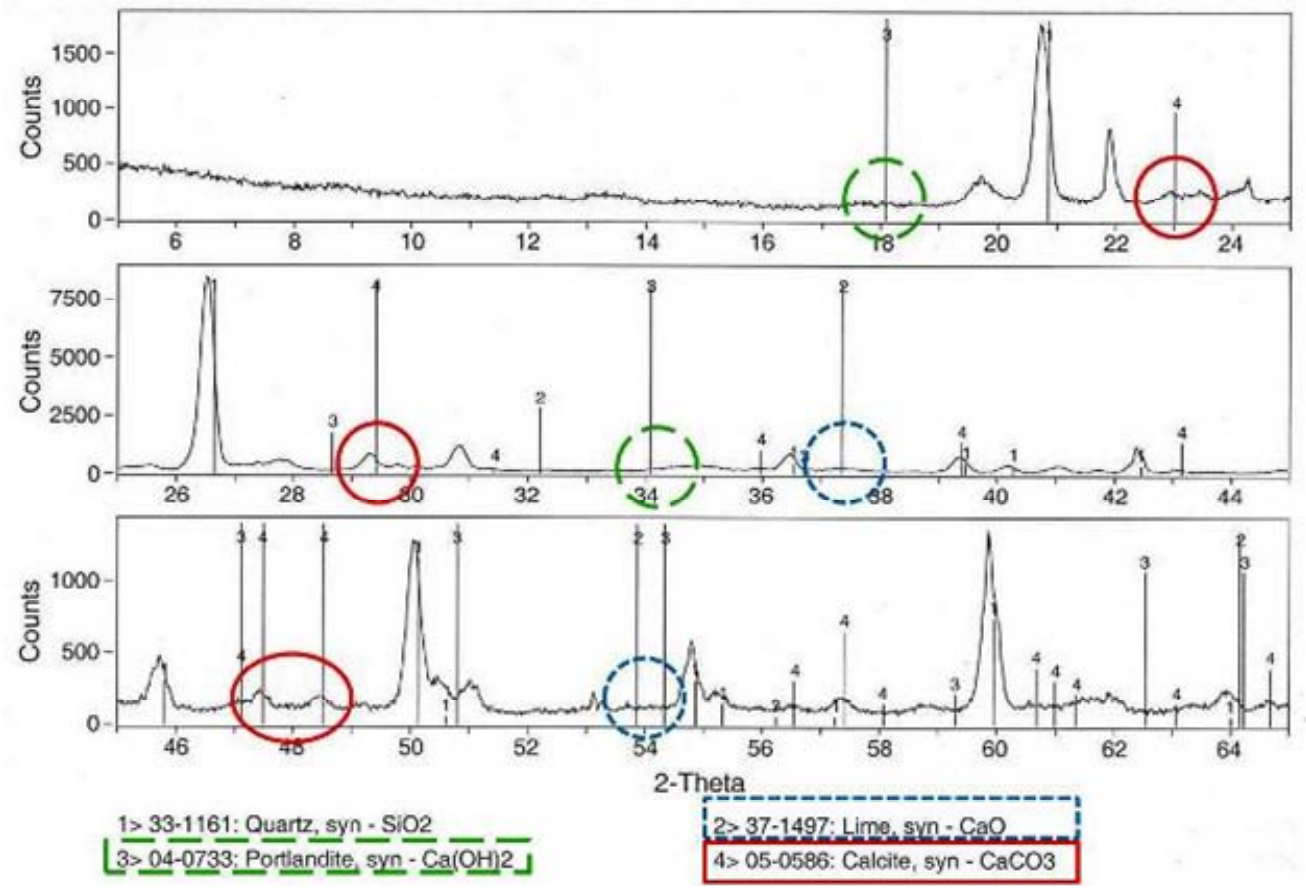

Figure 3.44 XRD pattern for chemically treated soil sample at 12-in. depth at STA. $6+600$. Section (2). 
Quantification of the minerals is determined from the TGA tests. Figures 3.45 to 3.56 show the results of the TGA tests on the chemically treated soil samples collected at sections (1) and (2). The soil samples used for the TGA tests were the same as those for the XRD tests. All figures show that the weight of the treated soil has a sharp decrease within a range of temperatures between 650 and $750{ }^{\circ} \mathrm{C}$. This is within the temperature range where $\mathrm{CaCO}_{3}$ decomposes into $\mathrm{CaO}$ and $\mathrm{CO}_{2}$, and so the weight loss represents the $\mathrm{CaCO}_{3}$ content. The figure also includes the derivative of the weight loss (depicted as a dotted line in the figures) with respect to time, and shows a clear peak at about $700{ }^{\circ} \mathrm{C}$. LKD typically has a reactive lime content of 30 to $60 \%$ in the form of $\mathrm{CaO}, \mathrm{MgO}$ and $\mathrm{Ca}(\mathrm{OH})_{2}$. Considering that $5 \% \mathrm{LKD}$ was used for the chemical treatment, the chemically treated subgrade soil should have a reactive lime content of 1.5 to $3 \%$, which corresponds to a $\mathrm{CaCO}_{3}$ content of 3 to $7 \%$ considering that all lime in the $\mathrm{LKD}$ has been transformed into $\mathrm{CaCO}_{3}$.

From Figure 3.45, the weight loss of the chemically treated soil sample was $12 \%$ which would correspond to an amount of $\mathrm{CaCO}_{3}$ of $27.3 \%$. Table 3.5 summarizes the percentage of calcium carbonate in the soil obtained from the TGA tests. At STA. $6+700$, the $\mathrm{CaCO}_{3}$ content was $27.3,25.0$, and $25.0 \%$ at depths of 2,8 , and 14 inches below the top of the subgrade, respectively (Table 3.5). The nearly constant values of the $\mathrm{CaCO}_{3}$ content with depth can be interpreted as well-mixing of the soil and LKD during the chemical treatment. The observation and interpretation can be applied to all three other locations. From Table 3.5, the $\mathrm{CaCO}_{3}$ content of the soil samples collected at section (1) ranges between 13.6 and $27.3 \%$, and between 9.1 and $15.9 \%$ at section (2). The fact that 
the $\mathrm{CaCO}_{3}$ content of the soil was larger than $7 \%$ indicates that the LKD itself used in the treatment had $\mathrm{CaCO}_{3}$, which is typical and is the result of the manufacturing process. Note that it is not possible to differentiate between the $\mathrm{CaCO}_{3}$ that was the result of the reaction of the lime with the soil and the $\mathrm{CaCO}_{3}$ that the LKD had before application because the TGA tests give the total $\mathrm{CaCO}_{3}$.

Table 3.6 compares the $\mathrm{CaCO}_{3}$ content of the treated soil with the $\mathrm{CBR}$ (averaged over the target thickness of treatment) of the treated subgrade soil layer. This is an attempt to determine whether there is a correlation between the $\mathrm{CaCO}_{3}$ content and $\mathrm{CBR}$. The CBR of the soil increases with increasing $\mathrm{CaCO}_{3}$ content of the soil at section (1) while the opposite is observed at section (2). This is an indication that there exist other factors that may affect the stiffness of the treated subgrade such as percentage of $\mathrm{CaO}$ and $\mathrm{Ca}(\mathrm{OH})_{2}$ (active lime) in the LKD before treatment, and construction quality. 


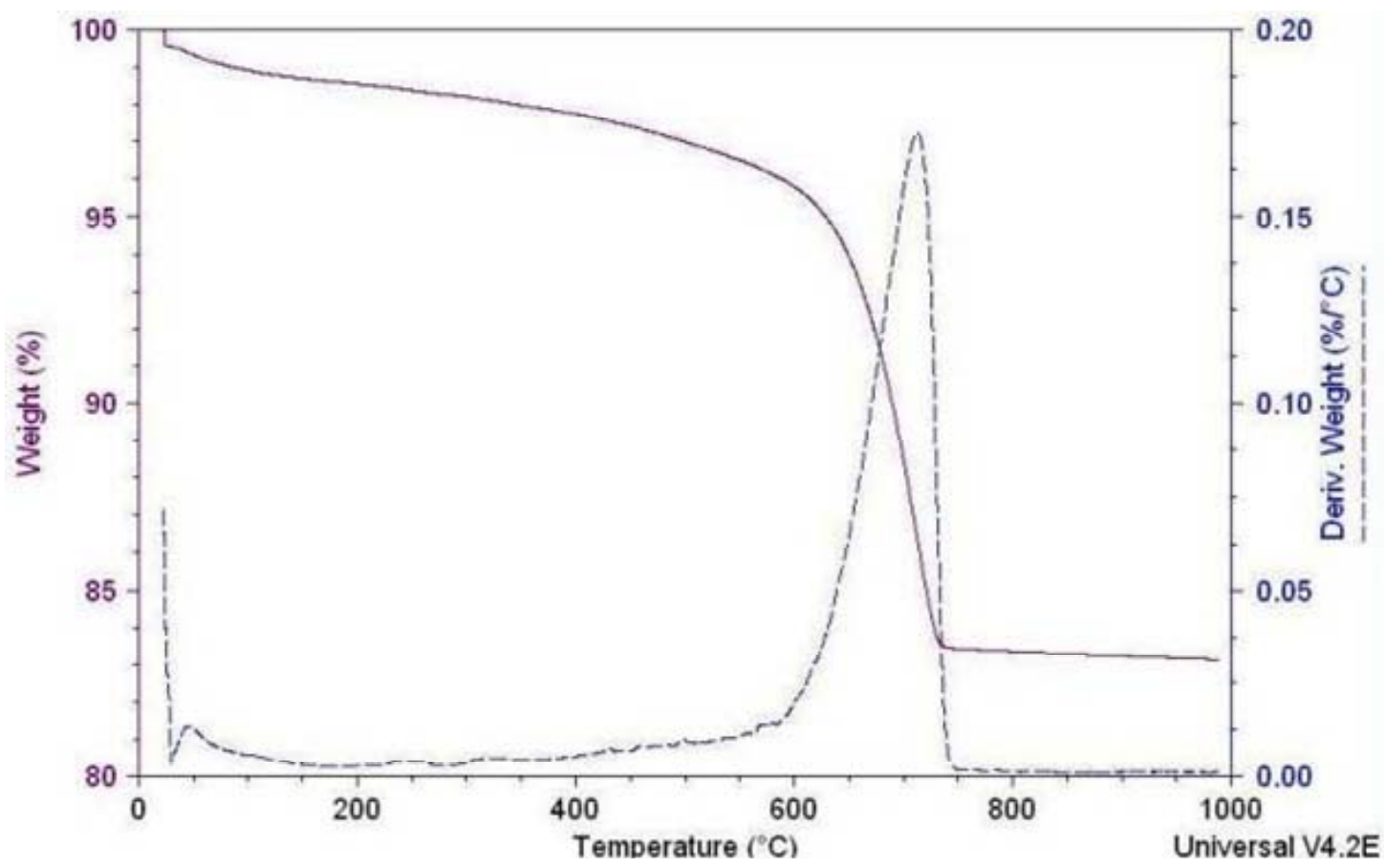

Figure 3.45 TGA result for chemically treated soil sample at 2-in depth at STA. $6+700)$. Section (1).

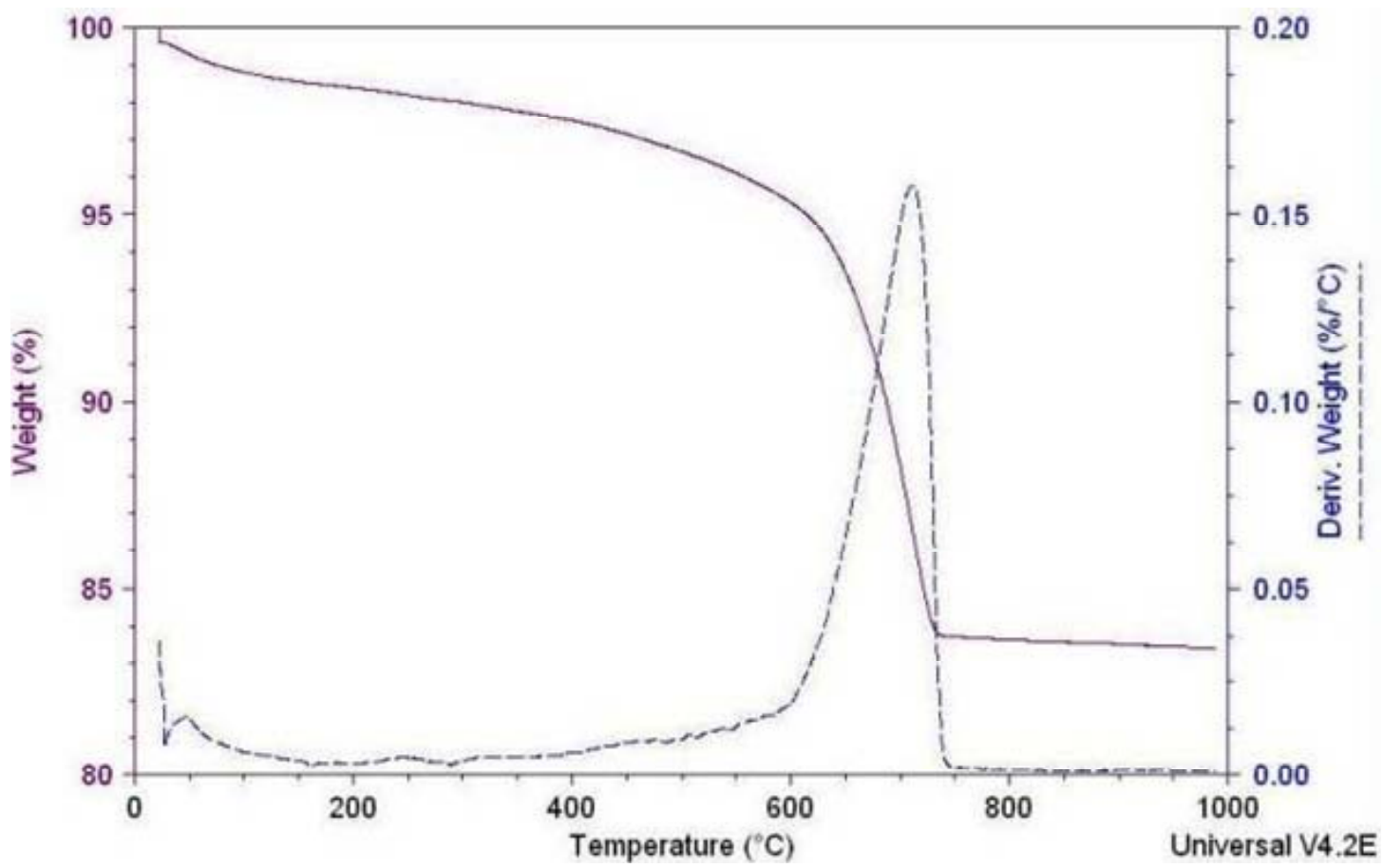

Figure 3.46 TGA result for chemically treated soil sample at 8-in. depth at STA. $6+700)$. Section (1) 


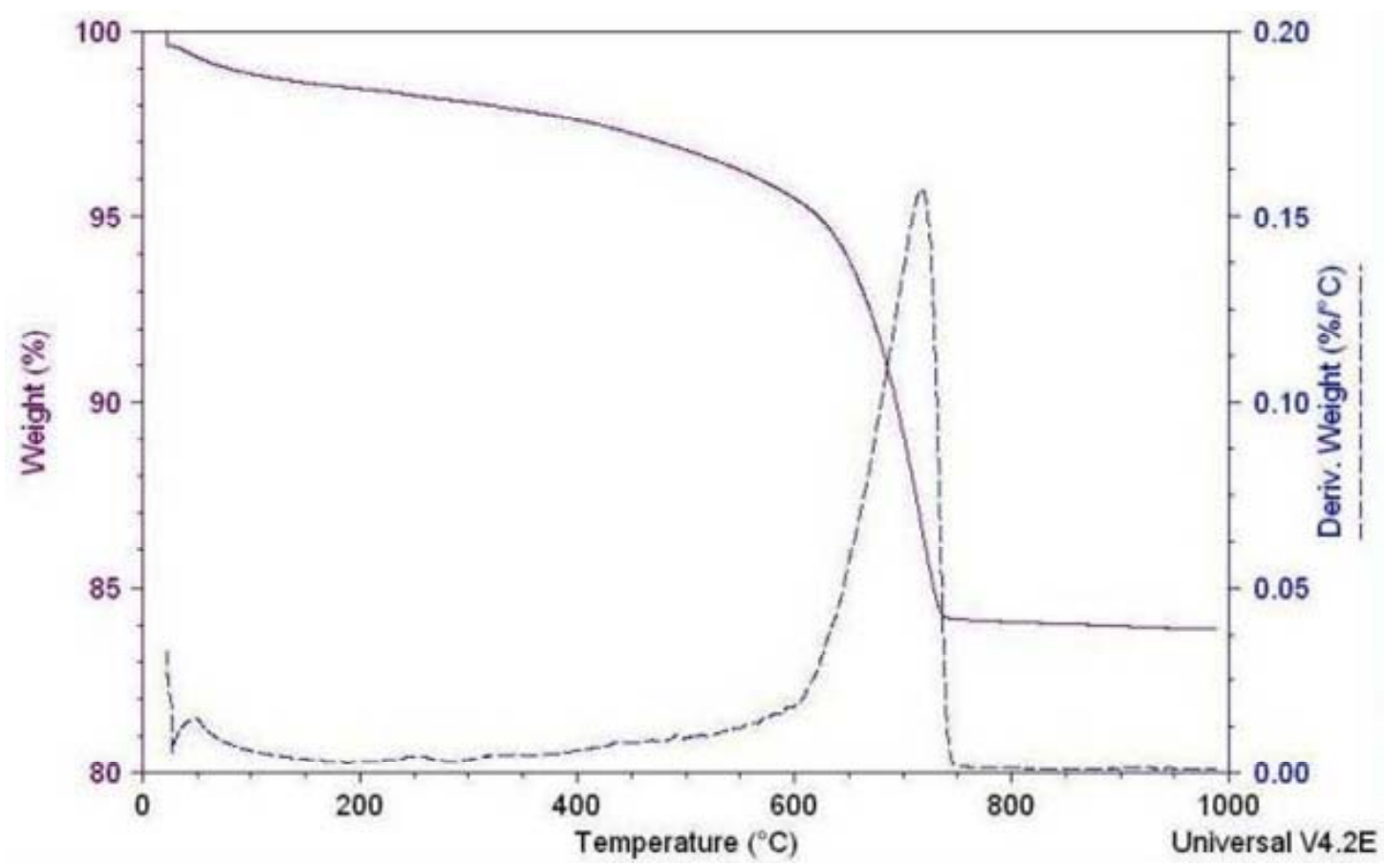

Figure 3.47 TGA result for chemically treated soil sample at 14-in. depth at STA. $6+700$. Section (1)

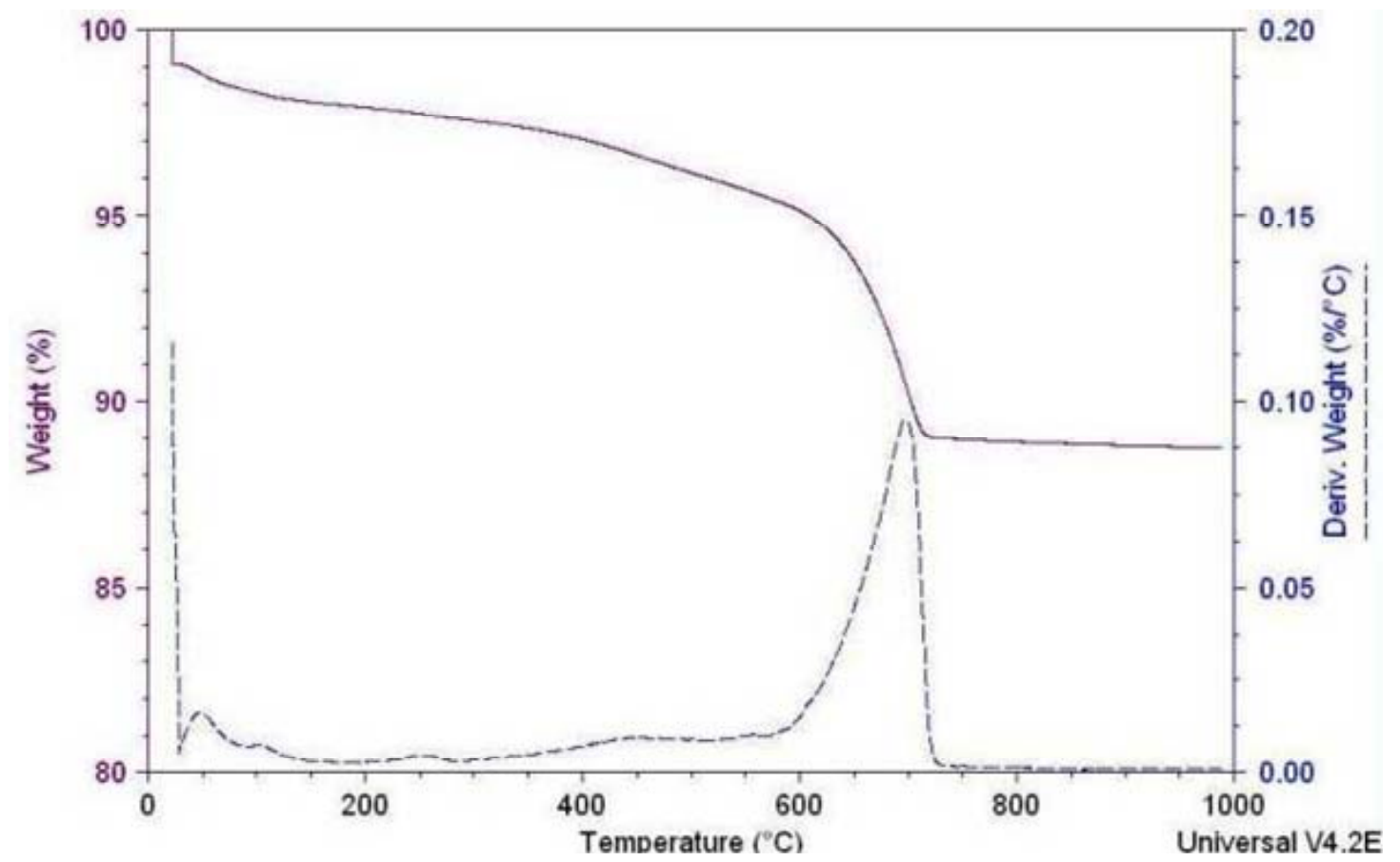

Figure 3.48 TGA result for chemically treated soil sample at 2-in. depth at STA. $6+760$. Section (1) 


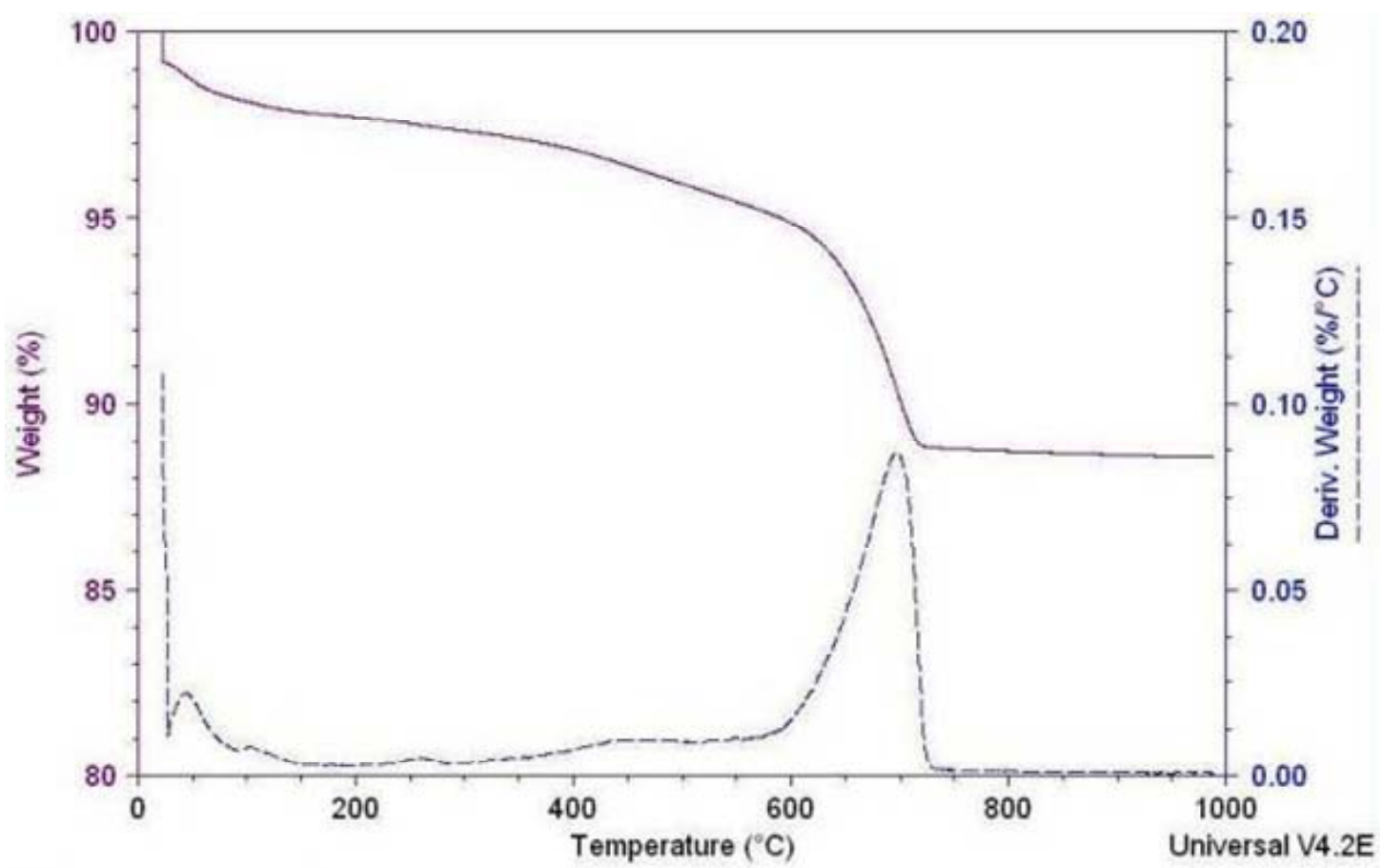

Figure 3.49 TGA result for chemically treated soil sample at 8-in. depth at STA. $6+760$. Section (1)

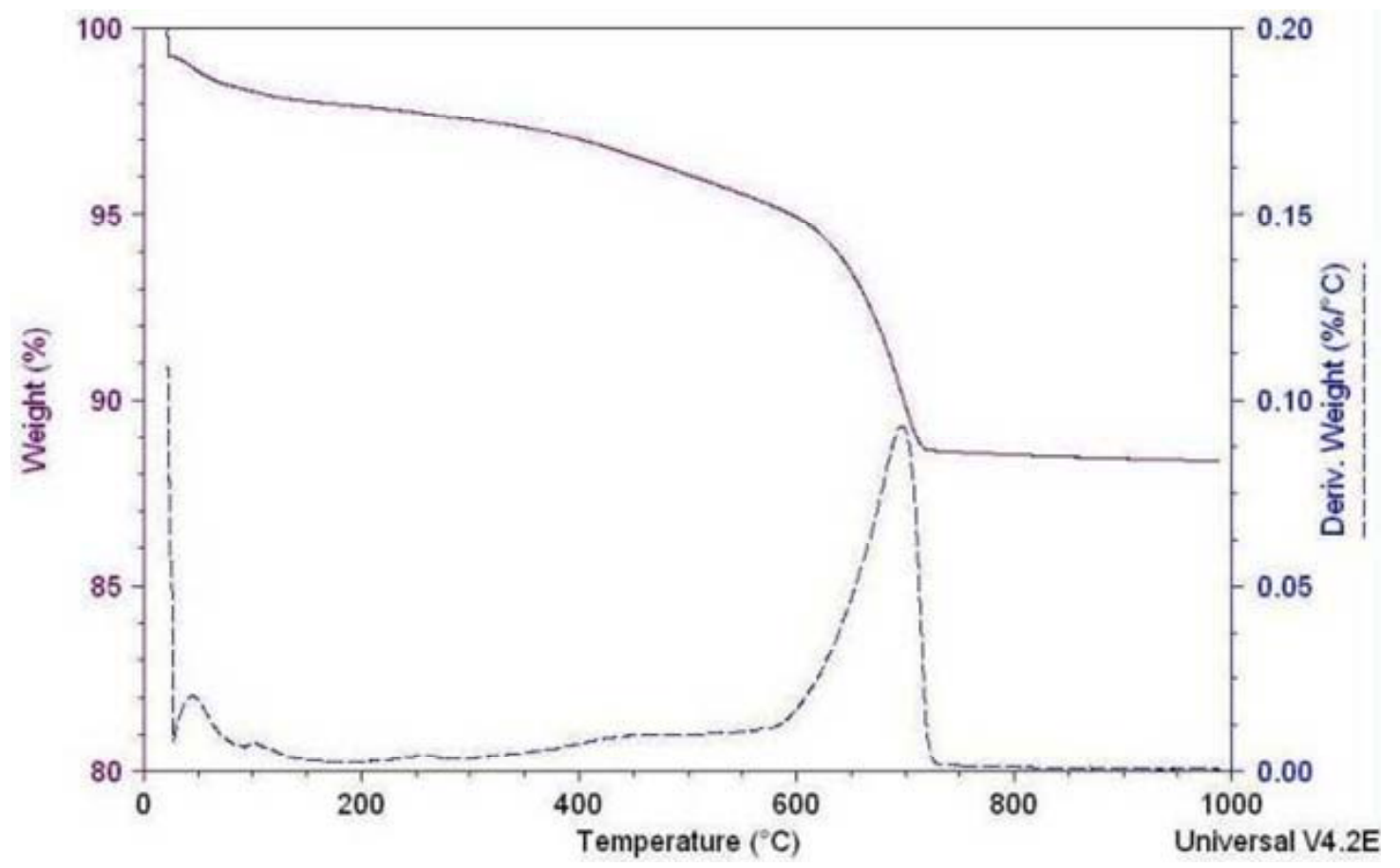

Figure 3.50 TGA result for chemically treated soil sample at 14-in. depth at STA. $6+760$. Section $(1)$ 


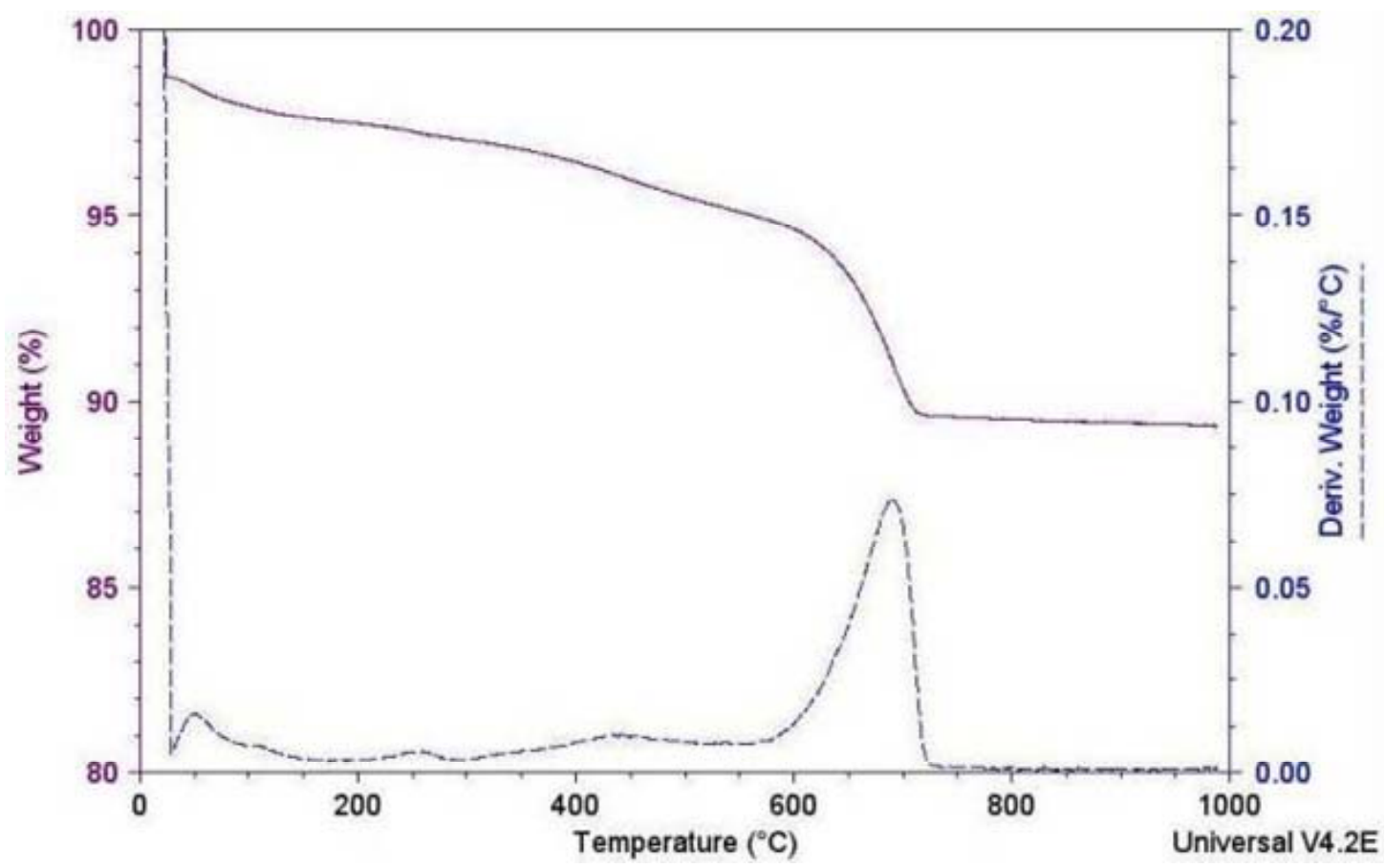

Figure 3.51 TGA result for chemically treated soil sample at 2-in. depth at STA. $6+560$. Section (2)

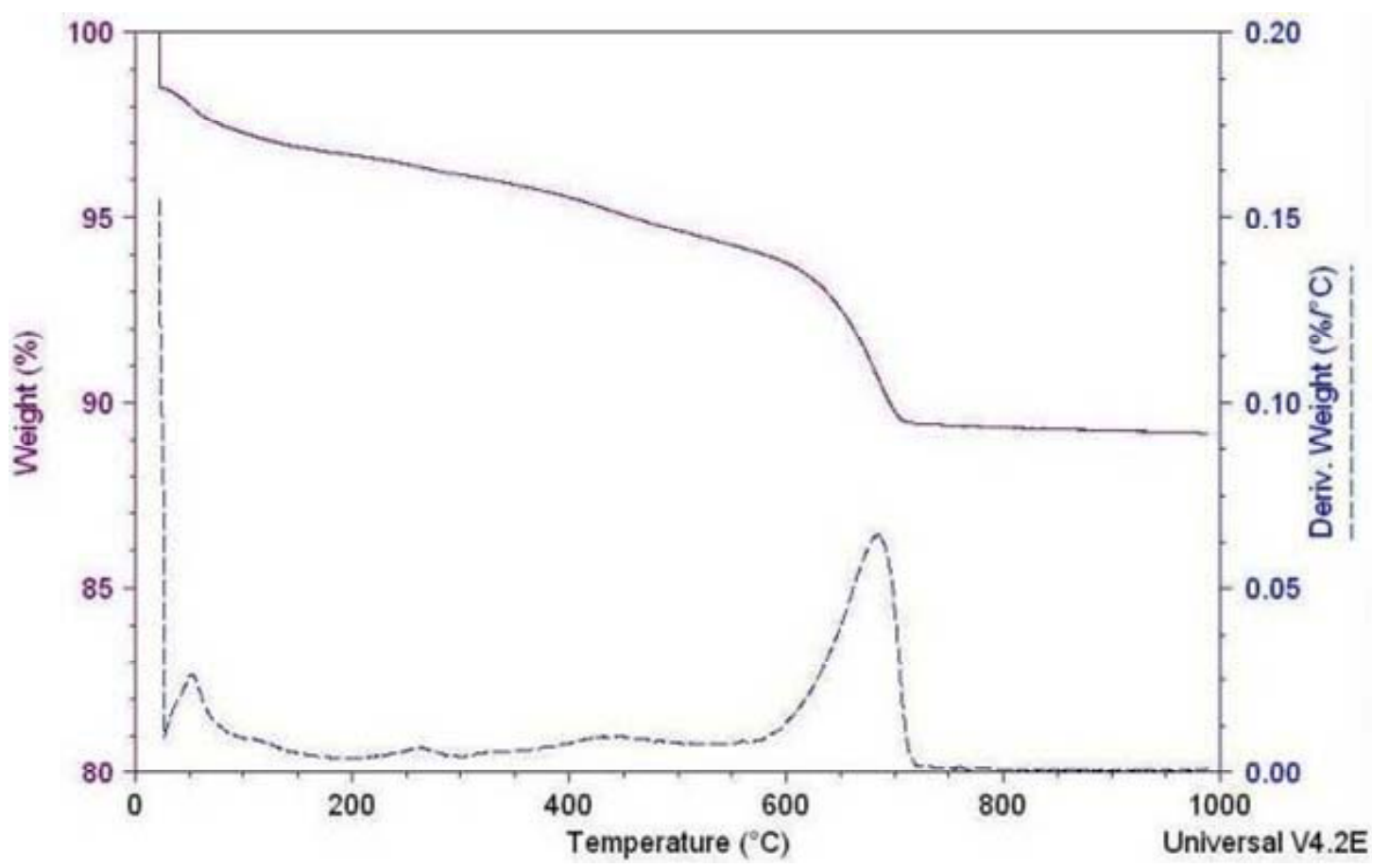

Figure 3.52 TGA result for chemically treated soil sample at 7-in. depth at STA. $6+560)$. Section (2). 


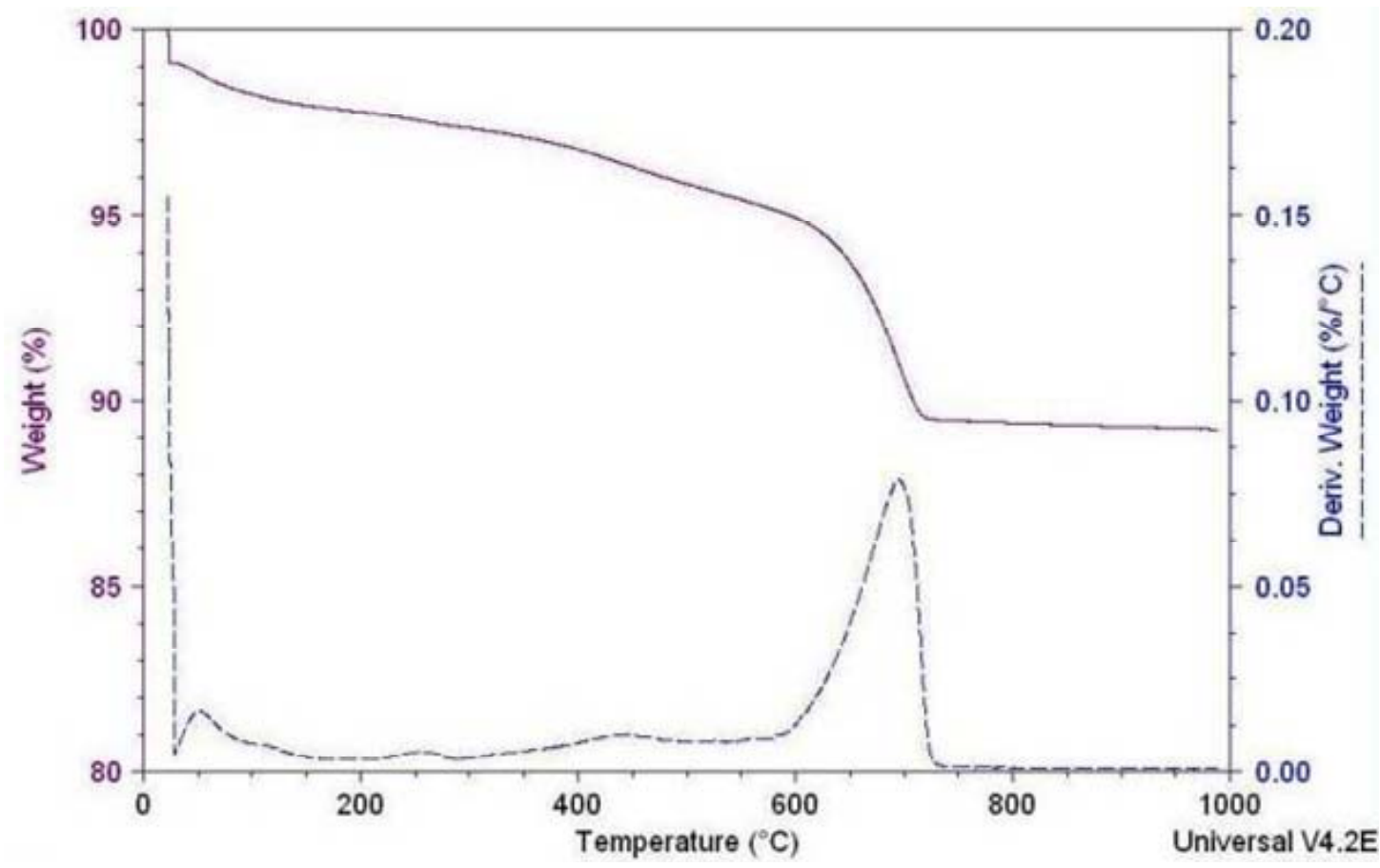

Figure 3.53 TGA result for chemically treated soil sample at 12-in. depth at STA. $6+560$. Section (2)

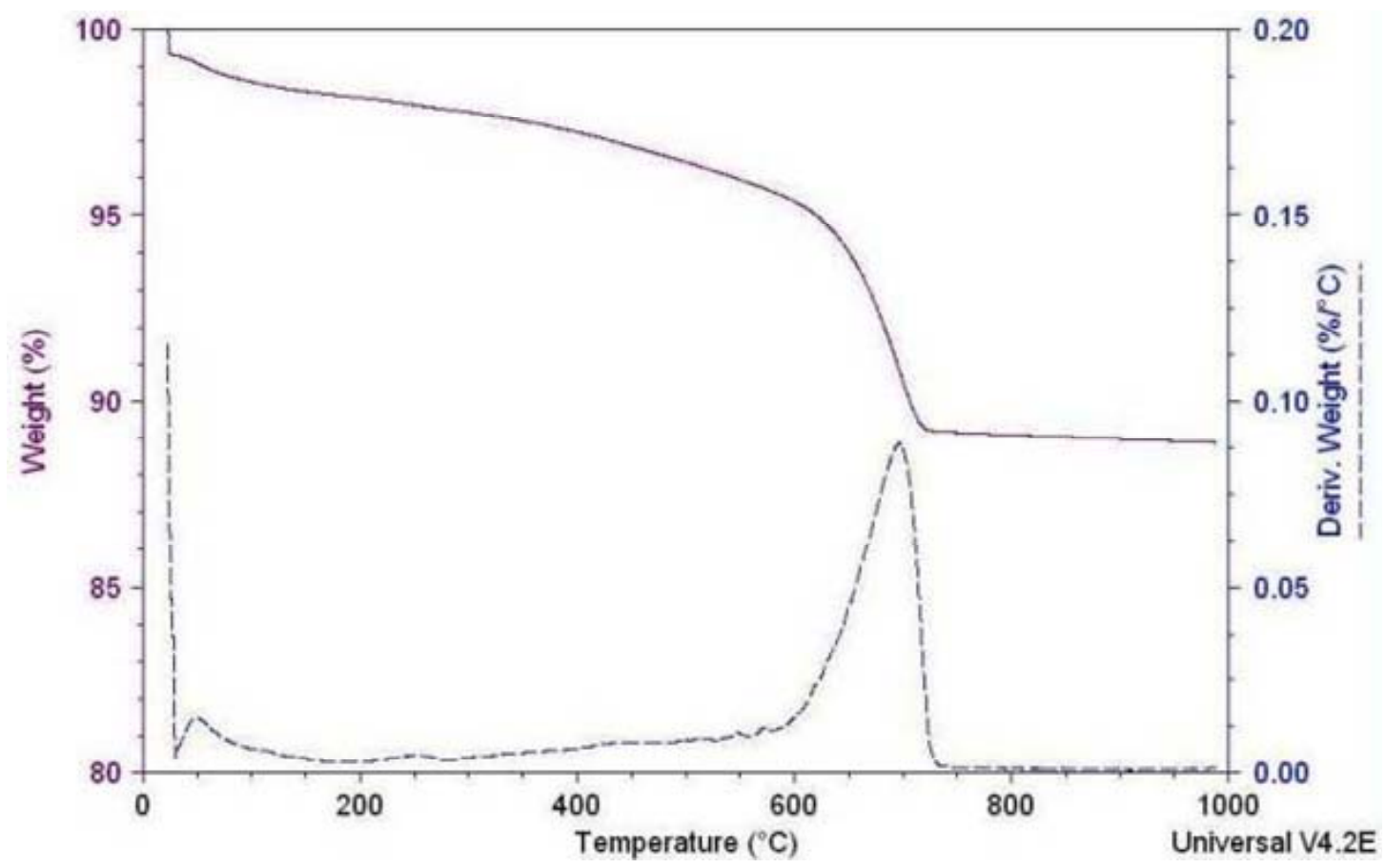

Figure 3.54 TGA result for chemically treated soil sample at 2-in. depth at STA. 6+600. Section (2). 


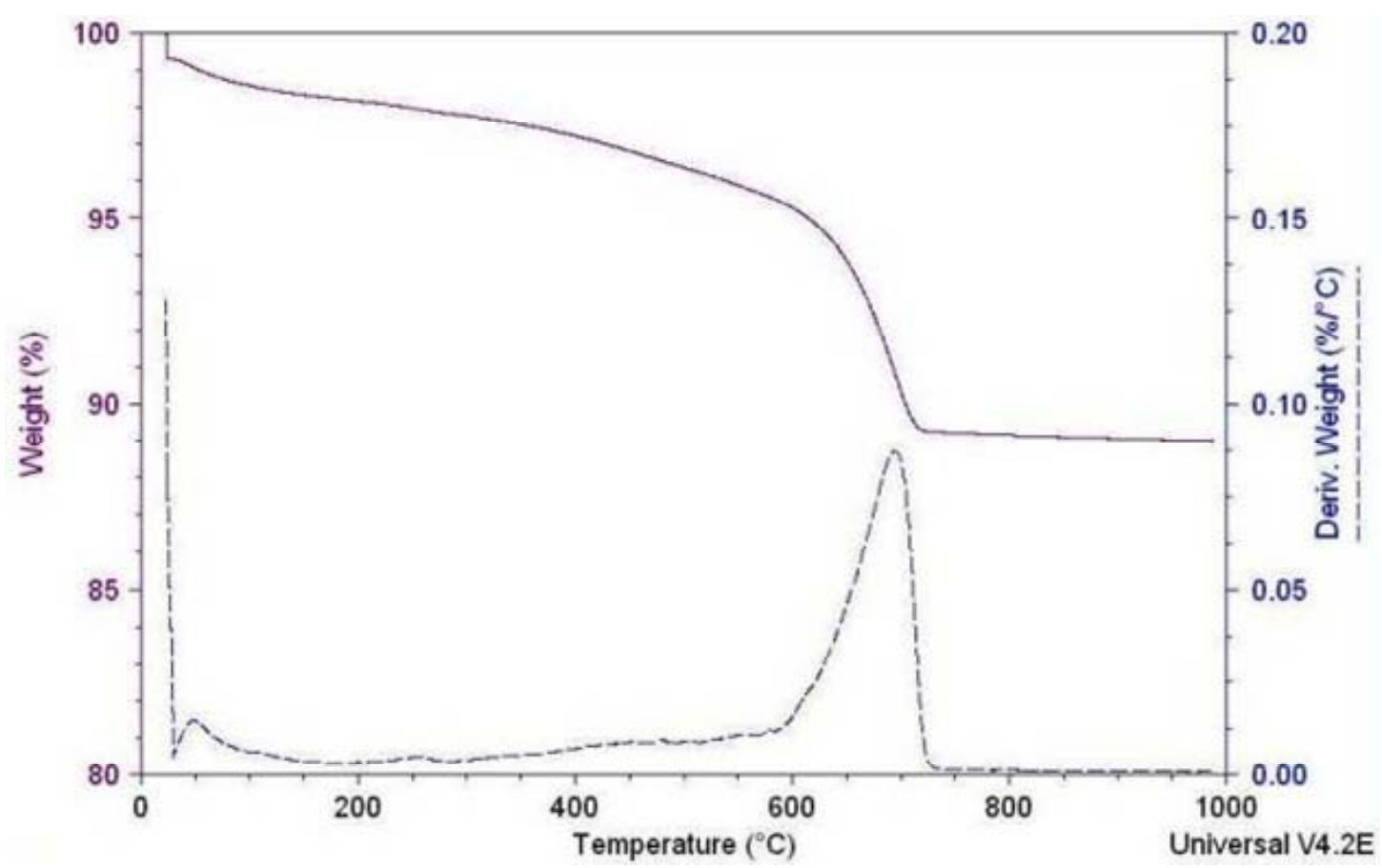

Figure 3.55 TGA result for chemically treated soil sample at 7-in. depth at STA. $6+600$. Section (2).

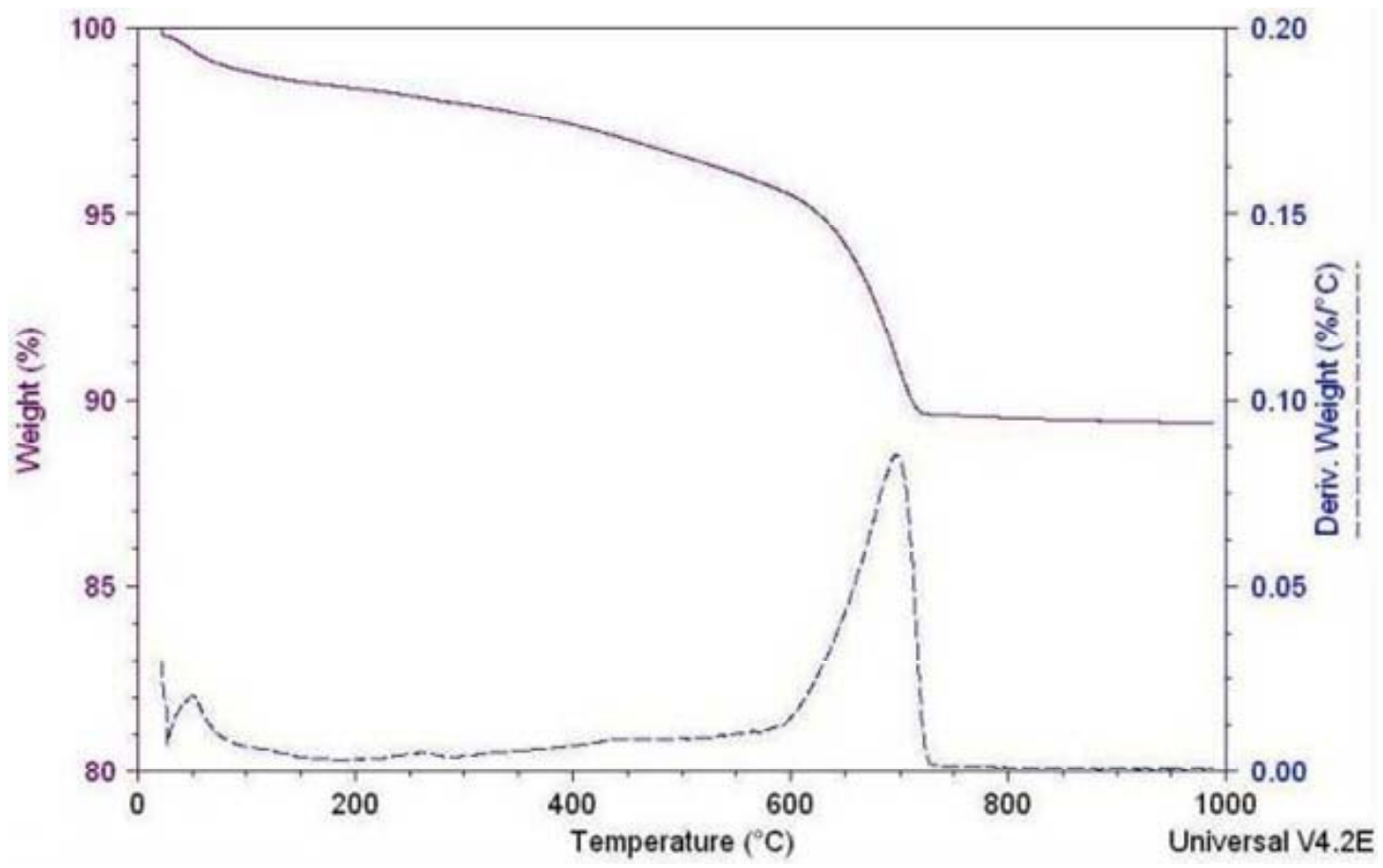

Figure 3.56 TGA result for chemically treated soil sample at 12-in. depth at STA. $6+600$. Section (2). 
Table 3.5 Percentage of calcium carbonate in soil

\begin{tabular}{|c|c|c|c|c|c|}
\hline \multicolumn{3}{|c|}{ Section (1) } & \multicolumn{3}{c|}{ Section (2) } \\
\hline Depth & STA. 6+700 & STA. 6+760 & Depth & STA. 6+560 & STA. 6+600 \\
\hline 2 & 27.3 & 13.6 & 2 & 11.4 & 15.9 \\
\hline 8 & 25.0 & 15.9 & 7 & 9.1 & 13.6 \\
\hline 14 & 25.0 & 14.8 & 12 & 13.6 & 13.6 \\
\hline Average & 25.8 & 14.8 & Average & 11.4 & 14.4 \\
\hline
\end{tabular}

Table 3.6 Comparison between percentage of calcium carbonate of treated soil and CBR of treated subgrade soil

\begin{tabular}{|c|c|c|c|c|}
\hline \multirow{2}{*}{} & \multicolumn{2}{|c|}{ Section (1) } & \multicolumn{2}{c|}{ Section (2) } \\
\cline { 2 - 5 } & STA. 6+700 & STA. 6+760 & STA. 6+560 & STA. 6+600 \\
\hline$\% \mathrm{CaCO}_{3}$ & 25.8 & 14.8 & 11.4 & 14.4 \\
\hline $\begin{array}{c}\text { CBR of treated } \\
\text { subgrade }\end{array}$ & 37.5 & 15.0 & 26.5 & 18.2 \\
\hline
\end{tabular}




\section{CHAPTER 4. SUMMARY AND CONCLUSIONS}

This chapter includes the summary of the research, as well as the conclusions reached from the work. It is divided into three Sections: Summary, Conclusions, and Recommendations.

\section{1. $\underline{\text { Summary }}$}

Field and laboratory tests were conducted to investigate the degree of uniformity and quality that is obtained with chemical treatment of the subgrade with LKD, using current construction techniques.

The INDOT road construction project, Des. 9738220 (R-28976), was chosen for this research. The test site is located along SR 641, South of Terre Haute, Indiana. A $280-\mathrm{m}$ long portion of the north-bound road (STA. $6+540$ to STA. $6+820$ ) was selected for the tests. The total $280-\mathrm{m}$ portion was divided into two construction and test sections. The first 140-m long subgrade section (STA. 6+540 to STA. 6+680), namely section (1), was chemically treated with LKD with a target thickness of 16 inches. The remaining 140-m long section (STA. $6+680$ to STA. $6+820$ ), or section (2), was treated with a target thickness of 14 inches. The field tests were conducted on the subgrade after seven days curing of the chemical treatment.

The field tests were conducted to evaluate in-situ engineering properties of the chemically treated subgrade and the laboratory tests were performed to estimate the lime content in the soil. Twenty three DCP tests were done at each section to obtain the 
stiffness (or strength) of the chemically-treated and natural (untreated) subgrade soil layers. The LWD tests were performed at the same locations where the DCP tests were done to estimate the stiffness of the treated subgrade soil layer. Nuclear gauge and sand cone tests were done to obtain the water content and dry density of the chemically treated subgrade. XRD and TGA tests were performed on soil samples collected in the field to identify and quantify the minerals contained in the soil. The engineering properties of the subgrade soil treated with a target thickness of 16 inches, which is a typical standard practice based on the current design and construction protocol for chemical subgrade treatment, are compared with those with a target treatment thickness of 14 inches.

\section{2. $\underline{\text { Conclusions }}$}

XRD and TGA laboratory tests show an adequate presence of lime in the subgrade, with somewhat better uniformity for the test site with 14 inches target thickness for the subgrade.

Field tests, namely density, DCP and LWD, show consistently better and more uniform results for the 14 inches target thickness site than for the 16 inches target site. The water content for the 16 inches thick subgrade was $11.0 \%, 30 \%$ higher than for the 14 inches thick subgrade, which had average water content of $8.4 \%$. This outcome is reflected in the dry density, which resulted in an average value of $1.73 \mathrm{Mg} / \mathrm{m}^{3}$ for the 16 inches, and $1.85 \mathrm{Mg} / \mathrm{m}^{3}$ for the 14 inches thick subgrade. The effective thickness of the treated subgrade, defined as the thickness of the soil over which the treatment was successful, ranged from 11 to 19 inches for the 16 inch thick subgrade site, while it ranged from 11 to 15 inches for the 14 inches target subgrade thickness site. The average 
and standard deviation of the effective thickness were 15.0 and 4.3 inches, respectively, for the 16 inches and 13.4 and 2.4 inches for the 14 inches thick subgrade site. A correlation between DCP tests and CBR resulted in an average CBR of 27.5 with a standard deviation of 7.4 for the thicker subgrade (16 inches) and average of 30.7 and standard deviation of 6.6 for the thinner (14 inches) subgrade. Again, the subgrade with a target treatment thickness of 14 inches shows better and more uniform results, as indicated by a larger average and smaller standard deviation. The immediate consequence was an improvement of the CBR over that of the natural soil in about $100 \%$, as an average value, for the 16 inches treated subgrade and about $350 \%$, also average value, for the 14 inches subgrade.

\section{3. $\underline{\text { Recommendations }}$}

It was decided to have a meeting with all interested parties to decide how to best incorporate the results of the implementation research project to design and construction. A meeting was celebrated October 22 in the INDOT office of Materials and Tests in Indianapolis. The following attended: Dave Andrewski, INDOT Pavement Engineering; Ron Heustis, INDOT Construction; Somanata Hiremata, INDOT; Athar Khan, INDOT Geotechnical Engineering; Nayyar Zia, INDOT Geotechnical Engineering; Kurt Sommer, INDOT Crawfordsville; Thomas Duncan, FHWA; Antonio Bobet, Purdue U.; Chulmin Jung, Purdue U.; and Sochan Jung, Purdue U.

After a brief presentation of the major findings from this project by Prof. Bobet and discussion of the major findings by all present, a consensus was reached to amend INDOT specifications for the following: 
1. Increase for design the CBR of the subgrade treated with LKD by $25 \%$ over that of the natural soil.

2. Implement recommendation for a target thickness of the treated subgrade of 14 inches.

3. Introduce special, one-type project where QC/QA is done by the contractor for design and construction, where full advantage of the subgrade improvement may be taken into consideration to minimize pavement thickness.

It was also agreed to monitor performance of new pavements where the subgrade is treated with LKD. The monitoring should include collection and analysis of field data regarding the stiffness of the treated subgrade, e.g. with DCP and LWD tests, depth of treatment, and resulting uniformity of the treatment. The objective is to build a database of the quality achieved during construction across the State. This recommendation is based on the potential for increasing the CBR of the subgrade beyond the $25 \%$ recommended, thus lowering the cost of the pavement. During the discussion on October 22 , and based on the results from this investigation, the members acknowledged the potential for such an increase of the CBR, but there was agreement that before doing this, further verification of the magnitude and uniformity of the improvement was needed, and that the CBR increase could be done gradually as additional supporting data is gathered. 


\section{LIST OF REFERENCES}

ASTM D 1556-07 (2007), "Standard Test Method for Density and Unit Weight of Soil in Place by Sand-Cone Method," Annual book of ASTM Standards, ASTM international, West Conshohocken, PA.

ASTM D 2216-05 (2005), "Standard Test Method for Laboratory Determination of Water

(Moisture) Content of Soil and Rock by Mass," Annual book of ASTM Standards, ASTM international, West Conshohocken, PA.

ASTM D 6938-09 (2009), "Standard Test Method for In-Place Density and Water Content of Soil and Soil-Aggregate by Nuclear Methods (Shallow Depth)," Annual book of ASTM Standards, ASTM international, West Conshohocken, PA.

ASTM D 6951-03 (2003), "Standard Test Method for Use of the Dynamic Cone Penetrometer in Shallow Pavement Applications," Annual book of ASTM Standards, ASTM international, West Conshohocken, PA.

ASTM E 2583-07 (2007), "Standard Test Method for Measuring Deflections with a Light Weight Delfectometer (LWD)," Annual book of ASTM Standards, ASTM international, West Conshohocken, PA.

INDOT SPR-3007 (2007), "Post-Construction Evaluation of Lime-Treated Soils," FHWA/IN/JTRP-2007, Final report, Project No. C-36-36UU, Indiana Department of Transportation, IN. 
Kim, J. R., Kang, H. B., Kim, D., Park, D. S., and Kim, W. J. (2007), “Using Portable Falling Weight Deflectometer and Plate-Bearing Load Test," Journal of Materials in Civil Engineering, 19(6), pp. 492-499.

MNDOT manual (2009), "MNDOT Grading and Base Manual: 5. Deflection Method (Zorn Light Weight Delfectometer)," Minnesota Department of Transportation, MN.

Ruta, P. and Szydlo, A. (2005), “Drop-Weight Test Based Identification of Identification of Elastic Half-Space Model Parameters," Journal of Sound and Vibration, 282, pp. 411-427.

Siddiki, N. Z., Khan, A., Kim, D., and Cole, T. (2007), "Use of In-Situ Tests in Compaction Control of a Bottom Ash Embankment," Transportation Research Record No.2045, pp. 10-18, TRB, National Research Council, Washington D.C.

Webster, S. L., Grau, R. H., and Williams, T. P. (1992). Description and Application of Dual Mass Dynamic Cone Penetrometer. Final Report, Department of Army, Waterways Experiment Station, Vicksburg, MS.

Zorn manual (2005), “Operating Manual: Light Drop Weight Tester ZFG 2000 (Light Weight Deflectometer, Portable Falling Weight Deflectometer)," Zorn company, Stendal, Germany. 


\section{APPENDIX}

This appendix contains boring logs obtained from the existing geotechnical data used for design of the road project. 


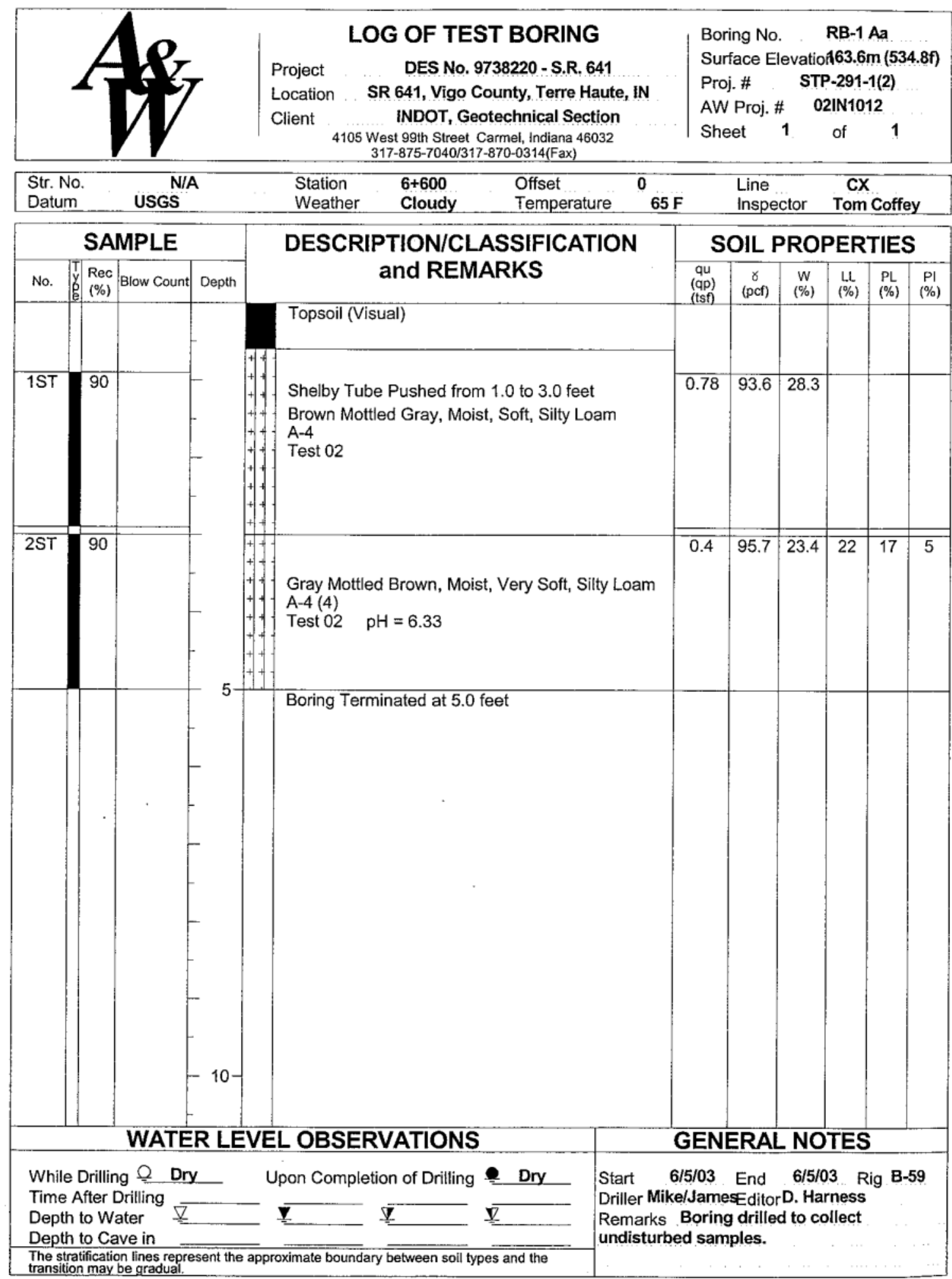

Figure A.1 Boring log for natural subgrade soil at 14-in. chemically treated section 


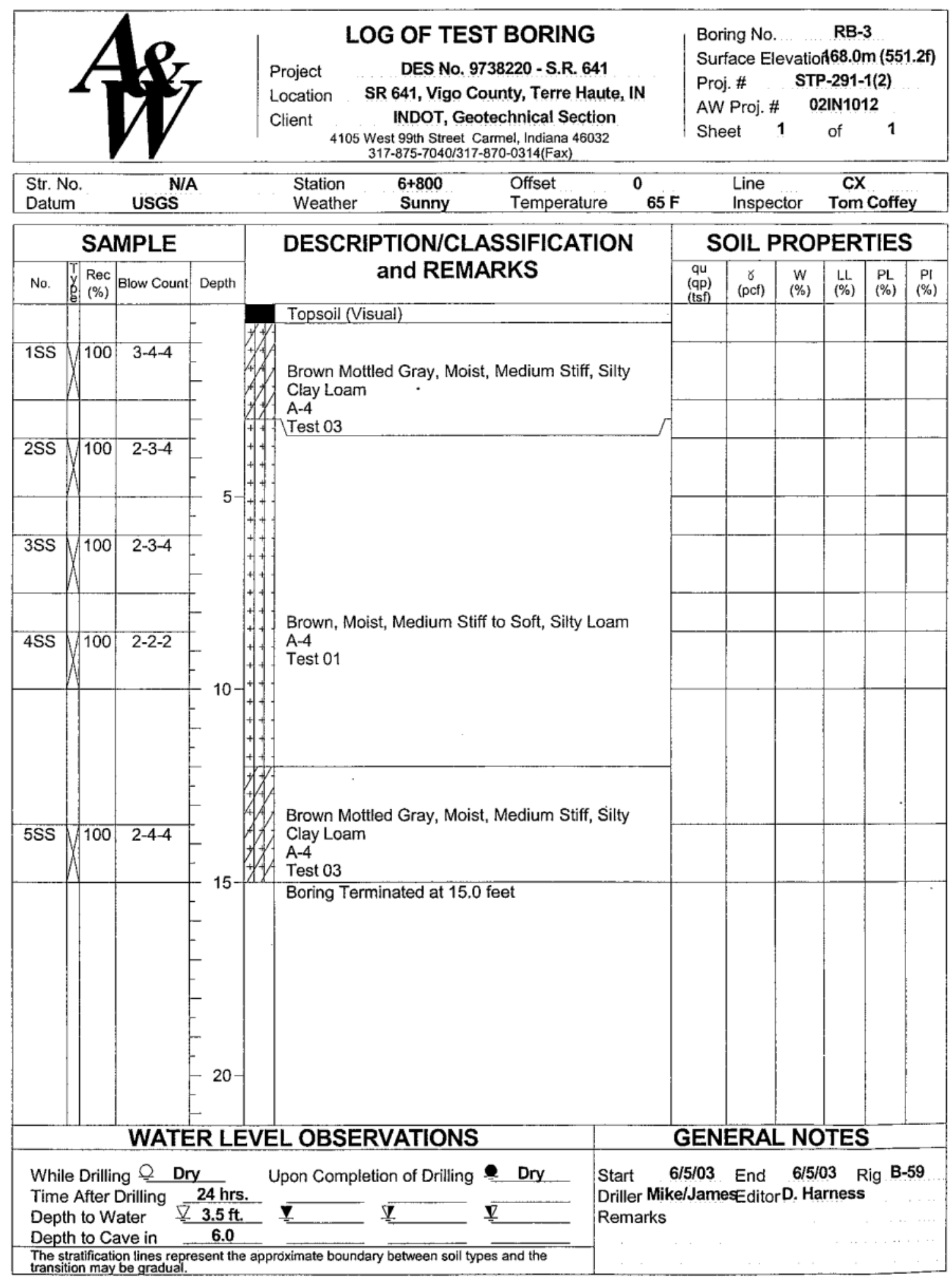

Figure A.2 Boring log for natural subgrade soil at 16-in. chemically treated section 